\author{
Universidade de São Paulo \\ Instituto de Física
}

\title{
Fenomenologias no Espaço de Parâmetros de Osciladores Caóticos
}

\author{
Everton Santos Medeiros \\ Orientador: Prof. Dr. Iberê Luiz Caldas \\ Co-orientador: Prof. Dr. Silvio Luiz T. De Souza \\ Tese de doutoramento apresentada ao \\ Instituto de Física para a obtenção do \\ título de doutor em ciências.
}

Prof. Dr. Iberê Luiz Caldas - IFUSP (Orientador)

Prof. Dr. José Carlos Sartorelli - IFUSP

Prof. Dr. Edson Denis Leonel - Unesp/IGCE - Rio Claro

Prof. Dr. Holokx Abreu Albuquerque - Universidade do Estado de Santa Catarina - Joinville

Prof. Dr. Rero Marques Rubinger - Universidade Federal de Itajubá - Itajubá

São Paulo

2014 
FICHA CATALOGRÁFICA

Preparada pelo Serviço de Biblioteca e Informação do Instituto de Física da Universidade de São Paulo

Medeiros, Everton Santos

Fenomenologias no espaço de parâmetros de osciladores caóticos. São Paulo, 2014.

Tese (Doutorado) - Universidade de São Paulo.

Instituto de Física. Depto. de Física Aplicada.

Orientador: Prof. Dr. Iberê Luiz Caldas

Área de Concentração: Física

Unitermos: 1. Sistemas dinâmicos; 2. Caos (Sistemas dinâmicos); 3. Fractais.

USP/IF/SBI-035/2014 


\section{Agradecimentos}

Aos meus avós Seu Otávio e Dona Nica, in memoriam. Serei eternamente grato.

À tia Lú, pelo carinho e confiança que sempre depositou em mim.

Ao meu irmão Marcelo, por tudo que já fez por mim.

À toda minha família, pelo constante apoio e torcida.

Ao Prof. Dr. Iberê Luiz Caldas pela orientação, apoio, incentivo e atenção ímpar que teve comigo ao longo da iniciação científica, mestrado e doutorado.

Ao Prof. Dr. Rene O. Medrano-T. por todas as discussões que acrescentaram muito em minha formação.

Ao Prof. Dr. Murilo Da Silva Baptista pela orientação e atenção durante o período que passei na Universidade de Aberdeen.

Ao Prof. Dr. Silvio L. T. De Souza pelas colaborações.

Aos meus grandes amigos: Daniel, Dorival, Reinaldo, Ricardo e Suigh.

Aos meus colegas do grupo controle de oscilações e da sala 228A e 232: Alberto, Bruno, Celso, David, Dennis, Felipe, Julio, Meirelen, Paula, Rafael, Thiago, Wilson e Zwinglio,. A todos sou grato pelo aprendizado e convivência diária.

Às secretárias, sempre prestativas, Eleonora, Elen e Lia.

Aos desenvolvedores de software livre. Suas apostilas e tutoriais online ajudaram nas tarefas diárias.

À Luz Moreira, uma grande fonte de alegria e inspiração em minha vida.

Agradeço ao CNPq e Capes pelo suporte financeiro concedido. 
“... comecei a pensar

Que eu me organizando posso desorganizar Que eu desorganizando posso me organizar"

Movimento Mangue Beat 


\section{Resumo}

Os principais resultados originais relatados ao longo desse texto provém de observações em experimentos numéricos, entretanto, na maioria dos casos, os resultados são fundamentados com instrumentos teóricos ou com modelos heurísticos. Inicialmente, introduzimos, nas equações que descrevem osciladores caóticos, uma pequena perturbação periódica a fim de observar no espaço de parâmetros a porção de parâmetros cujo comportamento caótico é extinto. Assim, constatamos que o conjunto de parâmetros correspondentes às órbitas caóticas extintas correspondem à replicas de janelas periódicas complexas previamente existentes no sistema não-perturbado. Posteriormente, utilizando as propriedades de torsão do espaço de estados dos osciladores caóticos, visualizamos transições existentes no interior das janelas periódicas complexas. Quando consideramos sequências dessas janelas sob a ótica da torsão do espaço de estados, observamos a existência de regras que relacionam janelas consecutivas ao longo dessa sequência. Adicionalmente, no espaço de parâmetros de osciladores caóticos e sistemas dinâmicos adicionais, fizemos uma estimativa da dimensão da fronteira entre o conjunto de parâmetros que leva às soluções periódicas e o conjunto que leva aos atratores caóticos. Para os sistemas investigados, os valores obtidos para essa dimensão estão no mesmo intervalo de confiança, indicando que essa dimensão é universal. 


\section{Abstract}

The main results reported along this text come from observations in numerical experiments, however, in most cases, results are explained by theoretical instruments or heuristic models. Initially we introduced in the equations that describe chaotic oscillators, a small periodic perturbation to observe, in the parameter space, the portion of parameters whose chaotic behavior is extinguished. Thus, we find that the set of parameters corresponding to the extinct chaotic orbits correspond to replicas of previously complex periodic windows existing in the unperturbed system. Subsequently, using the torsion properties of state spaces of chaotic oscillators, we visualize transitions within the complex periodic windows. When we consider sequences of these windows from the perspective of torsion properties of the state space, we observe the existence of rules that relate consecutive windows along these sequences. Additionally, in the parameter space of chaotic oscillators and additional dynamical systems, we estimate the dimension of the boundary between the set of parameters that leads to periodic solutions and the set that leads to chaotic attractors. For the systems considered here, the values for this dimension are in the same confidence interval, indicating that this dimension is universal. 


\section{Conteúdo}

1 Introdução 11

2 Osciladores Caóticos e Técnicas de Análise $\quad 19$

2.1 Introdução . . . . . . . . . . . . . . . . . . . . . . 19

2.2 Sistemas Dinâmicos . . . . . . . . . . . . . . . . . . . . . 22

2.3 Osciladores Não-Lineares Amortecidos e Forçados . . . . . . . . . . . . . . 22

2.4 Técnicas de Análise . . . . . . . . . . . . . . . . . . . . . . . . 24

2.4.1 Análise no Plano . . . . . . . . . . . . . . . . 24

2.4.2 Diagramas de Bifurcação . . . . . . . . . . . . . . . . 26

2.4.3 Expoentes de Lyapunov . . . . . . . . . . . . . . . . . . . . . 28

2.4.4 Cálculo Numérico dos Expoentes de Lyapunov . . . . . . . . . . . . 30

2.4.5 Número de Rotação para Osciladores Forçados . . . . . . . . . . . . 33

2.4.6 Espaço dos Parâmetros e Janelas Periódicas Complexas . . . . . . . 38

2.5 Conclusão . . . . . . . . . . . . . . . . . . . . . . . . . . . . 39

3 Replicação de Janelas Periódicas no Espaço dos Parâmetros 41

3.1 Introdução . . . . . . . . . . . . . . . . . . . . . . . . 41

3.2 Pequena Perturbação Periódica . . . . . . . . . . . . . . . . . . . . . 42

3.3 Replicação de Janelas Periódicas Pelas Pequenas Perturbações Periódicas . 43

3.3.1 Oscilador de Duffing . . . . . . . . . . . . . . . . . 44

3.4 Conclusão . . . . . . . . . . . . . . . . . . . . . . 47

4 Propriedades de Torsão $\quad 49$

4.1 Introdução . . . . . . . . . . . . . . . . . . . . . . . . 49 
4.2 Esqueleto de Janelas Periódicas Complexas . . . . . . . . . . . . . . . . 51

4.3 Número de Rotação em Janelas Periódicas Complexas . . . . . . . . . . . . 55

4.4 Número de Rotação em Sequências de Janelas Periódicas Complexas . . . . 56

4.5 Resultados Numéricos . . . . . . . . . . . . . . . . . . 57

4.6 Conclusão . . . . . . . . . . . . . . . . . . . . . . . 60

5 Dimensão Fractal no Espaço de Parâmetros $\quad 63$

5.1 Introdução . . . . . . . . . . . . . . . . . . . . . . 63

5.2 Fractais . . . . . . . . . . . . . . . . 66

5.2 .1 Dimensão Fractal . . . . . . . . . . . . . . 66

5.2 .2 Conjunto de Cantor . . . . . . . . . . . . . . . . . . 68

5.3 Fractais Gordos . . . . . . . . . . . . . . . . . 69

5.3.1 Dimensão Não-Fractal e Expoente de Incerteza . . . . . . . . . . 70

5.4 Expoente de Incerteza e Dimensão Exterior no Espaço de Parâmetros . . . 73

5.5 Dimensão Exterior Como Universalidade em Sistemas Dinâmicos . . . . . . 77

5.6 Modelo Heurístico para Dimensão de Fronteiras no Espaço de Parâmetros . 80

5.7 Conclusão . . . . . . . . . . . . . . . . . . . . . . . 84

6 Conclusões e Considerações Finais $\quad 87$

$\begin{array}{ll}\text { Referências Bibliográficas } & 92\end{array}$ 


\section{Capítulo 1}

\section{Introdução}

Durante os séculos 18 e 19, com o advento da mecânica Newtoniana, o determinismo cresceu no campo das ciências exatas e foi estritamente relacionado com a idéia de previsibilidade. Em 1814, o matemático Francês P. S. de Laplace em uma citação, conhecida como o manifesto do determinismo científico, declara que uma inteligência ideal que conheça às leis de evolução do universo e suas condições iniciais, seria capaz de predizer seu estado dinâmico em qualquer instante de tempo [1]. Entretanto, no começo do século 20, surgiram objeções quanto à capacidade de previsibilidade do determinismo. H. Poincaré constatou a existência de incertezas instrínsecas na definição das condições iniciais e que essas incertezas podem ser rapidamente amplificadas pelas leis deterministicas do próprio sistema, implicando em imprevisibilidade na definição do seu estado dinâmico final [2]. Posteriormente, em 1963, E. N. Lorenz confirmou através de simulações computacionais que as soluções de um sistema de equações não-lineares de fato exibem sensibilidade às pequenas variações nas condições iniciais. Nesse caso, Lorenz constatou que as soluções são irregulares, conferindo um caracter imprevisível ao comportamento do sistema [3]. Desde então, a obtenção de comportamento irregular e imprevisível à partir de processos deterministicos, i.e., sem a introdução de ruído de qualquer natureza, ampliou-se na física e matemática.

As descobertas de Poincaré e Lorenz se inserem em um novo campo de investigação científica, em que os processos deterministicos são tratados como sistemas dinâmicos. Um sistema dinâmico é conceitualmente definido pela existência de um espaço composto 
por todos estados disponíveis ao sistema, além de uma regra de evolução temporal para esses estados. Adicionalmente, sistemas dinâmicos possuem características intrínsecas que são usualmente consideradas nas regras de evolução através de constantes denominadas parâmetros. Assim, a solução de um sistema dinâmico consiste em conhecer seu estado a cada instante de tempo para um dado conjunto de parâmetros. Com essa evolução natural dos conceitos, as soluções irregulares e imprevisíveis provenientes da sensibilidade às pequenas variações nas condições iniciais foi associada à formação, no espaço de estados, de um comportamento assintótico denominado atrator caótico ou estranho $[4,5]$. Em contraste, as soluções regulares onde a evolução temporal promove a repetição sistemática e assintótica de estados foram denominadas órbitas periódicas.

Um mesmo sistema dinâmico pode apresentar diferentes tipos de comportamento assintótico, incluindo órbitas periódicas e atratores caóticos, dependendo do valores atribuidos aos seus parâmetros de controle. Para sistemas dinâmicos com dependência em mais de um parâmetro de controle, o conjunto de parâmetros correspondente ao comportamento periódico e caótico pode ser respectivamente representado em diagramas bidimensionais. Entretanto, inicialmente, a distinção e a delimitação dos parâmetros que fornecem comportamento caótico ou periódico era realizada com auxílio de curvas de bifurcação, i.e., a região de transição entre esses comportamentos.

Em 1982, S. Fraser et al. analisaram uma região no espaço de parâmetros de um sistema dinâmico contínuo (fluxo) descrito pelas equações de Rössler. Eles comunicaram a existência de uma área contínua de parâmetros correspondente a uma órbita periódica estavél de período três [6]. Eles verificaram que essa área está conectada, por um dos lados, a uma cascata de bifurcações dobramento de período levando à formação de órbitas subharmonicas, dando origem a uma estrutura periódica complexa, que chamaremos de janela periódica complexa. Nesse mesmo lado, a janela periódica complexa culmina em caos via bifurcações dobramento de período. No lado oposto, eles verificaram a existência de uma região de parâmetros correspondente a caos intermitente repentinamente interrompido por uma bifurcação do tipo sela-nó, i.e, criação de duas órbitas periódicas com estabilidade contrárias, delimitando o surgimento da órbita de período três. A fim de simplicar a análise dessa região, Fraser et al. utilizaram uma seção de Poincaré do fluxo 
investigado para associar a dinâmica de estados descrita pelas três equações diferenciais do sistema de Rössler a um sistema dinâmico discreto (mapa) unidimensional à dois parâmetros descrito por uma equação cúbica. Esse mapa associado possui características topológicas similares ao do sistema original e apresenta uma região contínua de parâmetros correspondente a uma óbita periódica de período três similar à observada no fluxo. O interior da estrutura periódica complexa existente no espaço de parâmetros do mapa associado foi rigorosamente analisado; verificou-se tratar de uma estrutura formada por parâmetros que correspondem a fenômenos complexos do ponto de vista dinâmico. Por exemplo, além da existência das curvas de bifurcação dobramento de período e sela-nó, no interior dessas regiões de estabilidade foram identificadas curvas de parâmetros correspondentes às órbitas super-estáveis (convergência instantânea para a órbita periódica). Também foram exploradas as consequências de um ponto cúspide (cusp) no interior da região de estabilidade; esse ponto é definido como o local de onde duas curvas de bifurcação sela-nó emergem, definindo nesse ponto uma bifurcação cúspide ( cusp). Esse cenário favorece a ocorrência de bi-estabilidade e histerese [6]. Todas as conclusões tiradas para a estrutura periódica complexa do espaço de parâmetros do mapa cúbico foram estendidas à região correspondente no fluxo de Rössler [6].

Assim, o trabalho de Fraser et al., com auxílio de curvas de bifurcações, definiram as janelas periódicas complexas no espaço de parâmetros de fluxos e mapas. Entretanto, em 1993, as janelas periódicas complexas foram redescobertas por J. A. C. Gallas de um ponto de vista diferente. Ao invés de curvas de bifurcação, J. A. C. Gallas utilizou um método de diagnóstico para qualificar quanto a caos ou periodicidade cada parâmetro em uma grade bidimensional formada pelos dois parâmetros de controle do mapa de Hénon [7]. Essa técnica parâmetro-a-parâmetro forneceu subsídios para uma análise global do espaço de parâmetros, possibilitando a investigação coletiva de várias janelas periódicas complexas e como elas estão relacionadas entre si. No espaço de parâmetros do mapa de Hénon, J. A. C. Gallas confirmou a existência de bifurcações dobramento de período conectadas ao corpo principal da janela periódica e argumentou que as órbitas subharmonicas provenientes dessas bifurcações formam novas janelas periódicas complexas, que por sua vez sofrem o mesmo processo, gerando uma infinidade de novas janelas conectadas [7]. J. A. C. 
Gallas também mostrou, para o mesmo sistema, que os conjuntos de janelas periódicas complexas são organizados de maneira regular, janelas com o mesmo período fundamental aparecem alinhadas ao longo de uma reta orientada em uma direção particular [7]. Desde então muitos trabalhos foram realizados explorando o espaço de parâmetros de sistemas dinâmicos discretos (mapas) [8-25].

Em 2005, C. Bonatto et al. confirmaram a existência de janelas periódicas complexas no espaço de parâmetros de um sistema dinâmico contínuo, um sistema de equações diferenciais que descreve um laser tipo $\mathrm{CO}_{2}$ com perdas moduladas [26]. Individualmente, as janelas periódicas numericamente observadas nesse trabalho possuem as mesmas propriedades definidas no fluxo de Rössler no trabalho de Fraser et al. Entretanto, utilizando a técnica de diagnóstico parâmetro-a-parâmetro, C. Bonatto et al. observaram que as características coletivas de janelas periódicas complexas são similares às observadas no espaço de parâmetros do mapa de Hénon discutidas no parágrafo anterior. Nesse trabalho, adicionalmente, os autores argumentam que a distribuição das janelas periódicas complexas é auto-similar, i.e., possuem o mesmo aspecto em diferentes escalas de observação, essa propriedade será explorada adiante nessa tese. À partir destes resultados, muitos trabalhos foram dedicados ao espaço de parâmetros de fluxos [27-49].

Em 2007, a mesma colaboração, C. Bonatto et al., investigaram a distribuição de janelas periódicas complexas no espaço de parâmetros de um laser semicondutor [27]. Nesse trabalho regiões do espaço de parâmetros apresentam janelas periódicas complexas alinhadas em sequências hierárquicas de crescimento do período da órbita periódica correspondente. Nessas sequências, janelas periódicas estão separadas por comportamento caótico, o período da órbita principal dentro da janela é adicionado sempre por uma constante em janelas subsequentes ao longo da sequência [27]. A medida que o período da órbita principal aumenta ao longo da sequência, as janelas ficam com extensões contínuas menores, a sequência acumula em uma região periódica do espaço de parâmetros cujo período coincide com a quantia acrescentada em cada janela ao longo da sequência [27]. Em 2008, as sequências de janelas periódicas complexas foram observadas em uma variedade de sistemas dinâmicos [29].

Com a diversidade de sistemas dinâmicos apresentando janelas periódicas complexas 
com mesma forma e padrão similar de distribuição, esforços começaram a ser empreendidos na tentativa de observar essas janelas diretamente a partir de experimentos. Assim, em 2008, D. M. Maranhão et al. obtiveram séries temporais à partir de um aparato experimental do circuito de Chua para diferentes valores de duas resistências no circuito. Com auxílio de um método para reconstruir o atrator, eles obtiveram as órbitas periódicas que compõem uma janela periódica complexa [50]. Em 2010, E. R. Viana et al. utilizaram uma fonte de voltagem variável e variaram a resistência em um aparato experimental do circuíto de Chua, obtendo um espaço de parâmetros experimental [51]. Nessa realização é possível observar diversas regiões de parâmetros que correspondem às janelas periódicas complexas, e ainda, no espaço de parâmetros experimental fica clara a ocorrência de sequências dessas áreas periódicas [51]. Mais tarde em 2010, R. Stoop et al. obtiveram experimentalmente o espaço de parâmetros de duas variantes do circuito eletrônico denominado Nishio-Inaba [52]. Nesse espaço as regiões de parâmetros correspondentes à periodicidade apresentam forma e padrão de organização de acordo com as previsões teóricas da teoria de bifurcações $[6,53]$ e de acordo com as simulações em sistemas dinâmicos contínuos [31].

Com isso, nos tempos atuais contamos com uma ampla literatura, e esforços continuam sendo investidos para maior compreensão do surgimento, da existência e da organização das janelas periódicas complexas existentes no espaço de parâmetros de sistemas dinâmicos contínuos e discretos. Essa tese contribui para essa literatura com três aspectos fenomenológicos originais: A replicação das janelas periódicas complexas quando as equações do sistema dinâmico investigado são submetidas a uma pequena perturbação periódica. A utilização de propriedades de convergência de órbitas periódicas para revelar uma estrutura interna às janelas periódicas complexas e uma nova regra que relaciona janelas adjacentes de uma sequência com seu ponto de acúmulo. A associação de uma dimensão fractal às regiões do espaço de parâmetros com ocorrência de janelas periódicas complexas com distribuição observada como sendo auto-similar. Essas investigações foram realizadas em experimentos numéricos de equações diferenciais ordinárias não-lineares que consideram perdas e ganhos energéticos através de mecanismo de dissipação e forçamento. Essa classe de equações diferenciais usualmente descreve osciladores não-lineares dissipativos 
forçados, que chamaremos de osciladores caóticos. Escolhemos essa classe de sistemas dinâmicos especialmente pela possibilidade de implementação experimental e verificação dos principais fenômenos aqui observados, além da existência de uma ampla literatura de apoio a esses sistemas [54-56].

No Capítulo 2, apresentamos uma introdução à classe de sistemas utilizado ao longo desta tese, bem como, as principais ferramentas necessárias para a descrição dos nossos resultados. Inicialmente, introduzimos os sistemas dinâmicos de um modo geral, bem como o conceito de período, estado periódico, estado caótico ou irregular, o conceito de atração e o atrator estranho. Em seguida, introduzimos a equação geral dos osciladores caóticos, os parâmetros e as variáveis dessas equações. Passamos então à descrição detalhada das principais técnicas de análise e diagnóstico aplicada aos osciladores caóticos: planos de fase, seções de Poincaré, diagramas de bifurcações, expoentes de Lyapunov, números de rotação e espaço de parâmetros. Com isso, ficamos habilitados à descrição dos fenômenos no espaço de estados e de parâmetros que serão discutidos nos capítulos seguintes.

No Capítulo 3, baseados no histórico da aplicabilidade de pequenas perturbações periódicas para a supressão de caos em osciladores não-lineares $[57,58]$, analisamos o espaço de parâmetros desses sistemas quando submetidos a esse tipo de perturbação. Variando a amplitude da perturbação, observamos que conjuntos de parâmetros sofrem transições entre os comportamentos caóticos e periódicos. Especificamente, observamos que, sob a perturbação, as janelas periódicas complexas sofrem replicações. A medida que a amplitude da perturbação é aumentada, a janela original e sua réplica afastam-se no espaço, gerando a transição entre comportamentos. Mostramos também que as órbitas periódicas existentes dentro das janelas periódicas replicadas são similares às órbitas existentes dentro da janela original. Esse resultado possui consequências relevantes para a supressão da dinâmica caótica, uma vez que fica estabelecido que a supressão de caos por pequenas perturbações periódicas ocorre para conjuntos de parâmetros dada uma amplitude de perturbação, conferindo robustez à periodicidade obtida por pequenas perturbações.

No Capítulo 4, como alternativa ao período de oscilação das órbitas periódicas, utilizamos, como diagnóstico para confeccionar o espaço de parâmetros, a torsão que essas órbitas provocam em sua vizinhança no espaço de estados. Essa estratégia nos proporcio- 
nou a visualiação de transições existentes no interior das janelas periódicas complexas, de acordo com as regras de convergência para pontos fixos de um mapa associado. Quando consideramos sequências de janelas periódicas complexas sob a ótica da torsão do espaço de estados, observamos a existência de regras de formação para a torsão que relacionam janelas periódicas consecutivas ao longo da sequência com o ponto onde a sequência culmina. Com isso, obtivemos uma regra para o adicionamento da torsão. Esse resultado é relevante por relacionar as janelas periódicas complexas que pertencem a uma mesma sequência com a região de acúmulo de sua respectiva sequência.

No Capítulo 5, discutimos a sensibilidade exibida por sistemas dinâmicos à variações em seus parâmetros de controle. Pequenas flutuações ou erros na sintonização desses parâmetros podem levar a comportamentos dinâmicos distintos. Consequentemente, surgem dificuldades no ajuste de parâmetros para obtenção do comportamento desejado. O exemplo mais dramático é a limitação na predição do ajuste de parâmetros que levam ao comportamentos caótico ou ao periódico. Neste capítulo, com auxílio de uma ferramenta denominada expoente de incerteza [59], quantificamos a incerteza de ajuste entre os parâmetros que levam à periodicidade ou ao caos. O expoente de incerteza é relacionado com a dimensão da fronteira do conjunto para o qual foi calculado, fornecendo uma estimativa para a dimensão dessa fronteira. Com isso, mostramos que a dimensão da fronteira entre o conjunto de parâmetros que levam ao comportamento periódico e o conjunto de parâmetros que levam ao caos é fractal. Verificamos que a dimensão dessa fronteira é universal para os sistemas dinâmicos investigados nesta tese. Adicionalmente, construímos um modelo heurístico para explicar essa universalidade baseado no decrescimento da largura das janelas periódicas complexas ao longo de sequências.

No Capítulo 6, apresentamos as conclusões e as considerações finais. 


\section{Capítulo 2}

\section{Osciladores Caóticos e Técnicas de}

\section{Análise}

A existência de estados irregulares que dependem sensivelmente de pequenas variações nas condições iniciais foi confirmada em osciladores não-lineares em diversos trabalhos na década de 1970. O comportamento assintótico desses estados é um conjunto atrator com estrutura extremamente complexa. A dinâmica associada com esses conjuntos atratores é denominada caótica. Daí a denominação osciladores caóticos. Nesse capítulo, além de apresentar as equações básicas dos osciladores caóticos, apresentamos as principais técnicas de detecção da dinâmica caótica, tais como: planos de fase, seções de Poincaré, diagramas de bifurcação, expoentes de Lyapunov e espaço de parâmetros. Adicionalmente, apresentamos os números de rotação e de torsão, que são medidas da torsão do fluxo local em torno de estados periódicos.

\subsection{Introdução}

Como cenário para nossas investigações no espaço de parâmetros, escolhemos uma classe de sistema dinâmicos a tempo contínuo que são representados por um sistema de três equações diferenciais ordinárias de primeira ordem. Devido aos mecanismos de ganho e dissipação de energia considerados nessas equações, os sistemas por elas descrito recebe o nome de osciladores não-lineares amortecidos forçados, que chamaramos de osciladores 
caóticos.

São exemplos desses osciladores, o movimento de uma haste metálica imersa em um campo magnético e o comportamento dinâmico de um circuito eletrônico contendo uma indutância não-linear, ambos são descritos por uma equação não-linear denominada equação de Duffing. Diversas realizações teóricas, experimentais e numéricas foram propostas para essa classe de sistemas dinâmicos. Inicialmente, em 1945, M. L. Cartwright e J. E. Littlewood encontraram evidências teóricas da ocorrência de comportamento irregular, isto é, a existência de atratores estranhos na dinâmica desses osciladores [54]. Já em 1978, Y. Ueda verificou em experimentos numéricos a ocorrência da dinâmica irregular. O aspecto aleatório da solução obtida levou Ueda a batizar o fenômeno observado de turbulência em circuitos eletrônicos [55]. Finalmente, em 1980 F. C. Moon confirmou experimentalmente a ocorrência da dinâmica irregular nos osciladores não-lineares [56], já conhecida como dinâmica caótica [5].

Subsequentemente à confirmação da existência dos estados caóticos em osciladores nãolineares, estudaram-se as rotas para esse comportamento a partir de um estado periódico. Em 1982, para um circuito eletrônico contendo componentes não-lineares, J. Testa et al., variando parâmetros de controle, verificaram o surgimento da dinâmica caótica através do dobramento consecutivo do período de uma órbita periódica [60]. Adicionalmente, em intervalos de parâmetros correspondentes a comportamento caótico, verificaram a existência de subintervalos de parâmetros correspondentes a estados periódicos, denominados janelas periódicas [60]. As janelas periódicas frequentemente aparecem alinhadas em extensões de parâmetros, formando estruturas denominados sequências de janelas periódicas. Muitos esforços foram concentrados na tentativa de estabelecer conexões entre as janelas periódicas de uma sequência. Em 1985, em um circuito contendo uma junção p-n, J. M. Perez observou a adição de incrementos constantes no período de estados periódicos de janelas periódicas pertencentes à determinada sequência [61]. Esse fenômeno é conhecido como adicionamento de período e foi experimentalmente observado em muitos outros sistemas [62-67].

Muitas técnicas de análise foram aplicadas aos osciladores caóticos. Começamos com os expoentes de Lyapunov. Para sistemas dinâmicos em geral, dada à evolução tempo- 
ral de um sistema dinâmico, os expoentes de Lyapunov medem a taxa de separação ou aproximação média de condições iniciais vizinhas no espaço de estados. Como a dinâmica caótica tem como característica básica a separação exponencial de condições iniciais, o expoente associado com esse comportamento é positivo, enquanto a dinâmica periódica é associada com expoentes de Lyapunov negativos. A obtenção numérica do espectro de Lyapunov para sistemas dinâmicos não-lineares foi introduzida em 1984 por Wolf et al. O algoritmo introduzido por eles fornece esse diagnóstico a partir das equações diferenciais que descrevem um sistema dinâmico contínuo em questão [68].

Os expoentes de Lyapunov foram calculados para conjuntos de parâmetros de controle igualmente distribuídos em grades bidimensionais. O diagrama obtido com esse procedimento foi denominado de espaço de parâmetros. Conforme introduzimos neste capítulo, no espaço de parâmetros, os parâmetros correspondentes ao comportamento periódico aparecem agrupados em áreas contínuas denominadas janelas periódicas complexas. Essas janelas periódicas possuem um corpo central denominado esqueleto (skeleton) formado pela junção de duas parábolas com as extremidades estendidas em quatro direções do espaço de parâmetros. O corpo central dessa janela é envolvido por curvas de bifurcação que separam a janela periódica do mar caótico externo $[6,7]$. As janelas periódicas complexas também foram observadas no espaço de parâmetros de osciladores caóticos [30, 69, 70]

Adicionalmente neste capítulo, ressaltamos que para osciladores caóticos, além do período de oscilação dos estados periódicos, outras propriedades são mensuráveis no espaço de estados. Introduzimos duas propriedades que descrevem a torsão do fluxo local em torno de órbitas periódicas. Em 1985, U. Parlitz e W. Lauterborn propuseram a existência do número de rotação para quantificar a torsão provocada por um estado periódico em sua vizinhança no espaço de estados, a cada período do forçamento do oscilador. Adicionalmente, o número de torsão quantifica a torsão no espaço de estados devido a cada período da órbita periódica [71]. Com isso, usando as propriedades de torsão no espaço de estados como diagnóstico para conjuntos de parâmetros, novas interpretações a respeito de janelas periódicas complexas e suas sequências são aqui relatadas. 


\subsection{Sistemas Dinâmicos}

A solução de um sistema dinâmico dissipativo de dimensão $n$ consiste em conhecer, assintoticamente, o estado definido por $\mathbf{x}(\mathbf{t})=\mathbf{F}(\mathbf{x}(0), t)$, sendo $\mathbf{F}$ um operador evolução temporal definido no espaço $\mathbb{R}^{n}$, denominado espaço de estados. Assim, a solução no instante $t$ é obtida pelo operador evolução $\mathbf{F}$ aplicado sobre a condição inicial $\mathbf{x}(0)$. A evolução temporal do estado é explicitada pelas $n$ equações diferenciais de primeira ordem:

$$
\begin{array}{r}
\frac{d x_{1}}{d t}=f_{1}\left(x_{1}, x_{2}, \ldots x_{n}, t\right), \\
\frac{d x_{2}}{d t}=f_{2}\left(x_{1}, x_{2}, \ldots x_{n}, t\right), \\
\frac{d x_{n}}{d t}=f_{n}\left(x_{1}, x_{2}, \ldots x_{n}, t\right),
\end{array}
$$

onde $f_{j}: \mathbb{R}^{n} \times \mathbb{R}_{+} \longrightarrow \mathbb{R}$ é o campo de velocidades. Admitindo que $\mathbf{F}(\mathbf{x}(0), t)$ é a única solução da Eq. (2.1), destacam-se diferentes tipos de soluções assintóticas. Por exemplo, no caso de $f_{n}\left(x_{1}^{*}, x_{2}^{*}, \ldots, x_{n}^{*}, t\right)=0$ o estado $\mathbf{x}^{*}(t)$ é uma solução estacionária denominada estado de equilíbrio. Diferentemente, se existir um $T>0$ tal que $\mathbf{F}(\mathbf{x}(0), t+T)=$ $\mathbf{F}(\mathbf{x}(0), t)$ para todo intervalo de tempo $t$, então a solução $\mathbf{F}(\mathbf{x}(0), t)$ é chamada de órbita periódica e $T$ é o período da órbita periódica. Por outro lado, a não existência de um período $T$ definido, fundamenta a existência de órbitas irregulares e consequentemente a existência, no espaço de estados, de atratores que apresentam sensibilidade às condições iniciais chamados de atratores estranhos.

\subsection{Osciladores Não-Lineares Amortecidos e Força- $\operatorname{dos}$}

As oscilações amortecidas e forçadas aparecem em diferentes campos de estudo da física, por exemplo, em sistemas mecânicos, elétricos e quânticos [72, 73]. Esse tipo de oscilação é descrita por uma classe de equações diferenciais do tipo:

$$
\frac{d^{2} x}{d t^{2}}+k \frac{d x}{d t}-\frac{d V(x)}{d x}=h(t)
$$


$k$ é o parâmetro responsável pelo amortecimento, $V(x)$ é a forma do potencial gerador da força restauradora da oscilação e $h(t)$ é o forçamento do oscilador com $h(t)=h(t+T)$. A Eq. (2.2) é de segunda ordem e não-autônoma e para o tratamento numérico, essa equação pode ser escrita como um sistema de três equações autônomas de primeira ordem:

$$
\begin{aligned}
\frac{d x_{1}}{d t} & =x_{2}, \\
\frac{d x_{2}}{d t} & =-k x_{2}+\frac{d V\left(x_{1}\right)}{d x_{1}}+h\left(T x_{3}\right), \\
\frac{d x_{3}}{d t} & =\frac{1}{T},
\end{aligned}
$$

onde a equação de segunda ordem foi convertida em duas de primeira ordem, a equação adicional consiste na conversão do tempo, $t$, em uma dimensão extra, $x_{3}$. Esse procedimento elimina a dependência explicita das equações com o tempo. Portanto, os osciladores não-lineares são descrito por três equações diferenciais ordinárias, configurando um espaço de estados tridimensional.

A Eq. (2.2) é geral para os osciladores, essa equação pode ser alimentada com diferentes potenciais geradores $V(x)$, e com diferentes tipos de forçamento $h(t)$. Entretanto, nesta tese, restringimos nossas análises a forçamentos periódicos do tipo $h(t)=A \cos (\omega t)$ e a dois potenciais geradores bem conhecidos na literatura. O primeiro é o potencial que resulta em oscilações descritas pela equação de Duffing:

$$
\frac{d^{2} x}{d t^{2}}+d \frac{d x}{d t}-a x+b x^{3}=A \cos (\omega t)
$$

onde $d$ é o parâmetro que controla a dissipação, $a$ e $b$ são parâmetros provenientes do potencial e controlam sua forma, enquanto, $A$ e $\omega$ são parâmetros que controlam o forçamento externo.

Adicionalmente, utilizamos um potencial proveniente da atração molecular cujo a oscilação correspondente é descrita pela Equação de Morse:

$$
\frac{d^{2} x}{d t^{2}}+d \frac{d x}{d t}+8 e^{-x}\left(1-e^{-x}\right)=A \cos (\omega t)
$$

onde o parâmetro $d$ descreve a dissipação de energia, $A$ e $\omega$ são responsáveis pelo forçamento externo. 
Embora utilizemos apenas dois osciladores em nossas análises, não existe razão para que os resultados obtidos nesta tese não sejam confirmados para demais potenciais passíveis de implementação na Eq. (2.2). Conforme estudo realizado na Ref. [74] para vários potenciais, a investigação de curvas de bifurcação no espaço de parâmetros desses osciladores apresentou similaridades.

Os osciladores não-lineares amortecidos e forçados foram amplamente investigados na literatura. Por exemplo, assintoticamente no espaço de estados, foi observada a ocorrência de estados de equilíbrio, órbitas periódicas e atratores estranhos [75, 76]. Variando individualmente cada parâmetro de controle do sistema foram observados diferentes tipos de bifurcações, intermitências e rotas para o caos [77-79]. Adicionalmente, no espaço bidimensional de parâmetros foi observada a ocorrência de janelas periódicas complexas, isto é, estruturas com um corpo central denominado esqueleto (skeleton) [80] formado pela junção de duas parábolas com as extremidades estendidas em quatro direções do espaço de parâmetros. O corpo central é envolvido por curvas de bifurcação sela-nó e dobramento de período. Assim, diversas técnicas de análise foram desenvolvidas e aplicadas aos osciladores não lineares amortecidos e forçados. Na seção seguinte fornecemos uma visão geral das técnicas de análise incluindo o número de rotação generalizado, introduzido inicialmente em 1985 por U. Parlitz e W. Lauterborn, porém pouco utilizado desde então.

\subsection{Técnicas de Análise}

\subsubsection{Análise no Plano}

Os osciladores descritos pela Eq. (2.2) geram um fluxo tridimensional no espaço $\mathbb{R}^{2} \times$ $\mathbb{S}^{1}$, onde é $\mathbb{S}^{1}$ é o espaço $\pi$-cíclico, isto é, $\mathbb{S}:(t) \rightarrow(t+\pi)$. Porém, a dinâmica do oscilador pode ser visualizada em $\mathbb{R}^{2}$ através de projeções (planos de estados) e de seções transversais à órbita tridimensional (seções de Poincaré).

Para ilustrar a confecção de planos de estados e seções de Poincaré, utilizamos a Eq. 
(2.5) com a amplitude do forçamento periódico fixa em $A=2,5$, assim obtemos:

$$
\frac{d^{2} x}{d t^{2}}+d \frac{d x}{d t}+8 e^{-x}\left(1-e^{-x}\right)=2,5 \cos (\omega t)
$$

Através da variação dos parâmetros $d$ e $\omega$ ajustamos esse oscilador para oscilar periódica ou caoticamente.

A Equação 2.6 não é integrável. Para examinarmos suas soluções é necessário o emprego de técnicas numéricas. Nesta tese utilizamos o método de Runge-Kutta de quarta ordem com passo fixo em $h=0,005$.

Na Figura 2.1 mostramos um plano de estados com a solução do oscilador descrito pela Eq. (2.6). Este plano é obtido graficando a velocidade $\frac{d x}{d t}$ em função da posição $x$ para cada instante de tempo $t$. Na Figura 2.1(a), para os parâmetros de controle e as condições iniciais inseridas na Eq. (2.6), descontando um tempo inicial transiente na integração numérica, a trajetória tende a um estado final periódico. Por outro lado, na Fig. 2.1(b), os parâmetros de controle e as condições iniciais utilizadas levam a uma trajetória com estado final caótico.
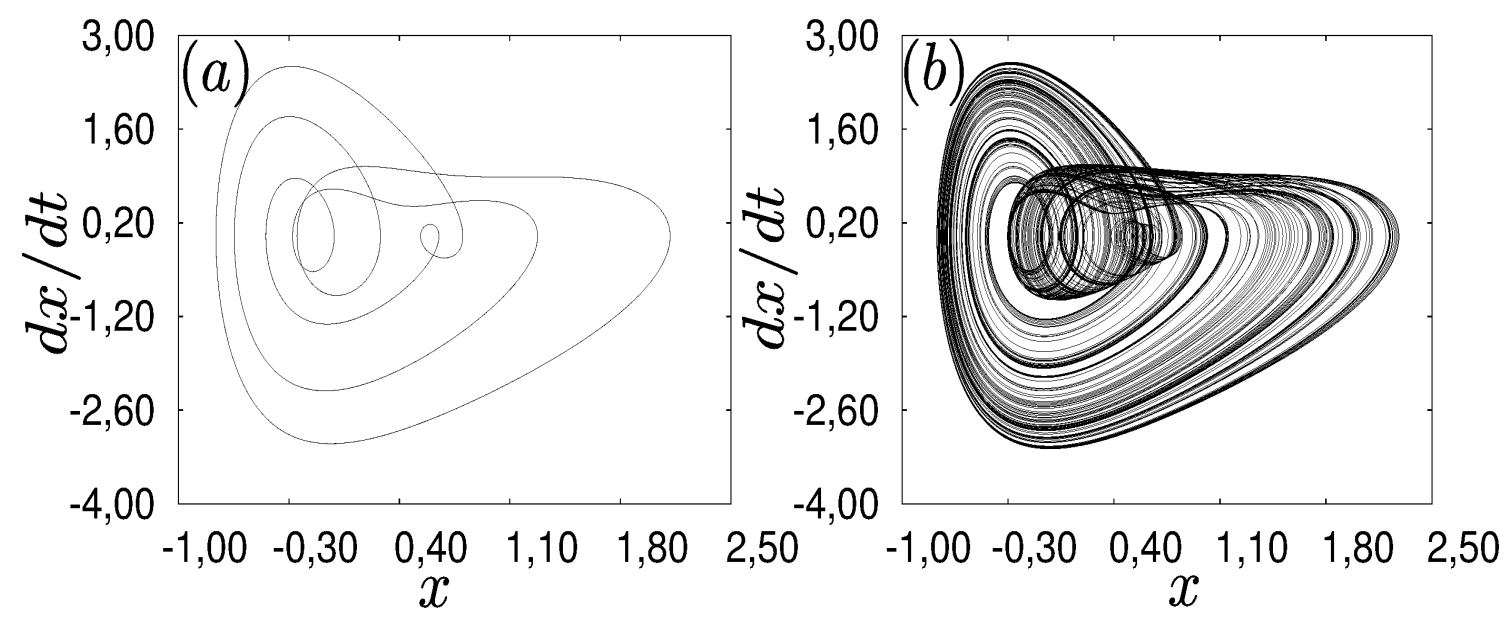

Figura 2.1: Plano de fase do oscilador de Morse. (a) Órbita periódica com parâmetros $d=0,7$ e $\omega=1,04$ (b) Órbita caótica com parâmetros $d=0,7$ e $\omega=1,0$.

Na Figura 2.2 mostramos uma seção de Poincaré estroboscópica da Eq. (2.6), onde a velocidade $\frac{d x}{d t}$ e a posição $x$ são coletadas no fluxo quando o tempo é um múltiplo inteiro do período de forçamento $T=2 \pi / \omega$. Na Figura 2.2(a), a seção estrosboscópica é obtida a partir de um estado periódico, cuja trajetória é obtida descontando-se um tempo 
transiente inicial. Na Figura 2.2(b), a seção estrosboscópica é obtida, também após um tempo transiente, a partir de um estado caótico.

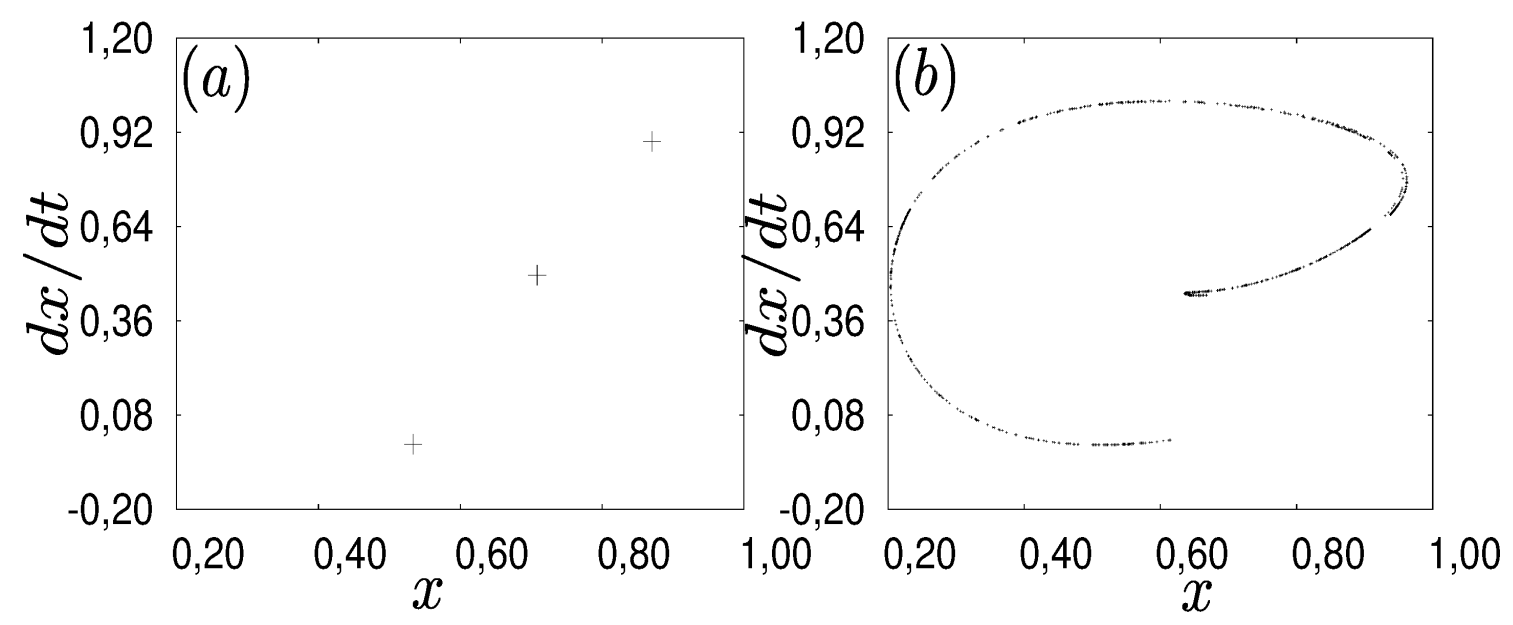

Figura 2.2: Seção de Poincaré estroboscópica do oscilador de Morse. (a) Órbita periódica com parâmetros $d=0,7$ e $\omega=1,04(b)$ Órbita caótica com parâmetros $d=0,7$ e $\omega=1,0$.

\subsubsection{Diagramas de Bifurcação}

O comportamento de trajetórias no espaço de estados está sujeito às perturbações nos parâmetros de controle do sistema. Sob tais variações, a trajetória em retratos de fases pode permanecer topologicamente equivalente ou pode ser topologicamente alterada. Nesse caso, a aparição de retratos de fases topologicamente não equivalentes configura uma bifurcação. Em geral, sistemas dinâmicos podem possuir um número indeterminado de parâmetros de controle, entretanto, bifurcações podem ocorrer sob a variação de apenas um deles. O número de parâmetros de controle a serem variados para que uma bifurcação ocorra é chamado de codimensão de uma bifurcação. Neste trabalho discutiremos apenas bifurcações de codimensão 1. Para bifurcações de codimensão 1, a análise é frequentemente realizada em diagramas em que os respectivos retratos de fases do parâmetro variado são estratificados em um intervalo fechado desses parâmetros, esses diagramas são denominados diagramas de bifurcação.

Em sistemas dinâmicos não-lineares de tempo contínuo, os diagramas de bifurcação são obtidos mapeando-se as variáveis de estado em mapas de Poincaré. Assim, a coordenada escolhida é graficada para um conjunto de parâmetros de controle igualmente espaçados. 
No diagrama de bifurcações observam-se intervalos de parâmetros correspondentes à dinâmica irregular interrompida por intervalos de parâmetros correspondentes à dinâmica regular, chamadas janelas periódicas. A Figura 2.3 mostra um diagrama de bifurcação da velocidade $\frac{d x}{d t}$ em função da amplitude do forçamento $A$. Nessa figura ilustramos a ocorrência de uma janela periódica delimitada por regiões de parâmetros correspondentes ao comportamento caótico.

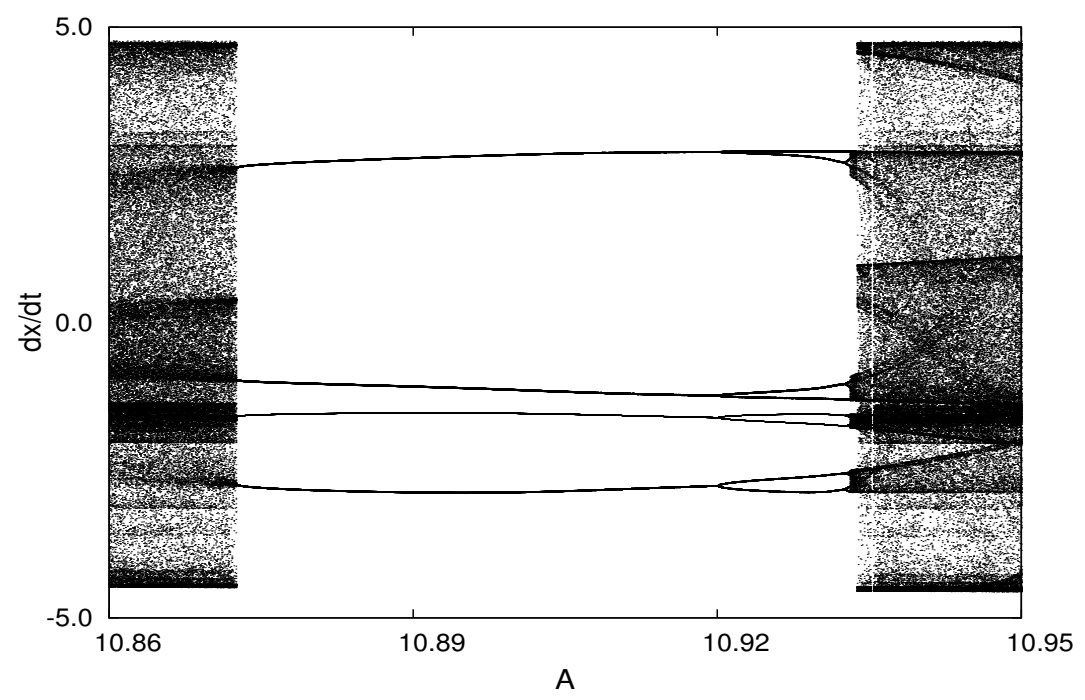

Figura 2.3: Diagrama de bifurcação da velocidade $\left(\frac{d x}{d t}\right)$ em função da amplitude do forçamento $A$, os demais parâmetros da Eq. (2.4) são fixados em $a=0,0, b=1,0, c=0,26$ e $\omega=1,0$.

As janelas periódicas são, geralmente, delimitadas por bifurcações tipo sela-nó e dobramento de período, conforme Figura 2.3. As bifurcações tipo sela-nó correspondem ao mecanismo no qual um de par de pontos de equilíbrio com estabilidade contrária é criado ou destruído. Na Figura 2.3, no sentido de aumento do parâmetro $A$, a janela periódica surge a partir de uma bifurcação sela-nó. Por outro lado, a bifurcação dobramento de período é o mecanismo no qual o período de estados periódicos é dobrado quando um parâmetro de controle atinge um valor crítico. Na Figura 2.3, uma vez dentro da janela periódica, o comportamento caótico à direita é oriundo de uma rota de dobramento de períodos.

Conforme verificamos nas Figuras 2.1, 2.2 e 2.3, planos de fases, seções de Poincaré e diagramas de bifurcação fornecem uma distinção visual entre o comportamento regular e o irregular, entretanto, esse diagnóstico é mais precisamente definido pelos expoentes de 
Lyapunov, discutidos a seguir.

\subsubsection{Expoentes de Lyapunov}

A principal propriedade dos sistemas dinâmicos caóticos é a sensibilidade às pequenas variações nas condições iniciais. Um sistema dinâmico representado por um operador evolução $\mathbf{F}$, que atua no espaço $\mathbb{R}^{n}$, apresenta sensibilidade às condições iniciais se sua evolução temporal satisfaz a seguinte definição [81]:

Definição 2.4.1 Dado $\epsilon>0$, tal que, para qualquer condição inicial $\mathbf{x}(0)$ e para qualquer número $\delta>0$, existe pelo menos uma condição inicial $\mathbf{x}^{\prime}(0)$ com $\left\|\mathbf{x}^{\prime}(0)-\mathbf{x}(0)\right\|<\delta$, tal que $\left\|F^{(k)}\left(x^{\prime}(0)\right)-F^{(k)}(x(0))\right\| \geq \epsilon$.

Então, a sensibilidade às condições iniciais expressa o fato que um sistema dinâmico caótico apresenta divergência de trajetória vizinhas em pelo menos uma das direções do espaço de estados. Essa é uma característica marcante da dinâmica caótica, sendo avaliada através do cálculo dos expoentes de Lyapunov. Com isso, esses expoentes de Lyapunov quantificam a divergência exponencial média da distância entre condições inciais.

Assim, no espaço de estados, o estado $\mathbf{x}(t)$ de um sistema dinâmico representado pelo operador evolução $\mathbf{F}$, que atua no espaço $\mathbb{R}^{n}$, possui $n$ números de Lyapunov, que medem a taxa média de separação de condições iniciais tomadas na vizinhança do estado inicial $\mathbf{x}(0)$. Assim, uma hiper-esfera infinitesimal preenchida com condições iniciais centrada no estado inicial $\mathbf{x}(0)$ pertencente à solução $\mathbf{x}(t)$, após a evolução temporal dada por $\mathbf{F}$, terá seu volume deformado, tornando-se um hiper-elipsóide. A Fig. 2.4 ilustra o caso $n=3$, em que uma esfera transforma-se em um elipsoide.

Supondo uma variação exponencial na $j$-ésima dimensão, $(j=1, \ldots, n)$, do raio inicial $r_{j}(0)$ da hiper-esfera, após um instante $t$ teremos:

$$
r_{j}(t)=r_{j}(0) e^{\lambda t}
$$

então a taxa de variação (número de Lyapunov) do raio da hiper-esfera, será:

$$
\frac{r_{j}(t)}{r_{j}(0)}=e^{\lambda t}
$$




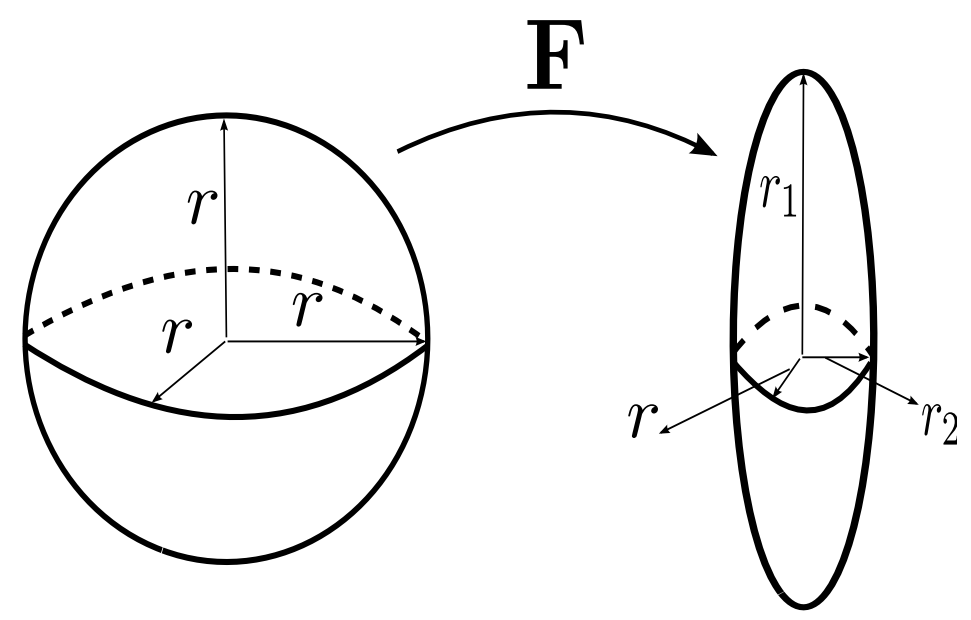

Figura 2.4: Deformação de uma esfera de condições iniciais causada pelo operador evolução F. A direção do deslocamento não sofre alteração, as demais direções participam do mecanismo de estica e dobra, ou seja, contração em uma direção e expansão em outra.

Reescrevendo essa relação teremos:

$$
\lambda_{j}=\frac{\ln \left[r_{j}(t) / r_{j}(0)\right]}{t}
$$

onde $\lambda_{j}$ são os chamados expoentes de Lyapunov.

Sistemas dinâmicos dissipativos contraem volume no espaço dos estados. Seja $V(t)$ o volume do hiper-elipsóide, temos:

$$
V(t) \propto \prod_{j=1}^{n} r_{j}(t)=V(0) e^{t \sum_{j=1}^{n} \lambda_{j}},
$$

assim, a dissipação $V(t)<V(0)$ implica:

$$
\sum_{j=1}^{n} \lambda_{j}<0
$$

Então, em um sistema dinâmico dissipativo, notamos que a soma dos expoentes de Lyapunov, sobre todas as direções do espaço de estados, é negativa.

O expoente de Lyapunov é nulo na direção correspondente à trajetória, já que dois pontos nessa direção, em média, sempre conservam a distância entre si. Nas direções onde a evolução temporal está, em média, aproximando dois pontos inicialmente afastados, os expoentes de Lyapunov serão sempre negativos. Por outro lado, dada uma direção em que dois pontos se afastam, em média, com a evolução temporal, o expoente de 
Lyapunov correspondente será positivo, nesse caso a dinâmica é denominada caótica com a ocorrência de atratores estranhos. A Tabela 1.1 mostra as diferentes configurações de expoentes Lyapunov para os diversos tipos de atratores existentes em um sistema dinâmico tridimensional.

\begin{tabular}{|c|c|}
\hline Atratores & Expoentes de Lyapunov \\
\hline Ponto de Equilíbrio & $\lambda_{1}<0, \lambda_{2}<0$ e $\lambda_{3}<0$ \\
\hline Ciclo Limite & $\lambda_{1}<0, \lambda_{2}<0$ e $\lambda_{3}=0$ \\
\hline Toro Bidimensional & $\lambda_{1}<0, \lambda_{2}=0$ e $\lambda_{3}=0$ \\
\hline Atrator Estranho & $\lambda_{1}>0, \lambda_{2}=0$ e $\lambda_{3}<0$ \\
\hline
\end{tabular}

Tabela 2.1: Valores assumidos pelos expoentes de Lyapunov em diferentes tipos de figuras atratoras em um espaço de estados tridimensional.

\subsubsection{Cálculo Numérico dos Expoentes de Lyapunov}

No caso de sistemas dinâmicos multidimensionais, a obtenção dos expoentes de Lyapunov apresenta dificuldades práticas. Especialmente na ocorrência de atratores estranhos, onde a divergência exponencial atrapalha o cálculo do afastamento médio de condições iniciais tomadas na sua vizinhança. Com isso, é necessário a utilização de técnicas que asseguram a existência de um valor médio para a separação (ou aproximação) das condições iniciais na vizinhança do atrator do qual desejamos obter o espectro de Lyapunov. Um algoritmo eficiente foi introduzido por Wolf et al. em 1985, onde a convergência das condições iniciais é avaliada através da variação no comprimento dos eixos principais definidos por uma linearização em torno do atrator em análise [68]. Pois, por definição, eixos principais definidos pelo sistema linearizado estão sempre infinitesimalmente separados do atrator.

Inicialmente, para um sistema dinâmico de dimensão $n$, as equações não-lineares que o descrevem são, numericamente, integradas a partir de $n$ condições iniciais. Depois de um tempo transiente, resulta a trajetória-referencial, para a qual obteremos o espectro de Lyapunov. Adicionalmente, informações do espaço tangente a essa trajetória são obtidas pela integração das equações linearizadas a partir de condições iniciais que definem um 
conjunto ortonormal de $n$ vetores centrados na trajetória-referencial. Com a evolução temporal, a magnitude desses vetores é afetada por mudanças topológicas no espaço de estados, registrando as possíveis deformações. Entretanto, os vetores linearizados também divergem em módulo e alinham-se na direção de maior rapidez na divergência, tornando-se indistinguíveis. Nesse ponto, a partir do vetor resultante que aponta na direção de maior rapidez na divergência, um conjunto de vetores ortogonais é reconstruído utilizando-se o método de Gram-Schmidt, o módulo dos vetores desse conjunto é armazenado para obter a divergência média em todas as direções. Então, o conjunto é renormalizado, o sistema é evoluído por mais um tempo característico, e esse processo é repetido por número prédeterminado de vezes para obtenção dos valores médios.

A Figura 2.5 ilustra, graficamente, a implementação do algoritmo discutido acima para um sistema dinâmico tridimensional. O conjunto $\left\{v_{1}^{(0)}, v_{2}^{(0)}, v_{3}^{(0)}\right\}$ representa os vetores ortonormais definidos inicialmente, as equações não-lineares e linearizadas são integradas por um tempo característico $\Delta t$. Os vetores, inicialmente ortonormais, alinham-se na direção de maior rapidez na divergência (nesse caso direção do vetor $v_{1}^{\left(0^{\prime}\right)}$ ), dando origem ao conjunto $\left\{v_{1}^{\left(0^{\prime}\right)}, v_{2}^{\left(0^{\prime}\right)}, v_{3}^{\left(0^{\prime}\right)}\right\}$ (vetores coloridos na Figura 2.5). Esses vetores são então ortogonalizados a partir da direção de $v_{1}^{\left(0^{\prime}\right)}$, seus módulos $\left(\left|v_{1}^{\left(0^{\prime}\right)}\right|,\left|v_{2}^{\left(0^{\prime}\right)}\right|,\left|v_{3}^{\left(0^{\prime}\right)}\right|\right)$ são então armazenados, em seguida esses vetores são normalizados dando origem à nova base $\left\{v_{1}^{(1)}, v_{2}^{(1)}, v_{3}^{(1)}\right\}$, o sistema é novamente integrado por um tempo característico $\Delta t$, esse processo é repetido por $j$ vezes, e a divergência média dos módulos desses vetores é obtida.

Na Figura 2.6, mostramos a convergência dos três expoentes de Lyapunov obtidos para o oscilador de Morse descrito pela Eq. (2.5). Na Figura 2.6(a) mostramos a convergência dos expoentes de Lyapunov para uma órbita periódica, notamos a ocorrência de dois expoentes negativos e um expoentes nulo, que correspondente a direção do movimento no espaço de estados. Por outro lado, na Figura 2.6(b) mostramos a convergência para os parâmetros ajustados em uma órbita caótica, nesse caso, destacamos a ocorrência de um expoente positivo referente a direção do espaço de estados que afasta condições iniciais durante a evolução temporal do sistema. 


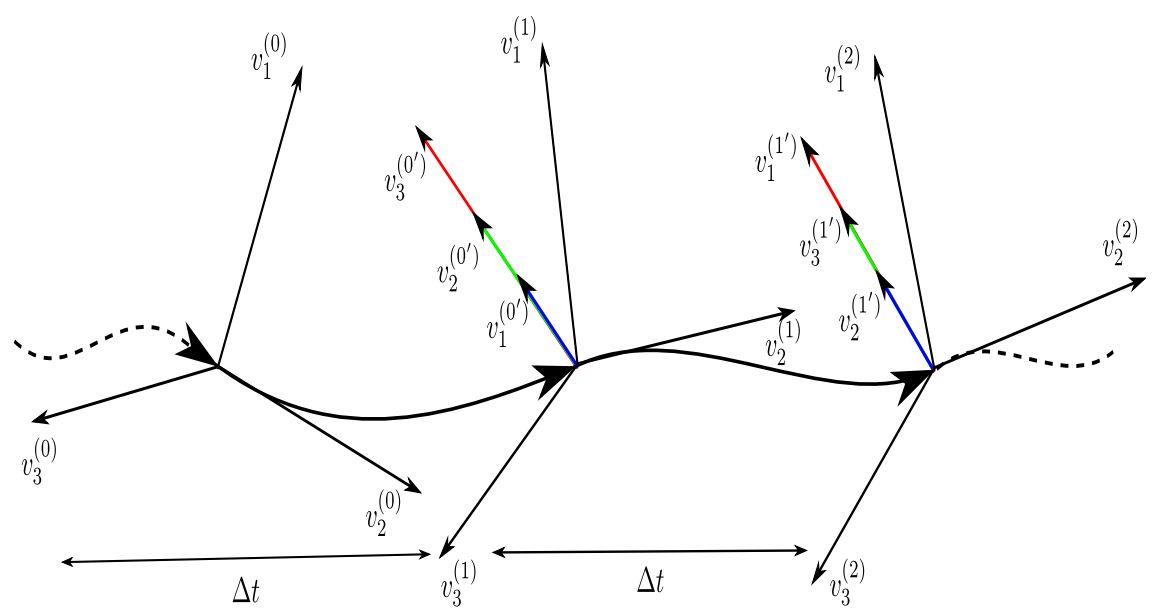

Figura 2.5: Os vetores $\left\{v_{1}^{(0)}, v_{2}^{(0)}, v_{3}^{(0)}\right\}$ formam uma base ortonormal, após um período de integração $\Delta t$ esses vetores alinham-se na direção de maior rapidez na divergência indicada pelo conjunto colorido de vetores $\left\{v_{1}^{\left(0^{\prime}\right)}, v_{2}^{\left(0^{\prime}\right)}, v_{3}^{\left(0^{\prime}\right)}\right\}$.
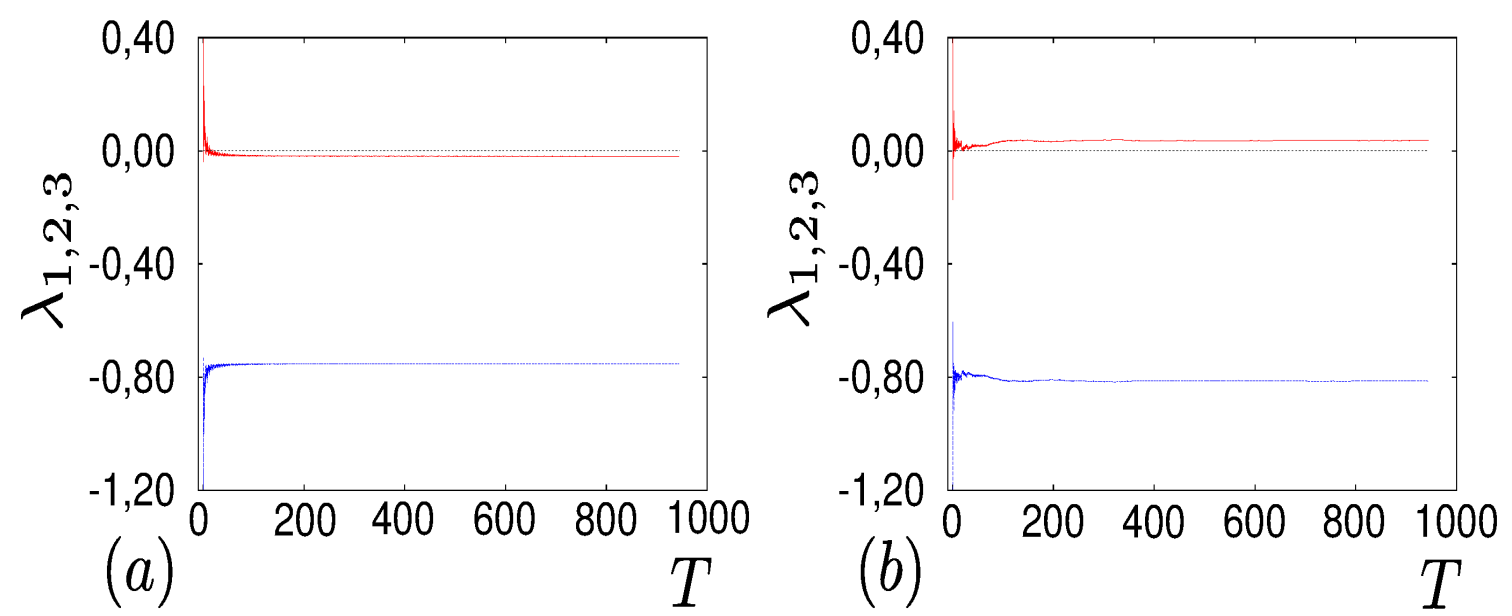

Figura 2.6: Perfil de convergência dos três expoentes de Lyapunov $\lambda_{1}, \lambda_{2}, \lambda_{3}$ como função do tempo em unidades do forçamento $T$ do oscilador de Morse descrito pela Eq. (2.5). (a) Órbita periódica com parâmetros de controle fixos em $A=2,5, d=0,771898$ e $\omega=0,593742$. (b) Órbita caótica com parâmetros de controle fixos em $A=2,5, d=0,777575$ e $\omega=0,593290$. A linha vermelha representa o maior expoente $\lambda_{1}$. 


\subsubsection{Número de Rotação para Osciladores Forçados}

Para sistemas dinâmicos conservativos com dois graus de liberdade, dada as constantes de movimento adequadas, o movimento no espaço de fases é convenientemente representado em superfícies toroidais. Nessas superfícies são definidas duas frequências específicas, a frequência poloidal $\omega_{1}$ na direção transversal ao torus, e a frequência toroidal $\omega_{2}$ definida no plano do torus. A razão entre as frequências poloidal e toroidal é chamada de número de rotação,

$$
w=\frac{\omega_{2}}{\omega_{1}}
$$

onde $w$ fornece um diagnóstico do movimento na superfície toroidal. Se $w$ é um número racional, isto é, pode ser escrito por uma razão $w=n / m$ com $n$ e $m$ inteiros, então, a trajetória contida no toro se fecha após um número $n$ de voltas na direção poloidal e após um número $m$ de voltas na direção toroidal. Nesse caso, o movimento é chamado de periódico. Por outro lado, se $w$ é um número irracional, a trajetória não se fecha na superfície toroidal, nesse caso, para $t \rightarrow \infty$ a trajetória cobre toda a superfície do toro, e o movimento é chamado de quase-periódico [81].

Adicionalmente às superfícies toroidais, o conceito de número de rotação pode ser estendido às soluções atratoras periódicas características de sistemas dinâmicos dissipativos. Isso é realizado relacionando-se o próprio período de oscilação da órbita periódica atratora, ou períodos intrínsecos do sistema, com o período de torsão do fluxo em sua vizinhança. Por exemplo, considerando-se a rotação média de trajetórias vizinhas a uma determinada órbita periódica, U. Parlitz e W. Lauterborn propuseram uma definição de número de rotação generalizado para osciladores não-lineares [71, 82].

Assim, essa definição de número de rotação é introduzida para a classe de sistemas dinâmicos descritos pela seguinte equação diferencial,

$$
\frac{d^{2} x}{d t^{2}}+j\left(x, \frac{d x}{d t}\right)=h(t)
$$

onde $h(t)=h\left(t+T_{f}\right)$ é o forçamento periódico do sistema com período $T_{f}=2 \pi / \omega_{f}$. Essa classe de sistemas dinâmicos corresponde aos osciladores caóticos, apenas renomeamos o período do forçamento como $T_{f}$ ao invés $T$. Escrevendo a Eq. (2.13) como um conjunto 
de equações diferencias de primeira ordem, obtemos,

$$
\begin{aligned}
\frac{d x_{1}}{d r} & =x_{2} \\
\frac{d x_{2}}{d t} & =-j\left(x_{1}, x_{2}\right)+h\left(T_{f} x_{3}\right) \\
\frac{d x_{3}}{d t} & =1 / T_{f}=\omega_{f} / 2 \pi .
\end{aligned}
$$

O sistema dinâmico descrito pela Eq. (2.14) gera um fluxo com coordenadas espaciais em $\mathbb{R}^{2}$ e coordenada temporal em $\mathbb{S}^{1}$ ( $\pi$-cíclico), fornecendo um espaço de estados tridimensional em $\mathbb{R}^{2} \times \mathbb{S}^{1}$. Adicionalmente, a Eq. (2.14) tem solução em cada instante, dada por $\mathbf{x}(t)=\mathbf{F}(\mathbf{x}(0), t)=\left(x_{1}(t), x_{2}(t), x_{3}(t)\right)$. Uma possível seção de Poincaré $P=\left.\mathbf{F}^{T_{f}}\right|_{\Sigma}$ para a solução $\mathbf{F}\left(\mathbf{x}_{\mathbf{0}}, t\right)$ é dada no seguinte plano transversal à trajetória,

$$
\Sigma=\left\{\left(x_{1}, x_{2}, x_{3}\right), \in \mathbb{R}^{2} \times \mathbb{S}^{1}: x_{3}=c=\text { constante }\right\} \approx \mathbb{R}^{2}
$$

Essa seção reduz a análise do fluxo a um mapa no plano $\mathbb{R}^{2}$, onde uma órbita de período $T$ é representada por $m$ pontos no mapa $P$, sendo o período $T$, escrito como $T=m T_{f}$. Por outro lado, considerando o mapa $P^{m}$, a trajetória definida pela solução $\mathbf{x}(t)=\mathbf{F}(\mathbf{x}(0), t)$ secciona $P^{m}$ em um ponto fixo com coordenadas definidas por $\mathbf{x}_{f}=\mathbf{F}_{f}(\mathbf{x}(0))=\left\{x_{1 f}, x_{2 f}\right\} \in \mathbb{R}^{2}$.

A torsão no espaço de fases causada pela solução $\mathbf{F}(\mathbf{x}(0), t)$ é obtida através do número de rotações média que uma órbita vizinha $\mathbf{y}(t)=\mathbf{F}(\mathbf{y}(0), t)$, descrita no plano $\Sigma$ por $\mathbf{y}_{f}(0)=\mathbf{F}_{f}(\mathbf{y}(0))$, realiza em torno da solução $\mathbf{F}(\mathbf{x}(0), t)$ em questão. A dinâmica de uma solução $\mathbf{y}(t)$ na vizinhança de $\mathbf{x}(t)$ é obtida aproximando-se a própria solução $\mathbf{x}(t)$ por séries de Taylor. Assim, escrevendo a Eq. (2.14) em uma forma genérica, obtemos:

$$
\begin{aligned}
\dot{x}_{1}=f\left(x_{1}, x_{2}, x_{3}\right) & =f\left(x_{1 f}^{*}, x_{2 f}^{*}, \text { constante }\right)+ \\
\left.\frac{\partial f}{\partial x_{1}}\right|_{P^{m}}\left(x_{1}-x_{1 f}^{*}\right)+\left.\frac{\partial f}{\partial x_{2}}\right|_{P^{m}}\left(x_{2}-x_{2 f}^{*}\right), & \\
\dot{x}_{2}=g\left(x_{1}, x_{2}, x_{3}\right) & =g\left(x_{1 f}^{*}, x_{2 f}^{*}, \text { constante }\right)+ \\
\left.\frac{\partial g}{\partial x_{1}}\right|_{P^{m}}\left(x_{1}-x_{1 f}^{*}\right)+\left.\frac{\partial g}{\partial x_{2}}\right|_{P^{m}}\left(x_{2}-x_{2 f}^{*}\right), & \\
\dot{x}_{3}=u\left(x_{1}, x_{2}, x_{3}\right) & =0,
\end{aligned}
$$

onde $P^{m}$ é a $m$-ésima iteração do mapa $P$. Como $x_{3}=$ constante, escolhemos $x_{3}=0$, 
escrevendo $\mathbf{y}(t)$ como

$$
\begin{aligned}
& y_{1}(t)=x_{1}(t)-y_{1 f}^{*} \\
& y_{2}(t)=x_{2}(t)-y_{2 f}^{*} .
\end{aligned}
$$

Em consequência obtemos,

$$
\begin{aligned}
& \dot{y}_{1}=\dot{x}_{1}, \\
& \dot{y}_{2}=\dot{x}_{2} .
\end{aligned}
$$

Além disso, na Eq. (2.16), temos:

$$
\begin{aligned}
& f\left(x_{1 f}^{*}, x_{2 f}^{*}, 0\right)=0, \\
& g\left(x_{1 f}^{*}, x_{2 f}^{*}, 0\right)=0, \\
& u\left(x_{1 f}^{*}, x_{2 f}^{*}, 0\right)=0,
\end{aligned}
$$

já que $\left(x_{1 f}, x_{2 f}\right)$ são pontos fixos do mapa $P^{m}$. Substituindo as Eqs. (2.17) e (2.18) na Eq. (2.16), obtemos:

$$
\begin{aligned}
& \dot{y}_{1}=\left.\left(\frac{\partial f}{\partial x_{1}}\right)\right|_{P^{m}} y_{1}+\left.\left(\frac{\partial f}{\partial x_{2}}\right)\right|_{P^{m}} y_{2}, \\
& \dot{y}_{2}=\left.\left(\frac{\partial g}{\partial x_{1}}\right)\right|_{P^{m}} y_{1}+\left.\left(\frac{\partial g}{\partial x_{2}}\right)\right|_{P^{m}} y_{2} .
\end{aligned}
$$

Substituindo na Eq. (2.19) as funções $f$ e $g$ de acordo com a Eq. (2.14), obtemos:

$$
\begin{aligned}
& \dot{y}_{1}=y_{2}, \\
& \dot{y}_{2}=-\frac{\partial j\left(x_{1}, x_{2}\right)}{\partial x_{1}} y_{1}-\frac{\partial j\left(x_{1}, x_{2}\right)}{\partial x_{2}} y_{2} .
\end{aligned}
$$

A solução da equação (2.20) descreve o comportamento de uma órbita $\mathbf{y}(t)$ vizinha à trajetória $\mathbf{x}(t)$ considerada.

Dado que inicialmente $\mathbf{y}(t)$ está afastada da trajetória periódica de uma distância $y(0)$, com a evolução temporal e com as características dissipativas do fluxo, $\mathbf{y}(t)$ descreve 
uma trajetória do tipo espiral em torno da trajetória periódica. Assim, reescrevendo a Eq. (2.20) em coordenadas circulares $(r, \beta)$, a variação temporal de $\beta$ será a velocidade angular com que $\mathbf{y}(t)$ gira em torno de $\mathbf{x}(t)$. Fazendo,

$$
y_{1}=r \operatorname{sen} \beta ; \quad y_{2}=r \cos \beta ; \quad r^{2}=y_{1}^{2}+y_{2}^{2},
$$

a variação temporal de $\beta$ é encontrado por

$$
\frac{d}{d t}(\operatorname{sen} \beta)=\dot{\beta} \cos \beta \rightarrow \dot{\beta}=\frac{\frac{d}{d t}(\operatorname{sen} \beta)}{\cos \beta}
$$

substituindo a Eq. (2.21) na Eq. (2.22), obtemos:

$$
\dot{\beta}(t)=\frac{y_{1} \dot{y}_{2}-\dot{y}_{1} y_{2}}{y_{1}^{2}+y_{2}^{2}} .
$$

A velocidade angular média $\Omega=|<\dot{\beta}(t)>|$ é obtida por

$$
\Omega=\lim _{t \rightarrow \infty} \frac{1}{t}\left|\int_{0}^{t} \dot{\beta}\left(t^{\prime}\right) \mathrm{d} t^{\prime}\right|=\lim _{t \rightarrow \infty} \frac{|\beta(t)-\beta(0)|}{t} .
$$

A frequência angular média Eq. (2.24) é chamada frequência de torsão. A Figura 2.7 ilustra o procedimento de obtenção dessa frequência, $\gamma$ e $\gamma^{\prime}$ são, respectivamente, a órbita periódica e sua vizinha obtida pela linearização, à partir da diferença angular $\beta(t)-\beta(0)$, mostrada nessa figura, obtivemos a frequência de torsão.

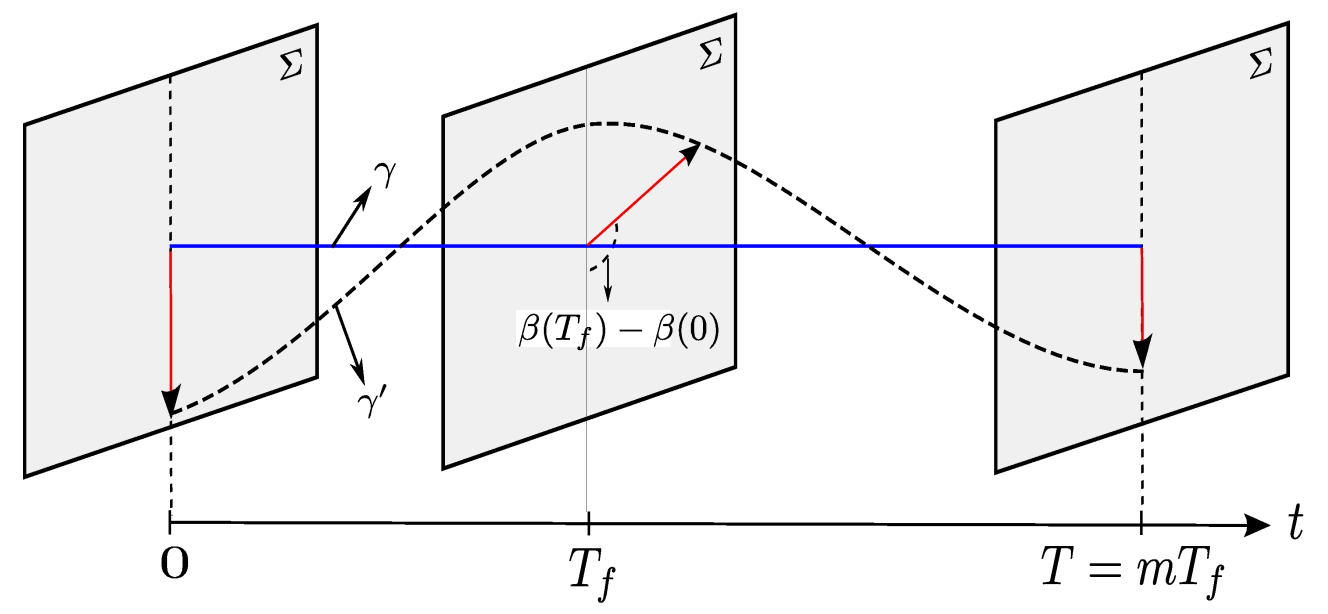

Figura 2.7: A linha azul indica a órbita periódica $\gamma$ de período $T$, enquanto a linha pontilhada representa a órbita vizinha $\gamma^{\prime}$ obtida através da linearização. Os planos $\Sigma$ reseprentam o mapa de Poincaré estroboscópico definido através do período de forçamento $T_{f}$ do oscilador. 
Assim, da expresão para a frequência de torsão obtemos facilmente o período de torsão dado por:

$$
T_{\Omega}=\frac{2 \pi}{\Omega}
$$

Com isso, o número de rotação $w$ para osciladores forçados é definido pela razão entre o período do forçamento $T_{f}$ e o período da torsão $T_{\Omega}$, então:

$$
w=\frac{T_{f}}{T_{\Omega}} \rightarrow w=\frac{\Omega}{\omega_{f}} .
$$

Na Figura 2.8 mostramos a convergência do número de rotação, $w$, em função do tempo de integração em unidades do período de forçamento do oscilador de Morse descrito pela Eq. (2.5). Destacamos que o método deduzido nessa seção oferece resultados convergentes, obtivemos $w=3,0$ para essa experiência teste.

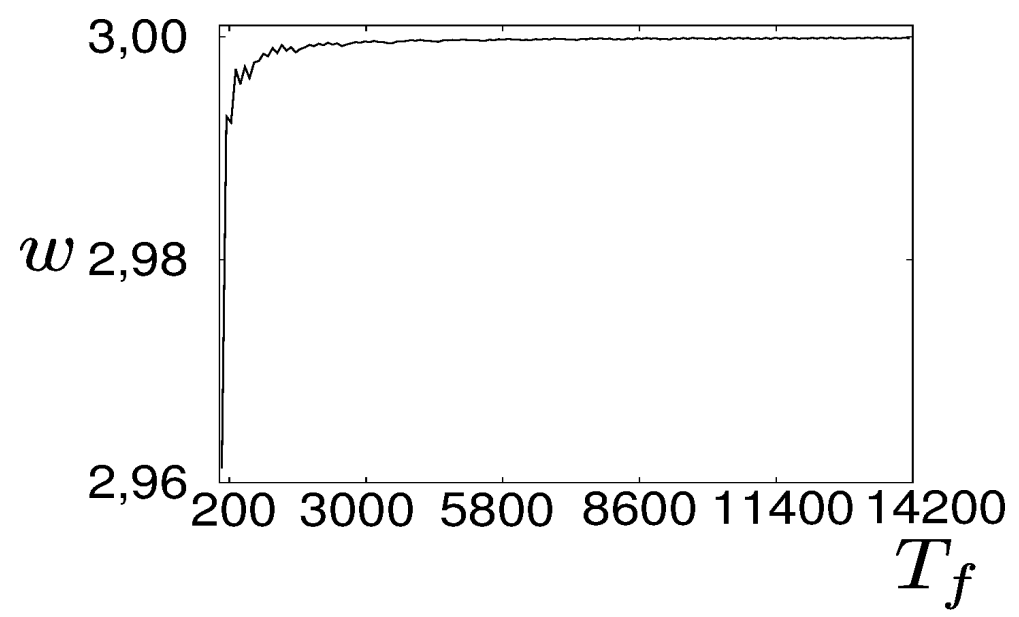

Figura 2.8: Perfil de convergência do número de rotação $w$ como função do tempo em unidades do forçamento $T_{f}$ do oscilador de Morse descrito pela Eq. (2.5). Os parâmetros de controle estão fixos em $A=2,5$, $d=0,771898$ e $\omega_{f}=0,593742$.

Adicionalmente ao número de rotação $w$, para órbitas periódicas, definimos o numero de torsão $n$ dado pela razão entre o período da órbita periódica $T$ e o período de torsão $T_{\Omega}$,

$$
n=\frac{T}{T_{\Omega}} \rightarrow n=\frac{m T_{f}}{T_{\Omega}} \rightarrow n=m w .
$$

Assim, $w$ e $n$ fornecem informações quantitativas das condições de torsão do fluxo vizinho às órbitas periódicas no espaço de fases de osciladores não-lineares forçados. 


\subsubsection{Espaço dos Parâmetros e Janelas Periódicas Complexas}

Usualmente, a dependência dos sistemas dinâmicos em relação aos parâmetros também é explorada em diagramas bidimensionais de parâmetros, chamados espaço de parâmetros [7]. Nestes diagramas, considera-se uma grade bidimensional de parâmetros de controle igualmente espaçados, para cada elemento na grade avalia-se a dinâmica através de uma ferramenta de diagnóstico, por exemplo, expoentes de Lyapunov, números de rotação, contagens de período, etc. No espaço de parâmetros, as janelas periódicas são estruturas bidimensionais complexas, Fig. 2.9(a). Possuem esqueleto (skeleton) central formado pela junção de duas parábolas com as extremidades estendidas em quatro direções do espaço de parâmetros, representado pelas curvas azuis na Fig. 2.9(b). O esqueleto é envolvido por curvas de bifurcação tipo sela-nó, curvas verdes na Fig. 2.9(b), e dobramento de período (flip), curvas vermelhas na Fig. 2.9(b), delimitando quatro áreas internas conforme mostrado na Figura 2.9. Essa estrutura será aqui denominada corpo principal da janela periódica, uma vez que a estrutura periódica contínua além das curvas de bifurcações tipo dobramento de período, representada na Figura 2.9(b) por $d p$.

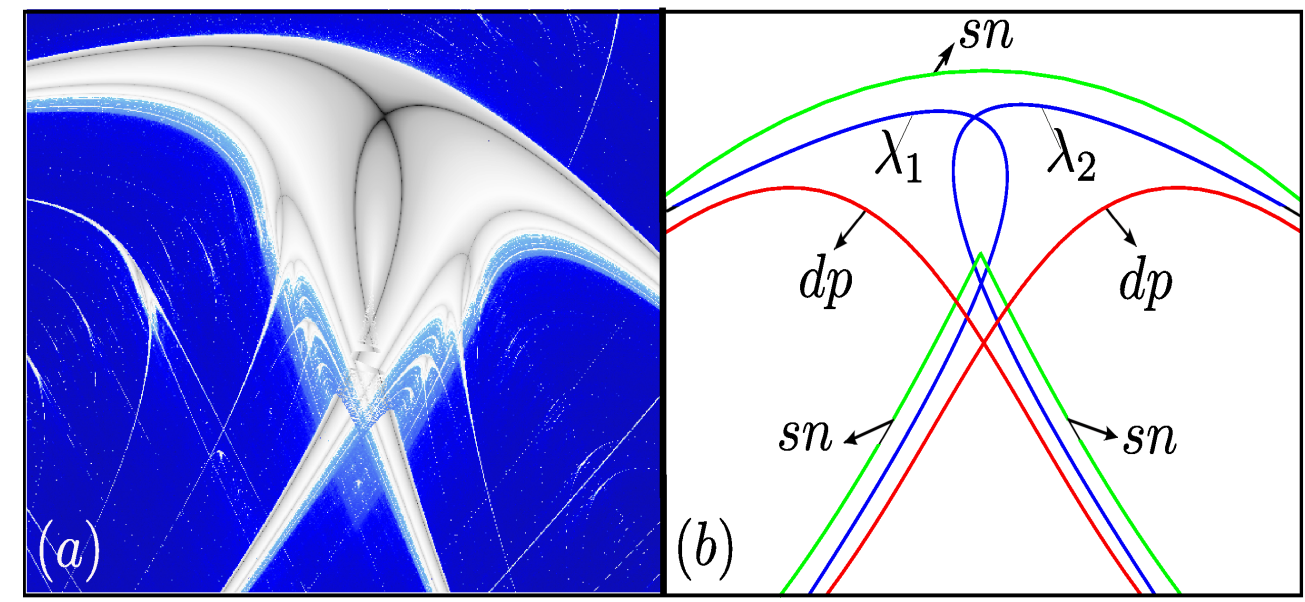

Figura 2.9: (a) Espaço de parâmetros obtido através do cálculo do maior expoente de Lyapunov de uma grade bidimensional de parâmetros. Os parâmetros marcados em escala de cinza correspondem à periodicidade, isto é, maior expoente de Lyapunov menor que zero (janela periódica complexa). Os parâmetros marcados em azul correspondem ao comportamento caótico, maior expoente de Lyapunov maior que zero. (b). Esquema destacando o corpo central de uma janela periódica complexa. As curvas $\lambda_{1}$ e $\lambda_{2}$ compõem o esqueleto da janela. Enquanto $s n$ são curvas de bifurcações tipo sela-nó e $d p$ são curvas de bifurcações tipo dobramento de período. 


\subsection{Conclusão}

Neste capítulo, inicialmente, introduzimos alguns conceitos gerais da teoria de sistemas dinâmicos com foco nos osciladores não-lineares. Em seguida discutimos as características do espaço de estados tridimensional desses osciladores e as principais técnicas para reduzir a análise das trajetórias para duas dimensões. Nesta tese, a identificação da dinâmica caótica é realizada com auxílio dos expoentes de Lyapunov, introduzidos conceitualmente na Subseção 2.3.3 e numericamente na subseção 2.3.4. Adicionalmente neste capítulo, introduzimos o número de rotação, grandeza que contabiliza a torsão média que o fluxo local realiza na vizinhança de um estado. 


\section{Capítulo 3}

\section{Replicação de Janelas Periódicas no Espaço dos Parâmetros}

Sistemas dinâmicos não-lineares são suscetíveis a mudanças de comportamento quando submetidos à perturbações em seus parâmetros de controle. Neste capítulo, adicionamos às equações dos osciladores caóticos uma pequena perturbação periódica para investigar a extinção de estados caóticos. Através da confecção do espaço de parâmetros, observamos as consequências da aplicação dessa perturbação em um conjunto de parâmetros. Assim, constatamos que as pequenas perturbações periódicas produzem réplicas das janelas periódicas complexas existentes no espaço de parâmetros desses osciladores. Com isso, verificamos que a supressão de caos obtida através de pequenas perturbações periódicas $[57,58]$ é robusta no espaço de parâmetros.

\subsection{Introdução}

Em osciladores caóticos, esforços foram concentrados na tentativa de controlar e suprimir o comportamento caótico. Destaca-se a utilização de técnicas de controle denominadas de sem-monitoramento (nonfeedback) [83]. Em contraste com métodos de controle com monitoramento (feedback) [84], essa técnica visa suprimir a dinâmica caótica sem a necessidade da identificação prévia e monitoração de órbitas periódicas instáveis imersas no estado caótico. Por exemplo, em 1991 Y. Braiman e I. Goldhirsch suprimiram a dinâmica 
caótica aplicando uma perturbação periódica de pequena amplitude às equações que descrevem o oscilador de Josephson [57]. Posteriormente, Z. Qu et al. demonstraram que o controle de caos em osciladores caóticos pode ser alcançado variando apenas a fase dessa pequena perturbação periódica [58]. Contudo, a eficácia da pequena perturbação periódica em suprimir a dinâmica caótica foi avaliada apenas para alguns intervalos limitados dos parâmetros de controle dos osciladores caóticos. Assim, uma avaliação coletiva da eficiência da supressão de caos para um conjunto amplo de parâmetros de controle do oscilador permanece em aberto na literatura.

Nesse capítulo, investigamos as alterações provocadas por uma pequena perturbação periódica em um conjunto de parâmetros de controle de osciladores caóticos. Inicialmente, através do cálculo dos expoentes de Lyapunov, obtemos o espaço de parâmetros do oscilador de Duffing não-perturbado e verificamos a existência de janelas periódicas complexas. Constatamos que a pequena perturbação periódica suprime a dinâmica caótica para um conjunto de parâmetros do oscilador de Duffing. Pela primeira vez na literatura, verificamos que a pequena perturbação periódica replica as janelas periódicas complexas no espaço de parâmetros dos osciladores caóticos.

\subsection{Pequena Perturbação Periódica}

A ocorrência de dinâmica irregular ou caótica é amplamente observada em diversos sistemas dinâmicos. Nas duas últimas décadas muitos esforços foram concentrados na tentativa de controlar esse comportamento [83-85]. Nesse cenário destacam-se dois métodos, controle com e sem monitoramento (feedback). O controle de caos com monitoramento está baseado na existência de infinitas órbitas instáveis imersas no atrator caótico. Uma órbita instável com período desejado é localizada, a trajetória é colocada em sua vizinhança através de uma perturbação, é então monitorada e, à medida que ela se afasta da orbita instável escolhida, novas perturbações são introduzidas [84]. A principal dificuldade de implementação dos métodos com monitoramento consiste em determinar a localização de uma órbita periódica com o período desejado. Por outro lado, os métodos sem monitoramento consistem em inserir pequenas perturbações nos parâmetros de controle do 
sistema ou o adicionamento de um pequeno forçamento externo no sistema [83].

Sabemos que os osciladores caóticos são descritos pela seguinte equação de movimento:

$$
\frac{d^{2} x}{d t^{2}}+j\left(x, \frac{d x}{d t}\right)=h(t)
$$

onde $h(t)=h\left(t+T_{1}\right)$ é uma função periódica com frequência angular $\omega=2 \pi / T_{1}$. O controle de caos através do adicionamento de um pequeno forçamento externo foi extensivamente investigado nestes sistemas $[57,58,83]$. Com o adicionamento de um pequeno forçamento, a equação que descreve esses osciladores é:

$$
\frac{d^{2} x}{d t^{2}}+j\left(x, \frac{d x}{d t}\right)=h(t)+f(t)
$$

onde $f(t)=f\left(t+T_{2}\right)$ também é uma função periódica com frequência angular $\Omega=2 \pi / T_{2}$.

Contudo, os estudos realizados, principalmente os numéricos, consideram apenas alguns parâmetros limitados do sistema. Uma análise do pequeno forçamento externo para um amplo conjunto de parâmetros fornecerá informações, por exemplo, se o período da órbita controlada é proveniente de órbitas periódicas de parâmetros vizinhos, se o controle é "robusto" nos parâmetros, ou seja, se a órbita controlada continua existindo para parâmetros vizinhos, etc.

\subsection{Replicação de Janelas Periódicas Pelas Pequenas Perturbações Periódicas}

A análise do pequeno forçamento externo para um conjunto de parâmetros pode ser realizada utilizando diagramas em que dois parâmetros são variados, os chamados espaços de parâmetros. Conforme discutido no Capítulo 1, o espaço de parâmetros é obtido calculando-se o maior expoente de Lyapunov para cada ponto de uma grade bidimensional de parâmetros de controle do sistema. No espaço de parâmetros, os parâmetros correspondentes às órbitas periódicas estão agrupados em áreas contínuas denominadas janelas periódicas.

Como visto no Capítulo 1, frequentemente, as janelas periódicas são estruturas complexas, com um corpo central denominado esqueleto (skeleton) formado pela junção de duas 
parábolas com as extremidades estendidas em quatro direções do espaço de parâmetros. O corpo central é envolvido por curvas de bifurcação sela-nó e dobramento de período. Com a aplicação do forçamento adicional, os parâmetros correspondentes às órbitas caóticas serão alcançados por estruturas periódicas complexas provenientes da replicação de janelas periódicas previamente existentes.

\subsubsection{Oscilador de Duffing}

O oscilador de Duffing é um modelo utilizado na descrição de uma massa sob a influência de um potencial simétrico de quarta ordem [30]. Conforme discutido no Capítulo 1, esses sistemas tem um grande número de aplicações, especialmente por modelar sistemas físicos, e foi extensivamente investigado em estudos teóricos, numéricos e experimentais.

A evolução temporal deste sistema é determinada pela solução numérica da seguinte equação diferencial adimensional:

$$
\frac{d^{2} x}{d t^{2}}+c \frac{d x}{d t}+x^{3}=A \cos (\omega t)
$$

O parâmetro $c$ é a amplitude do amortecimento do sistema, $A$ é a amplitude do forçamento natural do sistema e $\omega$ é a frequência do forçamento, em todas as simulações está fixada em $\omega=1$. A equação de Duffing Eq. (3.3) foi numericamente integrada através do método de Runge-Kutta de quarta ordem com passo fixo em $h=0,001$. Em todas as integrações numéricas realizadas nesse capítulo, a solução da Eq. (3.3) foi considerada após um tempo transiente inicial de 200 períodos do forçamento original do sistema dado por $T_{1}=2 \pi / \omega$.

Na Figura 3.1, mostramos o espaço de parâmetros bidimensional $(c \times A)$ obtido para o oscilador de Duffing. As características de maior expoente de Lyapunov de cada ponto na grade bidimensional são representadas através da atribuição de diferentes cores. $\mathrm{Na}$ Figura 3.1, os parâmetros correspondentes aos atratores caóticos (expoentes de Lyapunov positivos) são representados pela cor azul, enquanto os parâmetros correspondentes aos atratores periódicos (expoentes de Lyapunov negativos) são representados em escala de cinza. Em preto estão demarcadas as linhas correspondentes ao esqueleto das janelas periódicas, parâmetros em que o maior expoente de Lyapunov diferente de zero passa por um mínimo dentro de uma determinada janela periódica. 

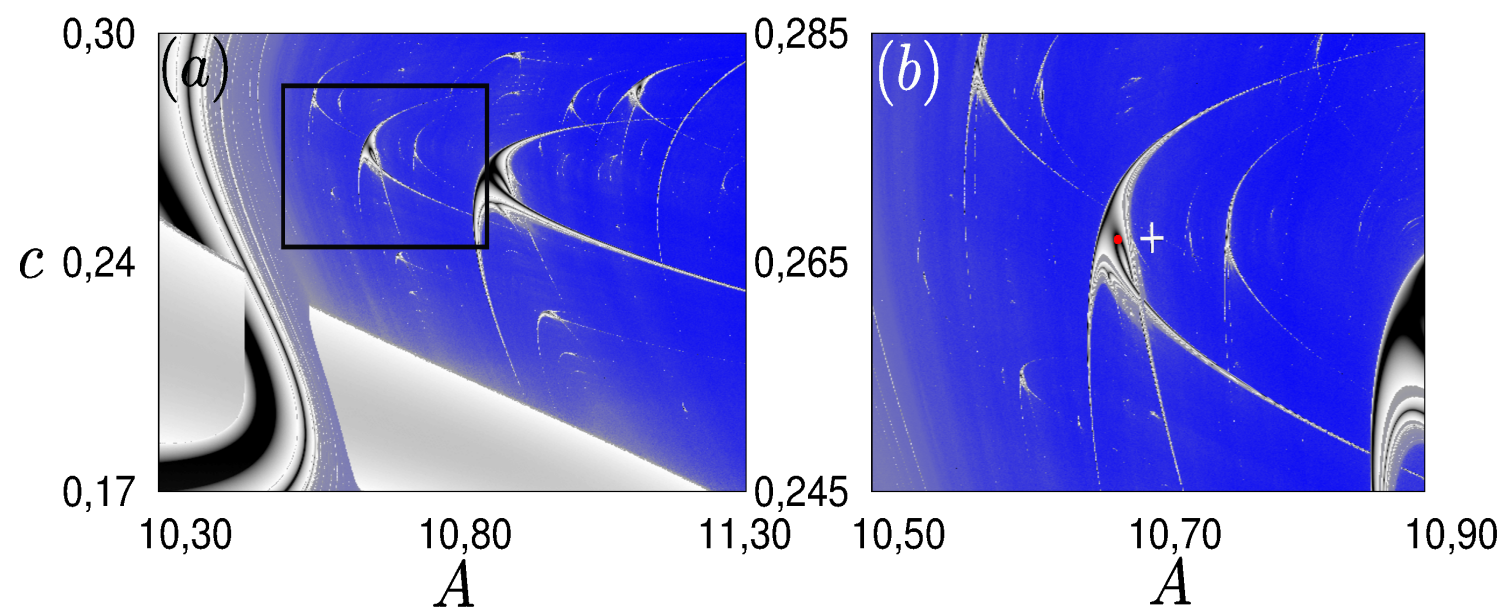

Figura 3.1: $(a)$ Espaço de parâmetros bidimensional $(c \times A)$ do oscilador de Duffing sem perturbação, a frequência do forçamento é $\omega=1,0$. (b) Ampliação da área destacada. O círculo vermelho preenchido indica os parâmetros correspondentes a um estado periódico, $A=10,6780$ e $c=0,2670$, os parâmetros indicados por uma cruz correspondem ao um estado caótico, $A=10,7020$ e $c=0,2670$.

Na Figura 3.1(b), o ponto vermelho e a cruz branca indicam pares de parâmetros correspondentes às órbitas periódicas e caóticas, respectivamente. Para mostrar o comportamento distinto entre os atratores marcados na Figura 3.1(b), obtivemos um mapeamento tomando o deslocamento $(x)$ e a velocidade $(d x / d t)$ para cada tempo $(t)$ múltiplo do período de forçamento $(2 \pi / \omega)$. Na Figura 3.2(a), mostramos a órbita periódica cujos parâmetros correspondentes estão indicados por um ponto vermelho na Figura 3.1(b). Da mesma maneira, na Figura 3.2(b) mostramos o atrator caótico cujos parâmetros estão representados por uma cruz branca na Figura 3.1(b).

Introduzimos uma pequena perturbação periódica adicionando um segundo termo harmônico no forçamento original do sistema de Duffing. A amplitude da pequena perturbação é considerada como um novo parâmetro de controle do sistema, enquanto a frequência da pequena perturbação é fixada em um razão inteira da frequência do forçamento original. Assim, a evolução temporal do sistema perturbado é determinada pela solução numérica da seguinte equação diferencial adimensional:

$$
\frac{d^{2} x}{d t^{2}}+c \frac{d x}{d t}+x^{3}=A \cos (\omega t)+B \sin (\Omega t)
$$

$B$ é a amplitude da pequena perturbação $(B<<A)$ e $\Omega$ é a frequência da perturbação, neste caso fixada em $\Omega=2 \omega$. Outros múltiplos da frequência de forçamento $\omega$ poderiam 


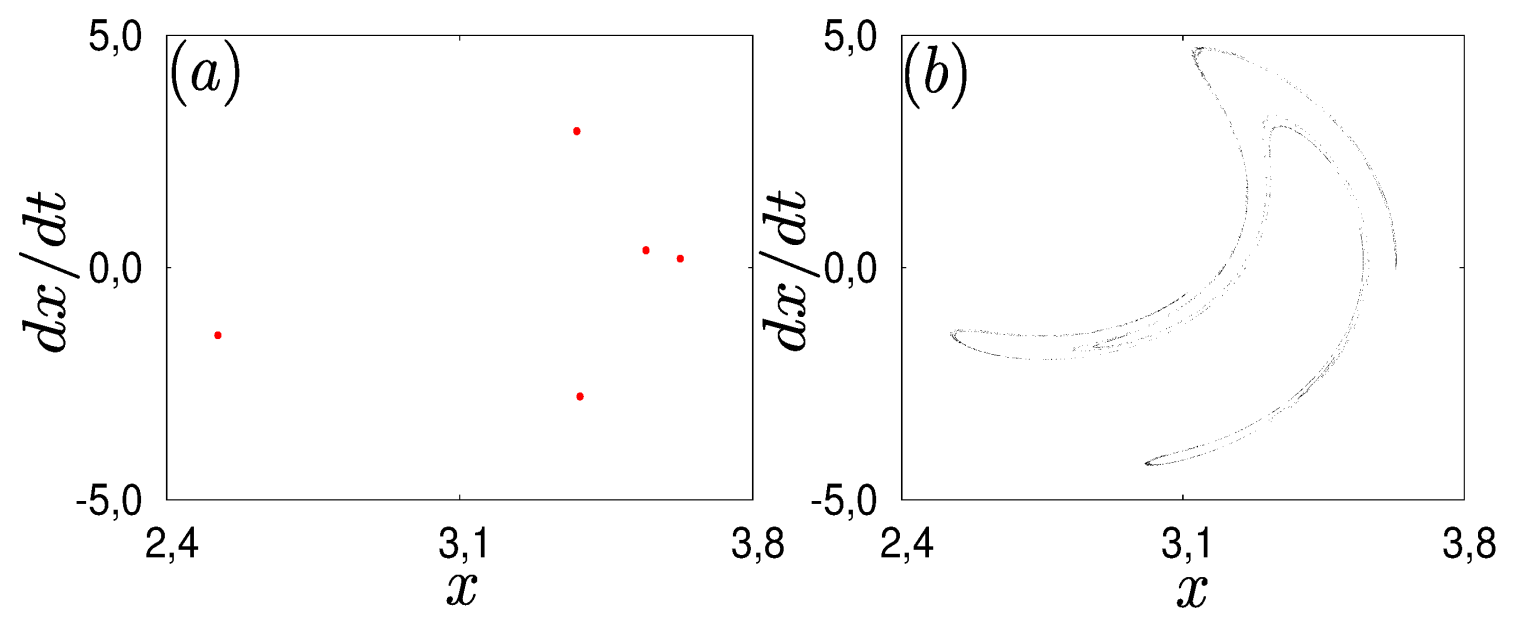

Figura 3.2: Mapa de Poincaré estroboscópico do oscilador de Duffing. (a) Órbita periódica correspondente aos parâmetros $A=10,6780$ e $c=0,2670$ (circulo vermelho na Figura 3.1(b)). (b) Atrator caótico correspondente aos parâmetros $A=10,7020$ e $c=0,2670$ (cruz branca na Figura 3.1(b))

ser utilizados [42].

Na Figura 3.3, mostramos o espaço de parâmetros do oscilador de Duffing perturbado para duas amplitudes da perturbação, $B=0,04$ e $B=0,08$. Comparando com o espaço de parâmetros mostrado na Figura 3.1(b), notamos a existência de réplicas das janelas periódicas previamente existentes. Em particular, a janela periódica central da Figura 3.1(b) está duplicada na Figura 3.3.

Adicionalmente, nas Figuras 3.3(a) e 3.3(b), as janelas periódicas apresentam diferentes distanciamentos. Na Figura 3.3, marcamos os mesmo parâmetros, ponto vermelho e cruz branca, indicados na Figura 3.1(b). Notamos que na Figura 3.3(a), para uma amplitude de perturbação $A=0,04$, a cruz branca continua representando uma órbita caótica, enquanto que na Figura 3.3, para uma amplitude da perturbação $B=0,08$, a cruz branca passa a representar uma órbita periódica dentro de uma periódica replicada. Por outro lado, a antiga órbita periódica com parâmetros representados pelo ponto vermelho continua periódica na Figura 3.3(a) e passa a ser caótica na Figura 3.3. Assim, a perturbação periódica modifica o espaço de parâmetros gerando réplicas de janelas periódicas com separações proporcionais à amplitude da perturbação. Enfatizamos que um atrator caótico no sistema não perturbado, Figura 3.1, foi transformado em um atrator periódico pela perturbação periódica, caracterizando supressão de caos. 

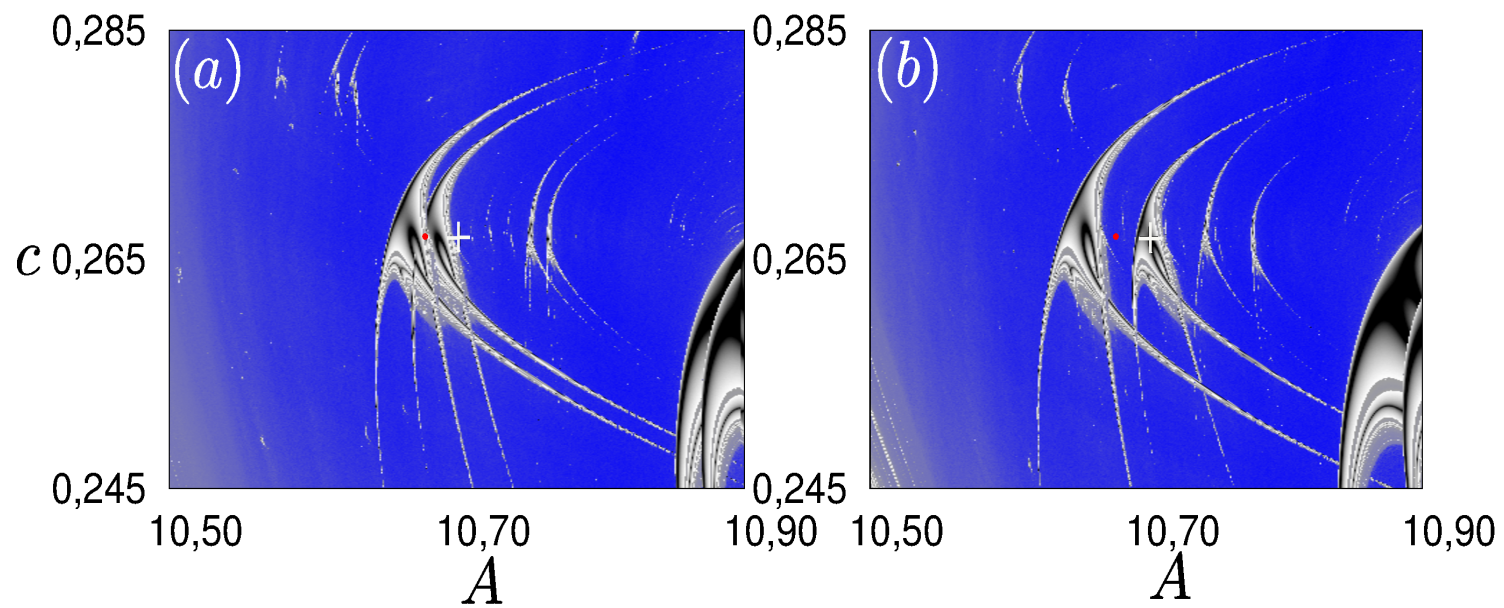

Figura 3.3: Espaço de parâmetros bidimensional do oscilador de Duffing perturbado, $\omega=1,0$ and $\Omega=2,0$. A amplitude da perturbação é (a) $B=0,04$. (b) $B=0,08$.

A seguir discutimos as transformações causadas pela pequena perturbação periódica no atrator caótico mostrado na Figura 3.2(b). Para esse propósito, na Figura 3.4(a), mostramos, no espaço de fases estroboscópico, a órbita periódica controlada (cruz preta) que substitui o atrator caótico da Figura 3.2(b). Além disso, mostramos que a órbita controlada possui a mesma periodicidade e forma da órbita periódica do sistema não perturbado mostrada na Figura 3.2(a) e reproduzida na Figura 3.4(a) (pontos vermelhos). Adicionalmente, na Figura 3.4(b) mostramos a convergência temporal do maior expoente de Lyapunov das duas órbitas periódicas mostradas na Figura 3.4(a). Essas órbitas possuem convergência similares dos expoentes de Lyapunov, alcançando valores limites comparáveis.

\subsection{Conclusão}

Neste capítulo, implementamos uma técnica de controle de caos amplamente utilizada na literatura, o controle através de pequenas perturbações periódicas. Constatamos a eficácia na supressão da dinâmica caótica deste método. Para distinguir as regiões periódicas e as caóticas no espaço de parâmetros, calculamos os expoentes de Lyapunov para os atratores existentes nos intervalos de parâmetros considerados. Em seguida, realizamos uma análise coletiva dos efeitos da perturbação para conjuntos de parâmetros de controle. 

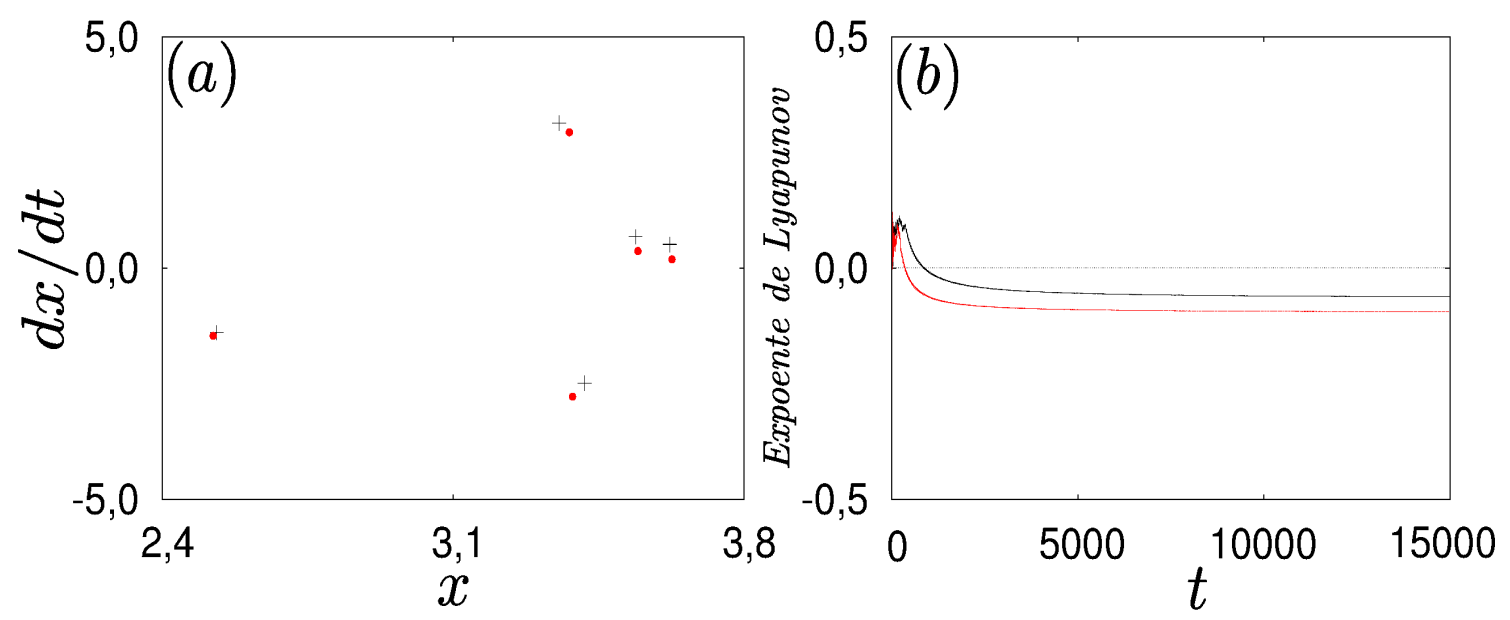

Figura 3.4: (a) O círculo vermelho representa a órbita periódica existente nos parâmetros $A=10,6780$, $c=0,2670$ e $B=0,0$, a mesma órbita da Figura 3.2. A cruz preta indica a órbita controlada para os parâmetros $A=10,7020, c=0,2670, \Omega=2,0$ e $B=0,08$. (b) A linha vermelha indica o maior expoente de Lyapunov da órbita periódica não perturbada. A linha preta indica o maior expoente de Lyapunov da órbita periódica controlada.

Concluímos que as perturbações periódicas controlam a dinâmica caótica através de replicações de janelas periódicas no espaço de parâmetros. Adicionalmente, constatamos que as janelas periódicas replicadas possuem estados periódicos com características dinâmicas (periodicidade, forma e expoente de Lyapunov) similares aos estados existentes em janelas previamente existentes [69]. 


\section{Capítulo 4}

\section{Propriedades de Torsão}

O período de oscilação de órbitas periódicas é a propriedade mais conhecida do espaço de estados de sistemas dinâmicos. Medidas numéricas e experimentais dessa grandeza possibilitaram o avanço das teorias em sistemas dinâmicos $[4,86]$. Entretanto, o espaço de estados possui outras propriedades relevantes, por exemplo, a torsão provocada no fluxo local por estados periódicos. Essa torsão pode ser quantificada pelo número de rotação e pelo número de torsão introduzidos no Capítulo 2. Neste capítulo, para conjuntos de parâmetros, analisamos as propriedades de torsão geradas por órbitas periódicas no espaço de estados dos osciladores caóticos. Baseados nessas propriedades apresentamos a existência de um novo panorama para a existência de janelas periódicas complexas, bem como a ocorrência de novos fenômenos no espaço de parâmetros de osciladores caóticos.

\subsection{Introdução}

Conforme discutimos no Capítulo 2, os parâmetros correspondentes à periodicidade estão agrupados no espaço de parâmetros formando janelas periódicas complexas. Além disso, essas janelas frequentemente aparecem alinhadas em sequências. No interior de cada janela periódica complexa, ao longo de uma sequência, existe um corpo principal cujos parâmetros correspondem a órbitas periódicas de mesmo período. O período, $m$, dessas órbitas era a única ferramenta disponível para classificar as janelas periódicas complexas ao longo dessas sequência. Assim, em 1982 para intervalos de parâmetros 
de um mapa unidimensional, K. Kaneko mostrou que as órbitas periódicas existentes em uma região periódica de parâmetros sofre um acréscimo constante em seu período a medida que os parâmetros são variados. Esse mecanismo é denominado adicionamento de período. Posteriormente, esse mecanismo foi numérica e experimentalmente observado entre janelas periódicas de diversos sistemas dinâmicos tais como, atividades neuronais [62, 63], circuitos eletrônicos [64], formação de bolhas [65], semicondutores [66] e reações químicas [67]. Posteriormente, o adicionamento de período foi observado entre as janelas periódicas complexas, separadas por comportamento caótico, que ocorrem em sequências do espaço bidimensional de parâmetros [27, 38, 46, 52].

Por outro lado, além do período de oscilação, as óbitas periódicas de sistemas dinâmicos dissipativos possuem propriedades de convergência ainda pouco exploradas na literatura. Por exemplo, a existência de órbitas periódicas estáveis provoca torsões no fluxo local do espaço de estados. Para osciladores caóticos, essa torsão pode ser descrita pelo número de torsão, $n$, que quantifica a frequência média, $\Omega$, de rotação que o fluxo local realiza em torno de uma órbita periódica durante o período de oscilação $m$ dessa órbita. Adicionalmente, o número de rotação, $w$, definido como $w=n / m$, fornece a mesma frequência média, $\Omega$, de rotação, porém durante o período do forçamento do oscilador caótico ao invés do período da órbita [71, 82, 87-89].

Neste capítulo, investigamos o comportamento do número de torsão, $n$, e do número de rotação, $w$, no interior das janelas periódicas complexas e ao longo de suas sequências no espaço de parâmetros. Inicialmente, obedecendo regras de convergência para pontos fixos de mapas bidimensionais, obtivemos uma estimativa teórica para comportamento do número de torsão, $n$, dentro das janelas periódicas complexas. Em seguida, baseados nas regras de adicionamento de período entre janelas periódicas complexas, conjecturamos a existência de regras para o adicionamento de torsão ao longo das sequências de janelas periódicas complexas. Com isso, obtivemos expressões para o número de rotação, w, no interior das janelas periódicas que compõem uma sequência e para o ponto de acúmulo dessas sequências. Em seguida, as proposições realizadas com base nesses conceitos foram numeriamente confirmadas com o oscilador de Morse. 


\subsection{Esqueleto de Janelas Periódicas Complexas}

O objetivo dessa seção é esclarecer como a estrutura básica existente no interior de janelas periódicas complexas, o esqueleto, está definida na literatura. Nesses termos a documentação existente é basicamente para sistemas discretos, entretanto, não perde utilidade uma vez que a análise de algumas propriedades de fluxos muitas vezes é reduzida ao estudo de mapas associados. Conforme discutimos na Seção 2.4.5, o fluxo tridimensional $\mathbf{F}=\mathbf{F}^{t}$ que descreve os osciladores caóticos pode ser associado ao mapa de Poincaré bidimensional $P=\left.\mathbf{F}^{T_{f}}\right|_{\Sigma}$ definido na Eq. (2.15). Assim, à partir desse mapa, podemos obter informações sobre as propriedades de convergência, bifurcações e até mesmo do esqueleto das janelas periódicas formadas pelo fluxo. A estabilidade de um ponto fixo $\mathbf{x}_{\mathbf{f}}$ do mapa de Poincaré $P^{m}$ associado a uma órbita $\gamma$ de período $m$ é garantida se todos os autovalores $\mu_{i}$ (multiplicadores de Floquet) da matriz Jacobiana desse mapa possuem módulo menor que um, explicitamente:

Teorema 4.2.1 Seja $\mathbf{P}$ um mapa em $\mathbb{R}^{n}$. Dado que $\mathbf{P}\left(\mathbf{x}_{\mathbf{f}}\right)=\mathbf{x}_{\mathbf{f}}$ e que $\mu_{i}=\left\{\mu_{1}, \mu_{2}, \ldots, \mu_{n}\right\}$ são os autovalores da Jacobiana $\mathbf{D P}\left(\mathbf{x}_{\mathbf{f}}\right)$.

- 1. Se $\left|\mu_{i}\right|<1$, então $\mathbf{x}_{\mathbf{f}}$ é assintoticamente estável.

- 2. Se $\left|\mu_{i}\right|>1$, então $\mathbf{x}_{\mathbf{f}}$ é instável.

Adicionalmente, as variações em parâmetros de controle do fluxo também geram consequências na estabilidade do mapa associado. Essas mudanças na estabilidade são tratadas pela teoria de bifurcações em mapas. Em nosso estudo estamos interessados principalmente em dois tipos específicos de bifurcação. Se um dos multiplicadores de Floquet entrar no círculo unitário pela linha dos reais positivos, exatamente sobre o círculo unitário, $\mu_{i}=1$, o sistema perde hiperbolicidade e ocorre uma bifurcação chamada sela-nó. Nesse caso, imediatamente depois da bifurcação a convergência para o ponto fixo $\mathbf{x}_{\mathbf{f}}$ do mapa $P^{m}$, criado na bifurcação, preserva orientação. Por outro lado, se um dos multiplicadores deixar o círculo unitário pela linha dos reais negativos, sobre o círculo unitário, $\mu_{i}=-1$, o sistema perde hiperbolicidade e ocorre uma bifurcação chamada dobramento 
de período. Nesse caso, imediatamente antes da bifurcação ocorrer, a convergência para o ponto fixo $\mathbf{x}_{\mathbf{f}}$ do mapa $P^{m}$, que perderá estabilidade na bifurcação, não preserva orientação. A Figura 4.1 ilustra o valor do multiplicador de Floquet e o tipo de convergência correspondente a cada bifurcação. Na Figura 4.1(a), representamos o comportamento de um dos autovalores na bifurcação sela-nó, onde a convergência para o ponto fixo criado ocorre com preservação da orientação (convergência monotônica). Na Figura 4.1(b), representamos o comportamento de um dos autovalores na bifurcação dobramento de período, onde a convergência para o ponto fixo que perderá estabilidade ocorre sem preservação da orientação (convergência não-monotônica).

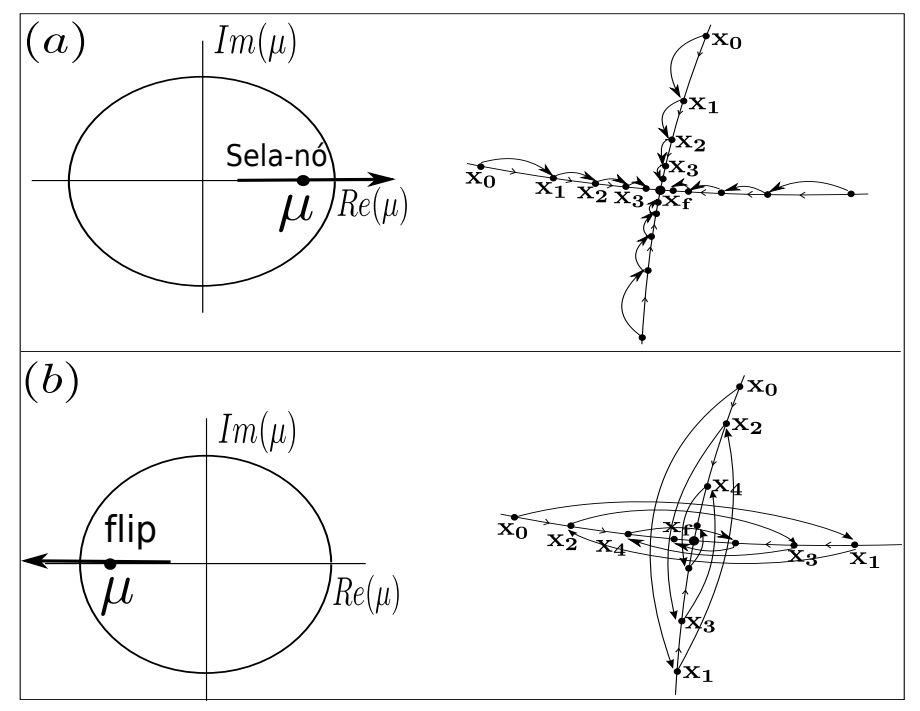

Figura 4.1: (a) Com a variação dos parâmetros, o multiplicador de Floquet deixa o círculo unitário sobre o eixo real positivo, para $\mu=1$ ocorre à bifurcação sela-nó, nesse caso a convergência, para um ponto fixo do mapa $P^{m}$, preserva orientação; (b) Variando os parâmetros, o multiplicador de Floquet deixa o círculo unitário sobre a linha dos reais negativos, para $\mu=-1$ ocorrem à bifurcação dobramento de período (flip), a convergência não preserva orientação.

Com isso, e dado que as janelas periódicas complexas são delimitadas por bifurcações tipo sela-nó de um lado e por bifurcações tipo dobramento de período do outro, verificamos que ocorrem mudanças na orientação da convergência, da trajetória para o ponto fixo do mapa $P^{m}$, no interior das janelas periódicas. Veremos na seção seguinte que isso implica em variações de $\pi$ no número de rotação em torno de $\mathbf{x}_{\mathbf{f}}$ durante a convergência. 
A mudança no tipo de convergência levanta a dúvida sobre o tipo de estrutura interna das janelas periódicas complexas. Para elucidar a questão começamos com mapas unidimensionais. Nesses mapas temos a ocorrência de apenas um multiplicador de Floquet. Assim para um dado parâmetro tal que o único autovalor do mapa unidimensional seja $\mu=0$, ocorrerá uma mudança no tipo de convergência. No espaço bidimensional de parâmetros desses mapas unidimensionais, os parâmetros correspondentes à $\mu=0$, formam as curvas que compõem o esqueleto das janelas periódicas complexas. Além disso, nesses mapas, $\mu=0$ implica em convergência instantânea para o ponto fixo ou órbita periódica. Essa condição define a superestabilidade para esses sistemas. Então, o esqueleto das janelas periódicas complexas no espaço de parâmetros de mapas unidimensionais demarca a mudança no tipo de convergência para o ponto fixo e coincide com as curvas de superestabilidade desses mapas. Adicionalmente, os parâmetros correspondentes à superestabilidade nos mapas unidimensionais são ditos como tendo codimensão $\rho=1$ no espaço bidimensional de parâmetros, uma consequência da necessidade de apenas uma restrição, $\mu=0$, para definir as curvas superestáveis. Contudo, concluimos que em mapas unidimensionais, as janelas periódicas complexas estão montadas em torno de curvas no espaço bidimensional de parâmetros.

Nosso interesse nesse capítulo é a estrutura interna (esqueleto) de janelas periódicas complexas de mapas bidimensionais, dado que o fluxo gerado pelos osciladores caóticos é associado com o mapa $P=\left.\mathbf{F}^{T_{f}}\right|_{\Sigma} \in \mathbb{R}^{2}$. A definição do esqueleto de janelas periódicas complexas em mapas bidimensionais exige um tratamento diferente dos mapas unidimensionais. Nesse caso, para definir nesses mapas um conceito análogo à superstabilidade, devemos considerar o tempo de convergência para um ponto fixo em ambas direções de convergência. Nesses mapas, os multiplicadores de Floquet são os autovalores $\left(\mu_{1}, \mu_{2}\right)$ da Jacobiana $\mathbf{D P}\left(\mathbf{x}_{\mathbf{f}}\right)$. Para facilitar o tratamento, as condições de estabilidade Teorema (4.2.1) são escritas em termos do traço $T=\mu_{1}+\mu_{2}$ e do determinante $D=\mu_{1} \mu_{2}$ da Jacobiana. Com isso, podemos avaliar a estabilidade de mapas bidimensionais em diagramas cujo os eixos coordenados são o determinante $D$ e o traço $T$ de sua matriz jacobiana, ver Figura reffig:stabilitytriangle. O mapa é assintoticamente estável para valores de $T$ e $D$ que caem dentro do triângulo da Figura 4.2. A parábola desenhada no interior da Figura 
4.2 separa as condições de $T$ e $D$ para ocorrência de autovalores complexos.

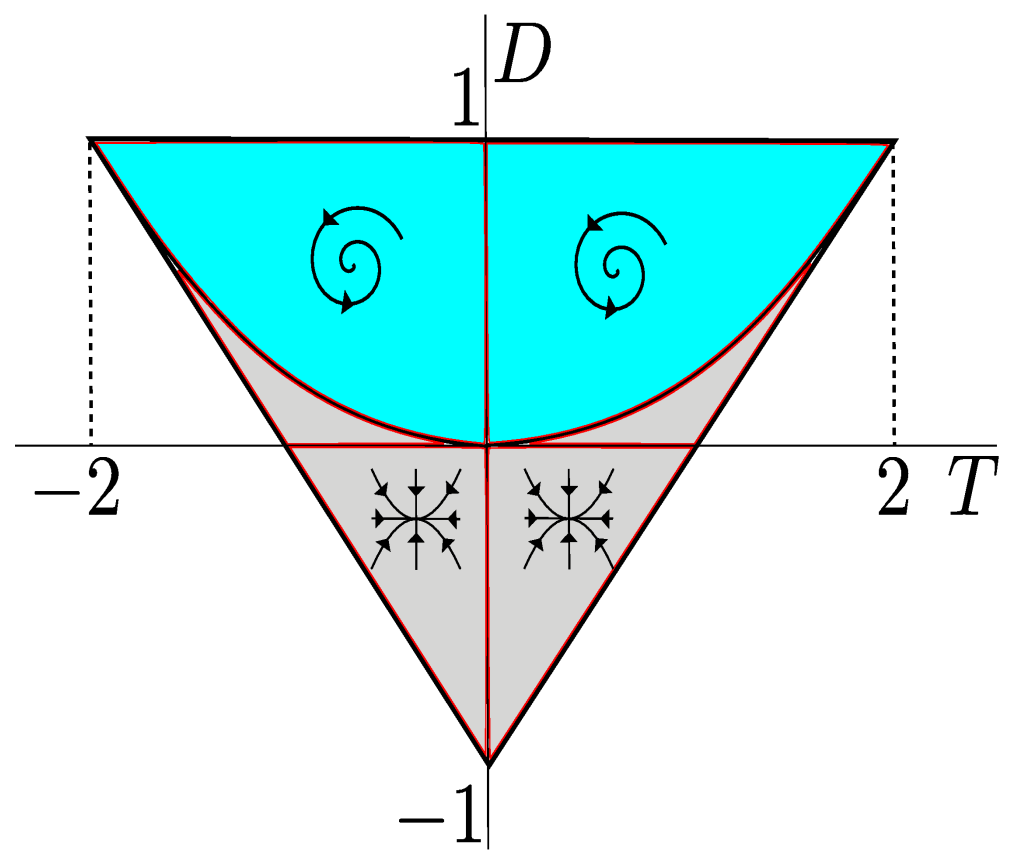

Figura 4.2: Triângulo de estabilidade. O ponto fixo de um mapa bidimensional é estável se os valores do traço $T$ e o determinante $D$ de sua Jacobiana estão dentro desse triângulo. Mostramos também, no interior do triângulo, os atratores existentes para respectivas regiões de $T$ e $D$.

Assim, na literatura, com o objetivo de definir o esqueleto de janelas periódicas complexas em mapas bidimensionais, foi traçado um paralelo com o caso unidimensional, i.e., definindo o equivalente à superestabilidade em mapas bidimensionais como sendo a condição $T=D=0$. Com isso, as estruturas de parâmetros formadas por essas restrições foram investigadas no espaço de parâmetros $[13,90]$. Em uma primeira inspeção notamos que, diferentemente do caso unidimensional, são necessárias duas restrições sobre os multiplicadores de Floquet para definir o equivalente da superstabilidade $(T=D=0)$. Assim, as estruturas formadas no espaço de parâmetros, de mapas bidimensionais, que satisfazem a condição $T=D=0$ são pontos ao invés de curvas conforme esperado para mapas unidimensionais [91]. Essas constatações indicam que as janelas periódicas complexas em sistemas com dimensões maiores estão montadas em torno de pontos ao invés de curvas como no caso unidimensional. Entretanto, em mapas bidimensionais dissipativos, i.e., que contraem áreas no espaço de estados, teremos $D=|\operatorname{det}(\mathbf{D P})|<1$, no interior de janelas periódicas complexas teremos órbitas periódicas com período fundamental $m$, e 
ao longo dessas órbitas teremos $D=[\operatorname{det}(D P)]^{m} \approx 0$. Assim, o determinante dos mapas que estamos interessados é quase nulo no interior de janelas periódicas complexas, uma particularidade que reduz o equivalente à superestabilidade à apenas uma restrição $T=0$. Com isso recuperamos o fato da estrutura correspondente a superestabilidade em mapas bidimensionais serem curvas no espaço de parâmetros como no caso de mapas unidimensionais. Concluimos que as janelas periódicas complexas de mapas bidimensionais $P^{m}$, associados com o fluxo dos osciladores caóticos, também estão montadas sobre esqueletos formados por curvas no espaço de parâmetros bidimensional. Nas seções seguintes chamamos essas curvas de $\lambda_{1}$ e $\lambda_{2}$.

\subsection{Número de Rotação em Janelas Periódicas Com- plexas}

Uma vez definida a estrutura interna das janelas periódicas complexas, as mudanças de orientação na convergência para o ponto fixo discutidas na seção anterior devem ser observadas nas medidas do número de rotação $w$ e, consequentemente, nas medidas no número de torsão $n$, definidos na seção 2.4.5. Assim, conjecturamos que no interior das janelas periódicas complexas existentes no espaço de parâmetros dos osciladores caóticos descritos pela (Eq. 2.13), os valores de $w$ e $n$ são distintos em quatro áreas diferentes delimitadas pelo esqueleto e pelas curvas de bifurcação. Na Figura 4.3 ilustramos o esqueleto, curvas $\lambda_{1}$ e $\lambda_{2}$, as áreas $A, B, C$ e $D$ com diferentes números de torsão $n$ e as curvas de bifurcação $s n$ e $p d$.

Sabemos que a diferença angular entre a convergência monotônica e não-monotônica é $\pi$. Estimamos que a mudança no tipo de convergência quando, variando um parâmetro, cruzamos o esqueleto da janela periódica deve alterar o número de torsão em $\pi$. Como o número de torsão $n$ definido na seção 2.4 .5 é medido em unidades de $2 \pi$, a variação de $\pi$ proveniente do cruzamento do esqueleto da janela deve alterar as medidas de $n$ em 1/2. Essas conjecturas serão numeriamente verificadas adiante nesse capítulo na seção 4.5, que trata os resultados numéricos para a torsão nas janelas periódicas complexas. 


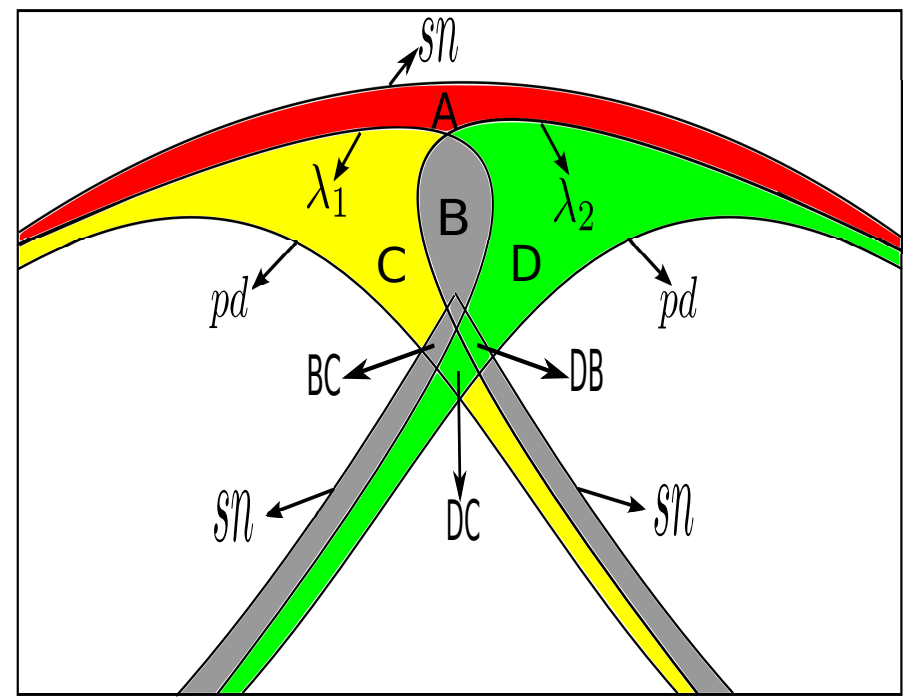

Figura 4.3: Dada as propriedades de convergência na vizinhança das curvas de bifurcação, no corpo principal das janelas periódicas complexas, identificamos quatro áreas $A, B, C$ e $D$ com números rotação $w$ e números de torsão $n$ constantes em seu interior.

\subsection{Número de Rotação em Sequências de Janelas Periódicas Complexas}

No espaço de parâmetros, os parâmetros correspondentes a estados caóticos são alternados com intervalos de parâmetros correspondentes a estados periódicos, que constituem as janelas periódicas complexas. Em diversos sistemas dinâmicos (discretos e contínuos), frequentemente, as janelas periódicas aparecem alinhadas em sequências que se acumulam em curvas de parâmetros correspondentes a estados periódicos, chamadas de horizontes de acúmulo. Cada janela periódica em uma sequência pode estar correlacionada com as janelas vizinhas através do fenômeno de adicionamento de período. Assim, a partir do período $m_{1}$ do corpo principal da janela inicial da sequência, o período do corpo principal da janela subsequente é acrescido de um valor constante. Assim, dado que o incremento no período é $\rho$, o período $m_{i}$ da $i$-ésima janela periódica é:

$$
m_{i}=m_{1}+(i-1) \rho
$$

Com o acréscimo de período nas janelas periódicas ao longo da sequência, é razoável propormos a hipótese de um aumento proporcional no número de torsão $n$, o qual cha- 
maremos de adicionamento de torsão. Lembrando que o número de torsão também muda com as áreas $R=A, B, C$ e $D$ dentro do corpo principal da janela periódica, devemos definir inicialmente a região $R$ a ser considerada. Assim, a partir do número de torsão $n_{1}$ da janela inicial, o número de torsão $n_{i}$ no corpo principal da $i$-ésima janela periódica é:

$$
n_{R_{i}}=n_{R_{1}}+(i-1) \tau
$$

onde $\tau$ é o incremento no número de torsão.

Com as Eqs. (4.1) e (4.2), a Eq. (2.27) nos fornece o número de rotação $w$ da $i$-ésima janela periódica na sequência:

$$
w_{R_{i}}=\frac{n_{R_{i}}}{m_{i}}=\frac{n_{R_{1}}+(i-1) \tau}{m_{1}+(i-1) \rho}
$$

A maneira com que as janelas periódicas se acumulam na curva de parâmetros correspondentes às soluções periódicas, sugere a possibilidade de existência de infinitas janelas periódicas na sequência. Então, para verificar tal possibilidade, tomamos o limite assintótico $\left(w_{R_{i}} \rightarrow \infty\right)$ da Eq. (4.3).

$$
\lim _{i \rightarrow \infty} w_{R_{i}}=\frac{\tau}{\rho}
$$

Com isso, constatamos, teoricamente, que o número de rotação assintótico da sequência de janelas periódicas é a razão entre o incremento no número de torsão $\tau$ e o incremento no período $\rho$ do corpo principal das janelas periódicas.

\subsection{Resultados Numéricos}

Os resultados deduzidos na seção anterior estão apoiados na hipótese de adicionamento de torsão. Assim, realizamos experimentos numéricos com exemplos da Eq. (2.2) para confirmar a existência desse fenômeno. Assim, consideramos o oscilador de Morse descrito pela equação:

$$
\ddot{x}+d \dot{x}+8 e^{-x}\left(1-e^{-x}\right)=2,5 \cos (\omega t),
$$

onde o parâmetro $d$ controla o amortecimento desse oscilador e $\omega$ a frequência do forçamento periódico. 
Inicialmente obtivemos a solução numérica da Eq. (4.5) através do método de RungeKutta de quarta ordem com passo fixo em 0,001. Com isso, obtivemos a frequência de torsão $\Omega$ através da Eq. (2.24), em seguida obtivemos o número de rotação $w$ através da Eq. (2.26). Assim, para uma grade $600 \times 600$ dos parâmetros $d \times \omega$ igualmente espaçados, obtivemos o número de rotação $w$. Na Fig. 4.4 escolhemos regiões dos parâmetros $d$ e $\omega$ nos quais janelas periódicas complexas são observadas.

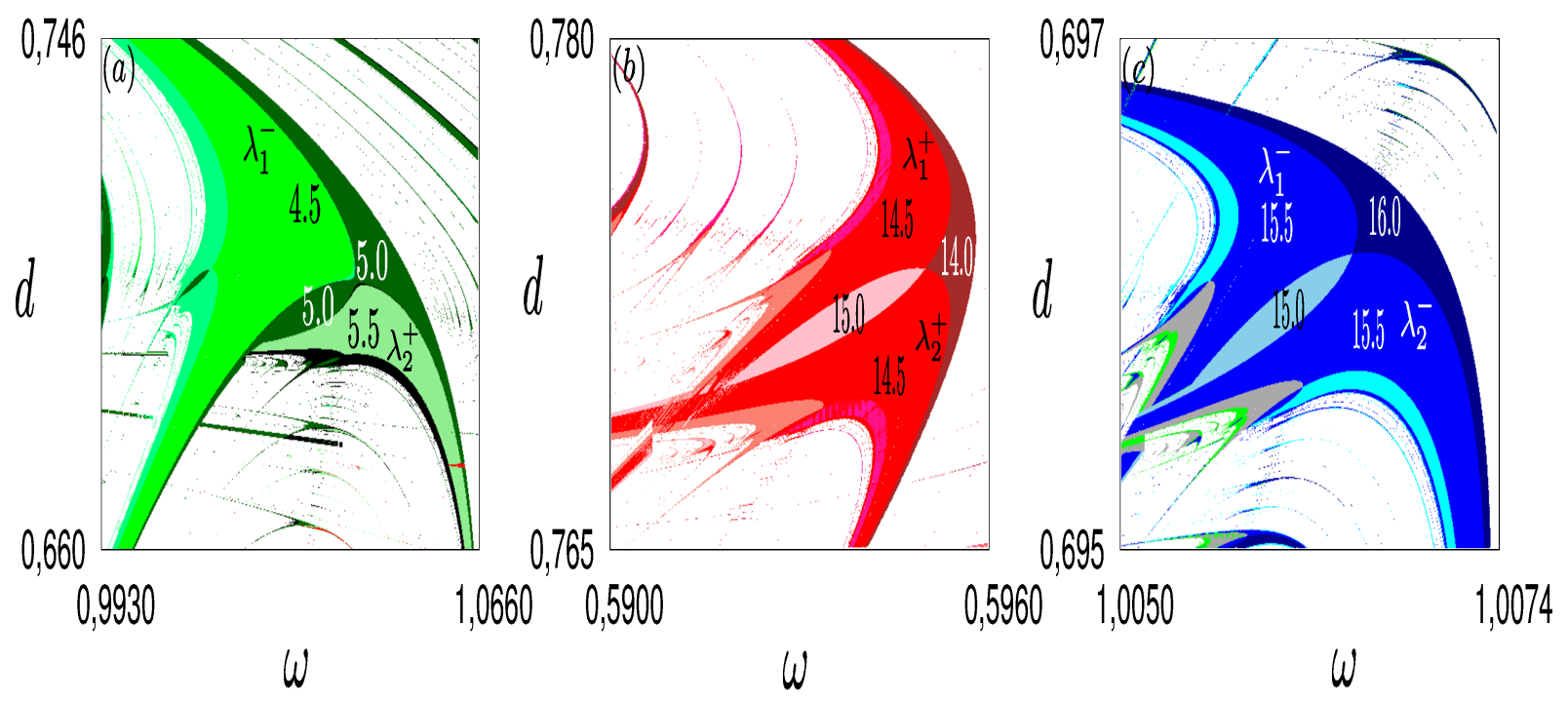

Figura 4.4: Número de rotação obtido para uma grade de parâmetros, a área branca indica a parâmetros correspondentes ao comportamento caótico, enquanto as janelas periódicas são coloridas de acordo com o número de rotação. Os números indicados nas áreas de diferentes números de rotação, $A, B, C$ e $D$, são os correspondentes números de torsão $n$. As curvas $\lambda$ indicam o esqueleto da janela periódica e os índices $+\mathrm{e}-$ indicam, respectivamente, crescimento e decrescimento dos números de torsão. $(a) n_{A}=n_{B}=5.0, n_{C}=4.5$ e $n_{D}=5.5$. (b) $n_{C}=n_{D}=14.5, n_{A}=14.0$ e $n_{B}=15.0$. (c) $n_{C}=n_{D}=15.5, n_{A}=16.0$ e $n_{B}=15.0$.

Na Fig. 4.4 as cores indicam diferentes números de rotação dentro de cada janela periódica. Os números de rotação para parâmetros correspondentes ao comportamento caótico em torno das janelas periódicas foram removidos. Conforme a Seção 4.3, verificamos numericamente a existência de áreas $(A, B, C$ e $D)$ dentro da janela periódica com números de rotação constante. Adicionalmente, entre essas áreas verificamos a ocorrência de uma variação de $\pm 1 / 2$ no número de torsão $n$ devido à variação de $\pm \pi$ na direção de convergência para o ponto fixo.

Assim, na Fig. 4.4 observamos três diferentes configurações para o número de rotação dentro de cada janela periódica. Na 4.4(a), o número de torsão decresce de 1/2 da região 
$A$ para a região $C$, com isso denominaremos a linha entre essas regiões de $\lambda_{1}^{-}$. Por outro lado, o número de torsão cresce de $1 / 2$ da região $C$ para a região $B$, cruzando uma linha $\lambda_{2}^{+}$. O esqueleto da janela periódica mostrada na Figura 4.4(a) é formado por duas linhas diferentes, $\lambda_{1}^{-}$e $\lambda_{1}^{+}$. Com isso, constatamos que o número de torsão entre as regiões $A$ e $B$ é o mesmo, isto é, $n_{A}=n_{B}$. Por outro lado, o esqueleto da janela periódica mostrada na Figura 4.4(b) é formado por duas linhas iguais, $\lambda_{1}^{+}$. Nesse caso, constatamos que $n_{C}=n_{D}$. Finalmente, o esqueleto da Figura 4.4(c) também possui duas linhas iguais, $\lambda_{1}^{-}$, resultando em $n_{C}=n_{D}$.

Para ilustrar a validade da Eq. (4.3), mostramos, na Fig. 4.5(a), uma sequência de janelas periódicas com esqueletos formados por linhas $\lambda_{1}^{-}$e $\lambda_{2}^{+}$. As janelas periódicas que compõem a sequência apresentam região central $B$ com diferentes números de rotação. Nessa Figura, para as janelas ao longo da sequência, obtemos o incremento no número de torsão $\left(\tau=n_{B_{i+1}}-n_{B_{i}}=12\right)$ e no período $\left(\rho=m_{i+1}-m_{i}=4\right)$, obtemos ainda o número de rotação, $w_{\infty}=3,0$, na região de acúmulo das janelas periódicas. Nesse ponto temos condições de verificar a validade da Eq. (4.3). No entanto, antes devemos escolher a região da janela periódica inicial que servirá de alimentação para a Eq. (4.3). Então, escolhendo a região $A$ da primeira janela para ser a referência. Assim,

$$
w_{R_{i}}=\frac{n_{A_{1}}+(i-1) \tau+(k-l) / 2}{m_{1}+(i-1) \rho},
$$

onde $w_{R_{i}}$ é o número de rotação da região $R=(A, B, C$ e $D)$ de $i$-ésima janela periódica, $k, l \in\{0,1,2\}$ é, respectivamente, o número de vezes que as curvas $\lambda^{+} \mathrm{e} \lambda^{-}$são cruzadas a partir da região $A$ para qualquer região $R$, desde que não cruze a mesma curva duas vezes. Finalmente, tomando o limite assintótico da Eq. (4.6), verificamos que $w_{B_{i}}=3,0$. Resultado que está de acordo com as medidas realizadas na Fig. 4.5(a). Adicionalmente, na Fig 4.5(b), mostramos os números de rotação $w$ obtidos para parâmetros ao longo de uma linha passando pela região $B$ das janelas na sequência, com isso, notamos que os números de rotação convergem para $w_{\infty}=3,0$, conforme previsto pela Eq. (4.6).

Na Fig. 4.5(c), mostramos uma sequência de janelas periódicas com esqueleto formado por linhas $\lambda_{1}^{+}$e $\lambda_{2}^{+}$. Nessa sequência, medimos $\tau=5, \rho=3$, o número de rotação na região central $w_{B}=5 / 3$ e o número de rotação $w_{\text {acum. }}=5 / 3$ na região de acúmulo. Assim, a Eq. (4.6) com $k=2$ e $l=0$, fornece $w_{R_{i}} \infty=5 / 3$, resultado em pleno acordo com as 
medidas realizadas na Fig. 4.5(c) e 4.5(d). Adicionalmente pela Eq. (4.6), verificamos que se uma janela periódica apresenta número de rotação $w_{B}=\tau / \rho$, então, o número de rotação da região $B$ de qualquer janela periódica na sequência é $w_{B_{i}}=\tau / \rho$. Conforme verificamos na Fig. 4.5(c) e Fig. 4.5(d).

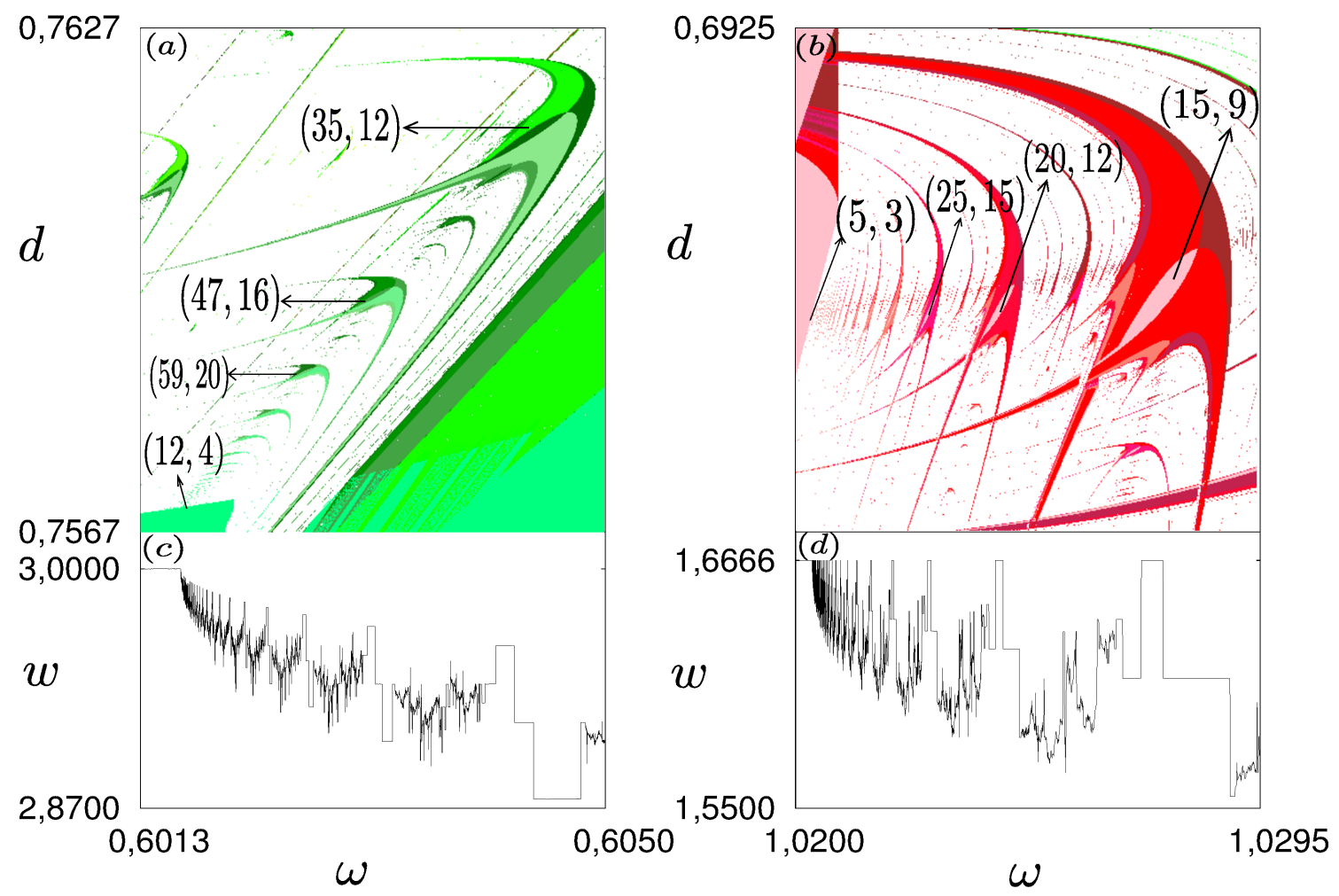

Figura 4.5: (a) Sequências de janelas periódicas obtidas através do número de rotação. Os pares $\left(n_{B}, m_{B}\right)$ indicados nas janelas periódicas são, respectivamente, o número de torsão da área $B$ e o período da janela. Os incrementos no número de torsão e no período são, respectivamente, $\tau=12,0$ e $\rho=4,0$. (b) Número de rotação como função do parâmetro $\omega$ calculados ao longo de uma linha que intercepta a área $B$ das diferentes janelas periódicas na sequência mostrada na parte $(a)$. O número de rotação assintótico para esta sequência é $w_{\infty}=3,0$, conforme predição teórica $\tau / \rho=3,0$. (c) Mesmas definições de (a) para outra região do espaço dos parâmetros (nesse caso $\tau=5,0$ and $\rho=3,0$ ). ( $d$ ) Mesmas definições de $(b)$ (nesse caso $\left.w_{\infty}=\tau / \rho=1,6666\right)$

\subsection{Conclusão}

Nesse capítulo, inicialmente, mostramos às condições necessárias para definir o esqueleto que compõe as janelas periódicas complexas de interesse nesse trabalho. Formulamos 
teoricamente o comportamento dos números de rotação e de torsão no interior de janelas periódicas complexas e em sequências dessas janelas. Constatamos que o número de torsão fornece um novo panorama para o tratamento de estruturas periódicas em sistemas dissipativos, revelando detalhes do interior de janelas periódicas que são invisíveis diante de análises apenas do período. Além disso, as sequências de janelas periódicas complexas podem agora ser classificadas de acordo com regras de adicionamento de torsão e de acordo com propriedades da região de acúmulo dessas sequências. Esses resultados foram numericamente confirmados em simulações para o oscilador de Morse. 


\section{Capítulo 5}

\section{Dimensão Fractal no Espaço de Parâmetros}

Sistemas dinâmicos não-lineares são sensíveis às pequenas perturbações em seus parâmetros de controle, resultando em incertezas na predição do ajuste de parâmetros de controle para obtenção do comportamento periódico ou caótico. Através da estimativa dessas incertezas para osciladores caóticos e sistemas adicionais, mostramos que a dificuldade de ajuste nos parâmetros de controle ocorre pela a dimensão da fronteira, entre o conjunto de parâmetros que leva a periodicidade e o conjunto que leva ao caos, ser fractal. Constatamos que o valor estimado para a dimensão de tal fronteira está no mesmo intervalo de confiança para todas as classes de sistemas dinâmicos investigados nesta tese. Adicionalmente, formulamos um modelo heurístico onde relacionamos o caráter universal da dimensão da fronteira com o decrescimento das janelas periódicas complexas ao longo de sequências no espaço de parâmetros.

\subsection{Introdução}

Conforme discutimos no Capítulo 1, o tipo de comportamento dinâmico exibido no espaço de estados de sistemas dinâmicos não-lineares é sensível às pequenas perturbações nos parâmetros de controle do sistema. Essa sensibilidade ocasiona incertezas na predição do tipo de comportamento assintótico previsto para um determinado parâmetro durante 
seu ajuste. A dificuldade de ajuste é dramática entre o conjunto de parâmetros que leva ao comportamento periódico e o conjunto que leva ao caótico, devido ao fato de que próximo à fronteira entre esses conjuntos, pequenas alterações nos parâmetros levam a grandes diferenças topológicas no espaço de estados.

Para formular a incerteza existente no ajuste de parâmetros para um determinado comportamento, partimos da distribuição, no espaço de parâmetros, dos parâmetros correspondentes à periodicidade. Sabemos que esses parâmetros estão agrupados em janelas periódicas complexas, e que essas janelas foram consideradas como sendo auto-similares, i.e., com mesma forma e padrão de distribuição em várias escalas de observação, em diversos trabalhos da literatura [7, 16, 43, 44, 48, 92]. Dada a dificuldade de ajuste e a auto-similaridade observada, nos perguntamos, seria o conjunto de parâmetros que leva às soluções periódicas ou o conjunto que leva às soluções caóticas objetos fractais? Quando inspecionamos o espaço de parâmetros notamos que as janelas periódicas complexas ocupam uma porção contínua da área desses diagramas, isso significa que o conjunto de parâmetros que compõem essas estruturas possuem medida de Lebesgue não-nula. Por outro lado, os parâmetros correspondentes às solução caóticas também foram demonstrados como possuindo medida de Lebesgue não-nula, i.e., também ocupam uma área no espaço de parâmetros [93]. Assim, veremos adiante, nesse capítulo, que o fato desses conjuntos possuirem medida de Lebesgue não-nula no espaço em que estão inseridos implica na não-fractalidade de ambos. Assim, em uma análise da dimensão, por exemplo, dimensão por contagem de caixas, nesses conjuntos encontraríamos a dimensão $d=2.0$, i.e., a mesma dimensão do espaço Euclidiano que ambos conjuntos estão imersos.

Com isso, a sensibilidade para o ajuste de parâmetros e a auto-similaridade observada para as janelas periódicas complexas não são incorporadas na descrição dos conjuntos através de medidas de dimensão por contagem de caixas. Contudo, na literatura, conjuntos com similaridades topológicas aos fractais usuais, por exemplo, auto-similaridade, mas com medida de Lebesgue não-nula, foram investigados e são denominados fractais gordos $[59,94,95]$. O tratamento matemático dos fractais gordos exige algumas definições e extensões no conceito de dimensão, que serão discutidas em detalhes na Seção 5.3. Entretanto, o tratamento consiste em uma estimativa da dimensão exterior, $d_{x}$, do 
conjunto de parâmetros que leva às soluções periódicas. Interpretamos essa medida como a dimensão da fronteira global entre o conjunto de parâmetros que leva a periodicidade e o conjunto de parâmetros que leva ao caos.

Neste capítulo, para estimar a dimensão exterior do conjunto de parâmetros correspondente às soluções periódicas no espaço de parâmetros, utilizamos uma abordagem proposta por Grebogi et al. em que a dimensão exterior de um conjunto é estimada através do cálculo dos elementos do conjunto que são incertos sob uma perturbação em sua localização [59, 96, 97]. Para obter a fração de parâmetros incertos, selecionamos aleatoriamente um conjunto de parâmetros e, com ajuda dos expoentes de Lyapunov, verificamos as condições do comportamento dinâmico (periódico ou caótico). Em seguida alteramos o valor desses parâmetros por uma perturbação, $\varepsilon$, então, analisando o expoente de Lyapunov do sistema perturbado. Calculamos a fração de parâmetros em que o comportamento periódico foi convertido em caótico, com isso obtemos a fração de incertos $f(\varepsilon)$. Repetindo esse procedimento para diversas ordens de grandeza da perturbação, $\varepsilon$, graficamos a fração de incertos, $f(\varepsilon)$, como função da perturbação, $\varepsilon$. Finalmente, ajustamos uma lei de potências nesse comportamento; o expoente desse ajuste é denominado expoente de incerteza, $\alpha$. O expoente de incerteza é relacionado com a dimensão exterior, $d_{x}$, do conjunto por $\alpha=D-d_{x}$.

Assim, verificamos que a dimensão exterior, $d_{x}$, do conjunto de parâmetros que leva à periodicidade, no espaço de parâmetros dos osciladores caóticos, é fractal. Estimando a dimensão exterior para classes de sistemas dinâmicos adicionais, verificamos que o valor obtido para a dimensão exterior para todos sistemas investigados está no mesmo intervalo de confiança. Adicionalmente, formulamos um modelo heurístico que relaciona a universalidade observada para a dimensão exterior com a razão de decrescimento da largura das janelas periódicas complexas ao longo das sequências em que aparecem no espaço de parâmetros. Finalmente, concluimos que a sensibilidade no ajuste de parâmetros de controle observada em sistemas dinâmicos pode ser atribuida à fractalidade da fronteira global dos parâmetros correspondentes à periodicidade. 


\section{$5.2 \quad$ Fractais}

O conceito de fractalidade está intimamente relacionado com escalas de observação. Para objetos fractais, grandezas como comprimento, largura e volume dependem da escala de observação considerada. Por exemplo, tentativas de medir o comprimento da costa da Grã-Bretanha em mapas geográficos falham sistematicamente, uma vez que são observados comprimentos maiores a medida que foram consideradas escalas menores de observação [98]. Adicionalmente, quando inspecionados de diferentes escalas de observações, objetos fractais apresentam auto-similaridade, i.e., sucessivas ampliações de suas partes apresentam características similares do objeto como um todo. A auto-similaridade é frequentemente encontrada em objetos do nosso cotidiano.

Apesar das dificuldades oriundas da dependência com a escala de observação, os objetos fractais precisam ser classificados e diferenciados. Assim, a seguir introduziremos a dimensão fractal.

\subsubsection{Dimensão Fractal}

A dependência com a escala de observação apresentada por objetos fractais pode ser considerada em sua descrição introduzindo-se o conceito de resolução no espaço Euclidiano em que o objeto está imerso. Esse espaço tem dimensão representada por $D$, com $D=1,2,3$. Inicialmente, particionamos esse espaço em elementos de lado $l$ igualmente espaçados, em seguida definimos $N(l)$ como o número desses elementos que são necessários para cobrir a extensão do objeto sob investigação. $V(l)$ será o volume total desses elementos, lembrando que esse volume está definido no espaço $D$-dimensional, podendo representar um comprimento ou uma área. A partir desses conceitos obteremos a dimensão por contagem de caixas, $d$, de um objeto imerso em um espaço Euclidiano, e formularemos uma definição para fractalidade.

Consideramos um objeto usual, por exemplo, uma curva $(d=1)$ de comprimento dado por L. Para definir uma resolução no espaço em que o objeto está imerso, particionamos a curva em elementos de comprimento $l$. Esses elementos são unidimensionais devido ao fato de que a dimensão mínima de um espaço Euclidiano para comportar uma curva é 
$D=1.0$. Para eliminar as unidades de medida do elemento de comprimento, fazemos:

$$
\gamma=\frac{l}{L}
$$

agora $\gamma$ representa o tamanho do elemento definido no espaço Euclidiano.

Com isso, o número de elementos $N(l)$ de lado $l$ necessários para cobrir toda extensão $L$ da curva sob investigação será:

$$
N(l)=\frac{L}{l} \rightarrow N(\gamma)=\gamma^{-1}
$$

Verificamos que o número de elementos $N(\gamma)$ aumenta a medida que o lado do elemento é reduzido como uma lei de potências, cujo expoente é um. O mesmo raciocínio pode ser generalizado para objetos de dimensões maiores, como um plano $(d=2)$ onde obteriamos o expoente da lei de potências como sendo dois, ou um cubo $(d=3)$, e o expoente seria três. Então, realizando a contagem do número de elementos do espaço Euclidiano necessário para cobrir a extensão do objeto de dimensão $d$, obteríamos:

$$
N(\gamma) \sim \gamma^{-d}
$$

Assim, verificamos que a dimensão $d$ do objeto é recuperada no ajuste do número de elementos $N(\gamma)$ como função do tamanho dos elementos $\gamma$ definidos no espaço em que o objeto está imerso. Então, definimos a dimensão por contagens de caixas como:

Definição 5.2.1 A dimensão de contagem de caixas, d, de um objeto imerso em um espaço Euclidiano de dimensão D particionado em $N(\gamma)$ elementos de lado $\gamma$, é:

$$
d=\lim _{\gamma \rightarrow 0} \frac{\ln N(\gamma)}{\ln \gamma}
$$

A definição 5.2.1 continua válida quando $d$ não é um número inteiro.

Adicionalmente, vamos definir o volume $V(\gamma)$ ocupado pelos $N(\gamma)$ elementos necessário para cobrir o objeto de estudo. Dado que um dos elementos definidos no espaço Euclidiano $D$-dimensional tem volume $\gamma^{D}$, então o volume total ocupado pelos $N(\gamma)$ elementos será $V(\gamma)=N(\gamma) \gamma^{D}$. Substituindo a Eq. (5.3), obtemos: 


$$
V(\gamma)=N(\gamma) \gamma^{D} \sim \gamma^{D-d}
$$

Como a dimensão do número de elementos ocupados pode no máximo preencher a dimensão $D$, isso implica $d \leq D$. Entretanto, para objetos fractais teremos que $d<D$, resultando no fato de que o volume $V(\gamma)$ dos elementos é nulo no limite $\gamma \rightarrow 0$ para fractais. Assim, definimos as condições para a fractalidade:

Definição 5.2.2 Um objeto auto-similar é fractal se o volume $V(\gamma)$ é nulo no limite $\gamma \rightarrow 0$ e a dependência de $V(\gamma)$ com $\gamma$ é uma lei de potências com expoentes não-triviais.

O fato de $V(\gamma)$ anular-se no limite $\gamma \rightarrow 0$ significa que o objeto fractal de dimensão $d$ possui medida de Lebesgue nula no espaço D-dimensional.

\subsubsection{Conjunto de Cantor}

A definição 5.2.2 pode ser verificada para o conjunto de Cantor, que constitui um exemplo tradicionalmente utilizado para exemplificar a fractalidade. Esse conjunto é construído a partir de um segmento de reta de comprimento unitário $L=1$. O terço central desse segmento é removido, resultando em dois intervalos de comprimento 1/3 cada. Removendo novamente o terço central desses intervalos resultantes, obtém-se quatro intervalos de comprimento 1/9. Repetindo esse procedimento sistematicamente, após $n$ passos obtém-se $2^{n}$ intervalos de comprimento $1 / 3^{n}$. (Veja ilustração na Figura 5.1.) Os pontos resultantes após a aplicação de infinitos passos $(n \rightarrow \infty)$ é o conjunto de Cantor [98].

Para calcular a dimensão fractal desse conjunto, dividimos o segmento de reta unitário $(L=1)$ em intervalos de comprimento $\gamma=3^{-n}$. O número $N(\gamma)$ de intervalos de comprimento $l=3^{-n}$ necessário para cobrir o conjunto de pontos após $n$ passos é $N(\gamma)=2^{n}$, com isso aplicando à Eq. (5.2.1):

$$
d=\lim _{\gamma \rightarrow 0} \frac{\ln N(\gamma)}{\ln \gamma} \rightarrow d=\frac{\ln 2}{\ln 3}=0.631,
$$




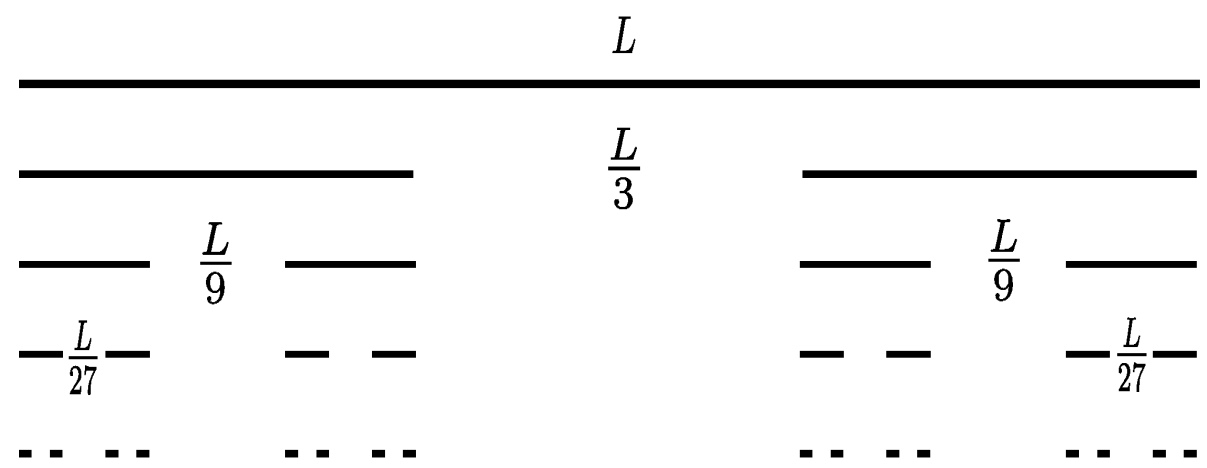

Figura 5.1: Esquema de construção do conjunto de Cantor, o terço central de cada segmento de reta é removido em cada passo da construção. O conjunto de Cantor é o conjunto resultante assintótico desse mecanismo.

Verificamos que o valor do expoente da lei de potências (dimensão fractal) é independente do passo $n$, i.e., independente da escala considerada. Esse fato ressalta a invariância de escala presente em objetos auto-similares.

A dimensão do conjunto de Cantor é $d=0.631$, o espaço Euclidiano que o conjunto está imerso possui dimensão $D=1.0$. Então, de acordo com a Eq. (5.4), para $d<D$ o volume do objeto deve anular-se para $\gamma \rightarrow 0$. Para verificar se o conjunto de Cantor reproduz essa característica, calculamos o comprimento total removido $R$ após os passos para construção do conjunto. Partindo de comprimento inicial unitário $L=1$, o processo consiste na remoção dos terços centrais, assim $R$ será dado por:

$$
R=\frac{1}{3}+\frac{2}{9}+\frac{4}{27}+\ldots=\frac{\frac{1}{3}}{1-\frac{2}{3}}=1,
$$

e o volume do conjunto final é $V=L-R=0$. Portanto o conjunto de Cantor tem medida de Lebesgue nula e obedece a definição 5.2.2.

\subsection{Fractais Gordos}

A definição 5.2.2 de fractais exige o anulamento do volume $V(\gamma)$ no limite $\gamma \rightarrow 0$, i.e., medida de Lebesgue nula. Entretanto, alguns objetos podem exibir estrutura topológica similar aos fractais, mas o volume $V(\gamma)$ não é nulo no limite $\gamma \rightarrow 0$, consequentemente, a dimensão de contagem de caixas desses objetos não é fractal. Esses objetos são chamados fractais gordos. Adiante daremos uma definição mais formal para esses objetos, 
entretanto, para elucidar esse conceito, utilizaremos um objeto fractal usual denominado tapete de Sierpinski. O tapete de Sierpinski, obtido à partir de uma regra para remoção sucessiva e sistemática de pequenos quadrados do interior de um quadrado inicial, é uma versão para o plano do conjunto de Cantor. O tapete de Sierpinski é auto-similar, possui dimensão fractal e medida de Lebesgue nula [98]. Para o nosso propósito de exemplificar conceitualmente um fractal gordo, em um experimento mental, considere que no centro do tapete de Sierpinski acrescentamos um círculo completamente preenchido. O objeto resultante é a união de um conjunto fractal com um objeto Euclidiano (não-fractal), mas se considerarmos o pequeno círculo como sendo imperceptivel às inspeções visuais, o objeto resultante possui aspecto estrutural de um fractal convencional. Entretanto, rigorosamente o objeto resultante não possui volume $V(\gamma)$ nulo no limite $\gamma \rightarrow 0$, essa é a idéia de um fractal gordo.

Um objeto cujo volume $V(\gamma)$ não é nulo no limite $\gamma \rightarrow 0$ não possui dimensão por contagem de caixas fractal. Assim, para incoporar na classificação desses objetos as propriedades similares aos fractais usuais, será necessário algumas novas definições e conceitos. A seguir discutiremos as ferramentas utilizadas nesse tratamento.

\subsubsection{Dimensão Não-Fractal e Expoente de Incerteza}

Se um objeto imerso em um espaço Euclidiano de dimensão $D$ possui medida de Lebesgue não-nula nesse espaço, então a dimensão do objeto é a mesma do espaço Euclidiano. Para ilustrar essa afirmação, consideramos uma construção semelhante ao conjunto de Cantor, mas ao invés de removermos o terço central dos segmentos de reta a cada iteração, removemos $1 / 3$ do comprimento inicial $L=1,0$ e em seguida removemos recursivamente 1/3 da quantidade removida no passo anterior. Assim, na enésima iteração a quantidade removida da extensão do segmento resultante é $1 / 3^{n}$ ao invés de $1 / 3$. Com isso, a extensão $L$ do conjunto após $n$ passos será.

$$
L_{n}=\prod_{m=1}^{n}\left(1-\frac{1}{3^{m}}\right)
$$


Tomando o limite assintótico $n \rightarrow \infty$, obtemos:

$$
L_{\infty}=\prod_{m=1}^{\infty}\left(1-\frac{1}{3^{m}}\right)=0.56 .
$$

A convergência dessa produtória foi verificada numericamente. A medida desse conjunto é $L_{\infty}=0.56$. Embora o conjunto resultante desse processo tenha similaridades topológicas com o conjunto de Cantor, seu comprimento assintótico não é nulo. Portanto, a dimensão desse conjunto é $d=1$. A dimensão usual obtida por contagem de caixas não é adequada para descrever a estrutura encontrada em fractais gordos, pois não incorpora os aspectos que são similares ao conjunto de Cantor, por exemplo, a auto-similaridade.

Para que a propriedade de auto-similaridade seja assimilada na descrição de objetos cujo volume, $V(\gamma)$, da Eq. (5.4) não é nulo, modificaremos o conceito usual de dimensão para considerar propriedades da borda desses objetos. Na Eq. (5.4), inicialmente, definimos a codimensão como $\rho=D-d$. Conceitualmente, a codimensão de um objeto de dimensão $d$ em um espaço de dimensão $D$ é a quantidade que falta na dimensão do objeto para que esse tenha a dimensão do espaço. Adicionalmente, na Eq. (5.4), acrescentamos um sinal de igualdade inserindo uma constante de proporcionalidade. Então,

$$
V(\gamma)=V_{0} \gamma^{\rho}
$$

no limite $\gamma \rightarrow 0$, a codimensão $\rho$ será:

$$
\rho=\lim _{\gamma \rightarrow 0} \frac{\ln V(\gamma)}{\ln \gamma} .
$$

Para fractais usuais tem-se que $\rho>0$. Contudo, para objetos com medida de Lebesgue não-nula, temos que $\lim _{\gamma \rightarrow 0} V(\gamma)=V_{0}>0$, e a condimensão é sempre $\rho=0$, tornando-se inútil, pois nesse caso a dimensão do objeto é a mesma do espaço $d=D$.

Entretanto, essa dificuldade pode ser contornada através de uma modificação conceitual na definição da codimensão, Eq. (5.10). O volume excedente $V_{0}$ que o objeto ocupa no espaço Euclidiano deve ser removido do cálculo da codimensão, para que $\rho$ seja diferente de zero e termos novamente condições de extrair informação dessa medida. Assim, subtraimos $V_{0}$ na definição de codimensão e obtemos:

$$
\alpha=\lim _{\gamma \rightarrow 0} \frac{\ln \left|V(\gamma)-V_{0}\right|}{\ln \gamma} .
$$


Note que para fractais usuais $V_{0}=0$, a definição usual de codimensão é recuperada, caracterizando essa nova definição como uma extensão do conceito original de codimensão.

Para que a remoção do volume $V_{0}$ tenha sentido, esse deve ser removido depois que pontos adicionais são acrescentados na estrutura do objeto. Na literatura, esse mecanismo é realizados de pelo menos de três formas diferentes [95]. Entretanto, nesse trabalho utilizaremos a técnica introduzida por Grebogi et al. [59], onde o volume do objeto de interesse é completado com um conjunto exterior de pontos até uma distância $\gamma$. Na Figura 5.2 ilustramos esse conceito em um pictograma.
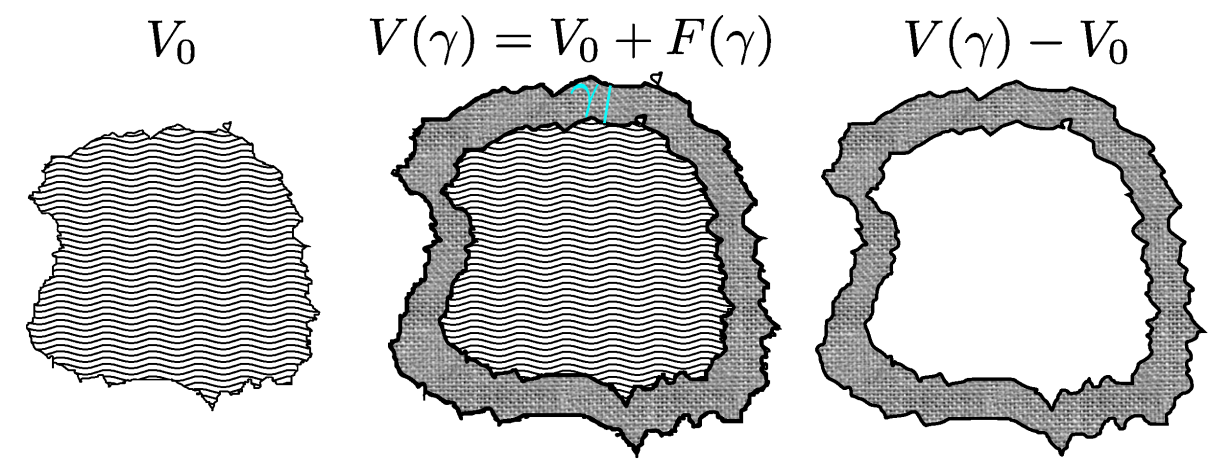

Figura 5.2: Pictograma ilustrando o artifício realizado para remover o volume $V_{0}$ que o objeto ocupa na grade definida no espaço Euclidiano que está imerso.

Nesse caso, a nova codimensão $\alpha$ refere-se ao volume $V(\gamma)-V_{0}$ que no limite $\gamma \rightarrow 0$ tende para a fronteira do objeto. Com isso, a codimensão $\alpha$ é relacionada com uma dimensão que chamaremos de dimensão exterior $d_{x}$, então:

$$
\alpha=D-d_{x}
$$

onde $D$ é a dimensão do espaço Euclidiano e $d_{x}$ é a dimensão exterior do conjunto, que conforme a literatura, é a dimensão da fronteira do objeto. Com isso, $N(\gamma) \sim \gamma^{d_{x}}$ refere-se ao número de elementos, definidos no espaço Euclidiano, ocupados pelo volume exterior $V(\gamma)-V_{0}$ do conjunto.

A obtenção direta da codimensão $\alpha$ à partir da Eq. (5.11) é inviável, especialmente devido à dificuldades de obtenção do volume, $V(\gamma)-V_{0}$, do conjunto exterior. Para contornar essa situação, utilizamos o fato desse volume tratar-se de uma área de fronteira, portanto, seus elementos podem sair do conjunto quando perturbados por um erro $\varepsilon$ em 
sua posição. Com isso, o volume $V(\gamma)-V_{0}$ será aproximado pela fração $f(\varepsilon)$ de seus elementos que são incertos quando perturbados por $\varepsilon$. Adicionalmente, fazendo o tamanho $\gamma$ do elemento de volume igual à perturbação $\varepsilon$ na posição $(\gamma=\varepsilon)$, teremos:

$$
f(\varepsilon) \sim V(\varepsilon)-V_{0}
$$

Usando a Eq. (5.4) e $N(\varepsilon) \sim \varepsilon^{d_{x}}$ :

$$
f(\varepsilon) \sim \varepsilon^{D-d_{x}} \sim \varepsilon^{\alpha}
$$

Assim, identificamos a codimensão $\alpha$ como o expoente da lei de potências que governa a fração de elementos do conjunto em função da perturbação aplicada, denominado expoente de incerteza. Essa condimensão é definida como:

$$
\alpha=\lim _{\varepsilon \rightarrow 0} \frac{\ln f(\varepsilon)}{\ln \varepsilon} .
$$

Para definir o intervalo de valores admitidos pelo expoente de incerteza nesse contexto, basta considerarmos a Eq. (5.12). A dimensão exterior delimita o conjunto fractal gordo. Para tal, seu valor mínimo permitido é $d=D-1$, implicando $\alpha \leqslant 1$, onde $D$ é a dimensão do espaço Euclidiano em que o sistema está imerso. Por outro lado, a dimensão exterior deve sempre ser menor que a dimensão do espaço $D$, implicando $\alpha>0$ [59, 97]. Com isso, temos uma definição para os fractais gordos:

Definição 5.3.1 Um objeto auto-similar é um fractal gordo se o volume $V(\gamma)$ é não-nulo no limite $\gamma \rightarrow 0$ e o expoente de incerteza, $\alpha$, está no intervalo $0<\alpha \leqslant 1$

Com auxílio do expoente de incerteza, investigamos as condições dos conjuntos formados por parâmetros que correspondem ao comportamento periódico no espaço de parâmetros dos osciladores caóticos.

\subsection{Expoente de Incerteza e Dimensão Exterior no Espaço de Parâmetros}

Conforme discutimos na seção 2.4.6, os parâmetros correspondentes às soluções periódicas e os correspondentes aos atratores caóticos dividem espaço em diagramas bidimensionais de parâmetros, denominados espaço de parâmetros. Adicionalmente, os parâmetros 
correspondentes às soluções periódicas estão agrupados em janelas periódicas complexas, a distribuição dessas janelas no espaço de parâmetros de diversos sistemas dinâmicos tem sido amplamente observada como sendo auto-similar, i.e., perfil de organização dos parâmetros nesse espaço é invariante em diversas escalas de observações. Entretanto, nenhuma investigação das condições topológicas desses conjuntos ou de suas fronteiras foi realizada. Dado que os parâmetros correspondentes às soluções periódicas (janelas periódicas complexas) evidentemente ocupam uma área não-nula nesses diagramas, o conjunto de parâmetros que leva às soluções periódicas é de medida não-nula. Adicionalmente, os parâmetros correspondentes aos atratores caóticos foram mostrados com também possuindo medida de Lebesgue não-nula [93]. Assim, descarta-se a possibilidade de ambos conjuntos serem fractais usuais. Entretanto, a configuração auto-similar das janelas periódicas complexas levanta a hipótese de existência de fractais gordos e, consequentemente, a existência de fronteiras fractais entre periodicidade e caos no espaço de parâmetros.

Assim, utilizamos os expoentes de incerteza, introduzidos na seção anterior, para caracterizar as condições topológicas das fronteiras entre os parâmetros correspondentes à periodicidade e caos no espaço de parâmetros de osciladores caóticos. Embora esses expoentes tenham sido utilizados na literatura para caracterizar as fronteiras entre os conjuntos bidimensionais de condições iniciais que levam à diferentes atratores [96, 97], no contexto de espaço de parâmetros esta é a primeira vez que eles são utilizados.

Para obter o expoente de incerteza e, consequentemente, a dimensão das fronteiras entre os conjuntos de parâmetros que levam respectivamente à periodicidade e caos, inicialmente selecionamos aleatoriamente $3,0 \times 10^{4}$ pares $(\omega, d)$ de parâmetros. Adicionalmente, perturbamos esses pares por um erro $\varepsilon$ em ambas orientações ao longo de uma das componentes, esse procedimento fornece $6,0 \times 10^{4}$ pares $(\omega \pm \epsilon, d)$ de parâmetros adicionais. Em seguida utilizamos os expoentes de Lyapunov, $\lambda$, para decidir se os estados correspondentes a cada par de parâmetros é caótico $(\lambda>0)$ ou periódico $(\lambda<0)$. Então, tomamos todos os pares de parâmetros $\left(\omega_{c}, d_{c}\right)$ não-perturbados cujo estado é periódico, comparamos com os estados dos respectivos parâmetros perturbados $\left(\omega_{c} \pm \varepsilon, d_{c}\right)$. Se pelo menos um dos dois estados foi convertido para caótico devido à perturbação, então o parâmetro periódico é computado como incerto. Esse procedimento é repetido para diferentes 
valores da perturbação $\varepsilon$ e a fração, $f(\varepsilon)$, dos parâmetros caóticos que são incertos é armazenado. A Figura 5.3 ilustra o procedimento discutido para obtenção dos expoentes de incerteza no espaço de parâmetros.

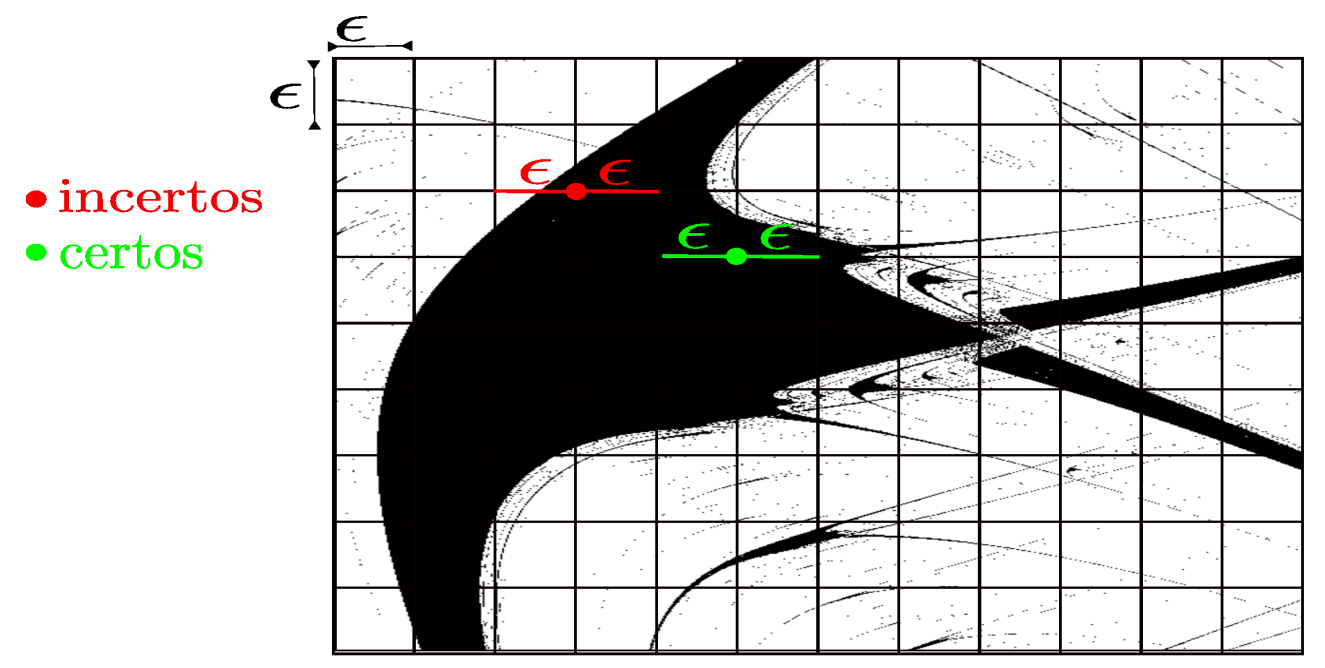

Figura 5.3: Ilustração do método utilizado para quantificar o número de parâmetros incertos.

Assim, na Figura 5.4(a) mostramos o espaço de parâmetros $(\omega \times d)$ do oscilador de Morse descrito pela Eq. (4.5) na Seção 2.3. Em preto indicamos os parâmetros que correspondem aos atratores caóticos, enquanto em branco indicamos os parâmetros correspondentes às janelas periódicas complexas. Nessa figura escolhemos uma região do espaço de parâmetros em que as janelas periódicas complexas estão alinhadas em sequências de adicionamento de período e torsão, e se acumulando em regiões periódicas do espaço de parâmetros. Na Figura 5.4(b), para a região do espaço de parâmetros mostrada na Figura 5.4(a), mostramos a fração de parâmetros incertos $f(\varepsilon)$ em função da perturbação $\varepsilon$. O intervalo de confiança para a fração de incertos $f(\varepsilon)$ foi obtido tomando-se $\sqrt{N(\varepsilon)}$, onde $N(\varepsilon)$ é o número de incertos. A linha preenchida é um ajuste como lei de potências, $f(\varepsilon)=$ A varepsilon $^{\alpha}$, que nos fornece o expoente de incerteza $\alpha=0,40 \pm 0,04$. O desvio padrão do expoente de incerteza, $\alpha$, foi obtido diretamente do graficados utilizados no ajuste como lei de potências.

Na Figura 5.5(a), mostramos o espaço de parâmetros do oscilador de Duffing descrito pelo Eq. (2.4) na Seção 2.3, a codificação de cores é a mesma da Figura 5.4(a). Com o mesmo critério utilizado na 5.4(b) de escolha para região do espaço de parâmetros, na 


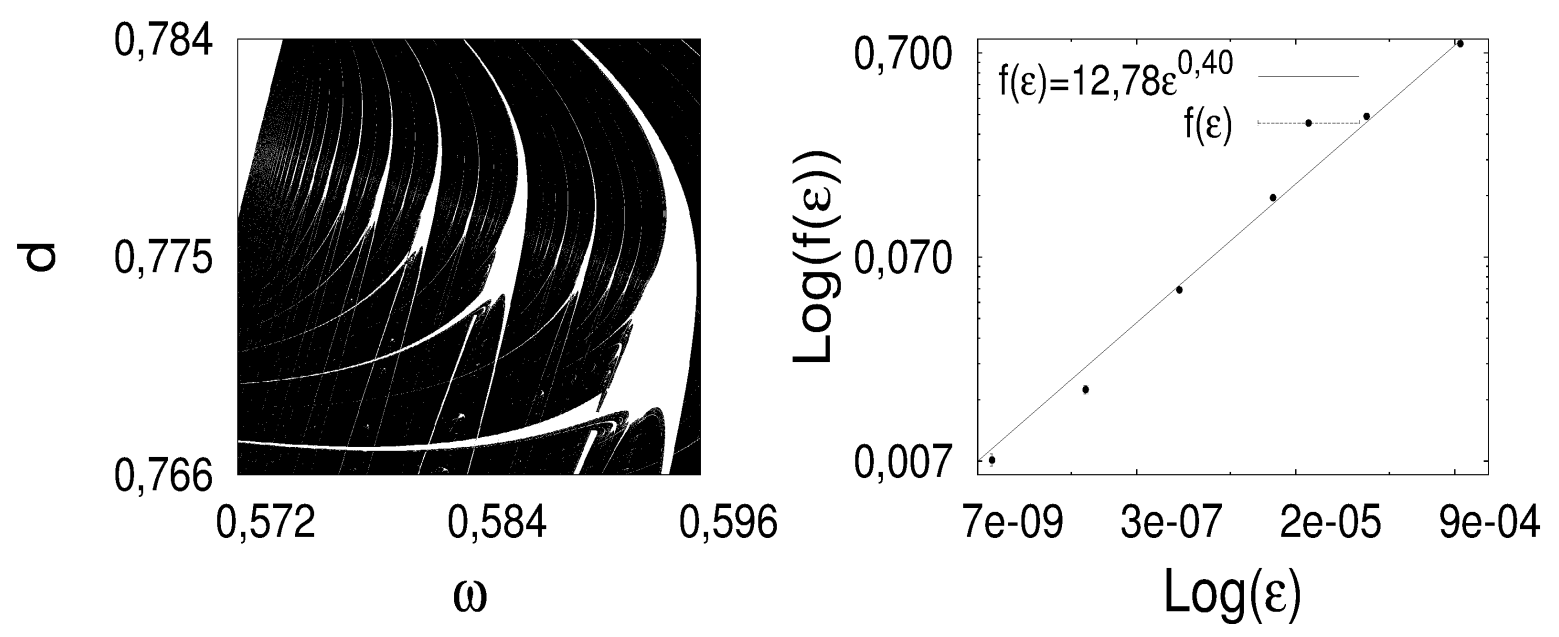

Figura 5.4: (a) Espaço dos parâmetros $(\omega \times d)$ do oscilador de Morse. Parâmetros representados em preto correspondem ao comportamento caótico, enquanto parâmetros representados em branco ao periódico. (b) Fração de parâmetros incertos $f(\varepsilon)$ dos parâmetros correspondentes ao comportamento ajustados como uma lei de potências com a perturbação/erro $\varepsilon$.

Figura 5.5(b) obtivemos a fração de parâmetros incertos como função da perturbação aplicada $\varepsilon$. Realizando o ajuste de uma função lei de potência, obtivemos o expoente de incertza, $\alpha=0,38 \pm 0,04$

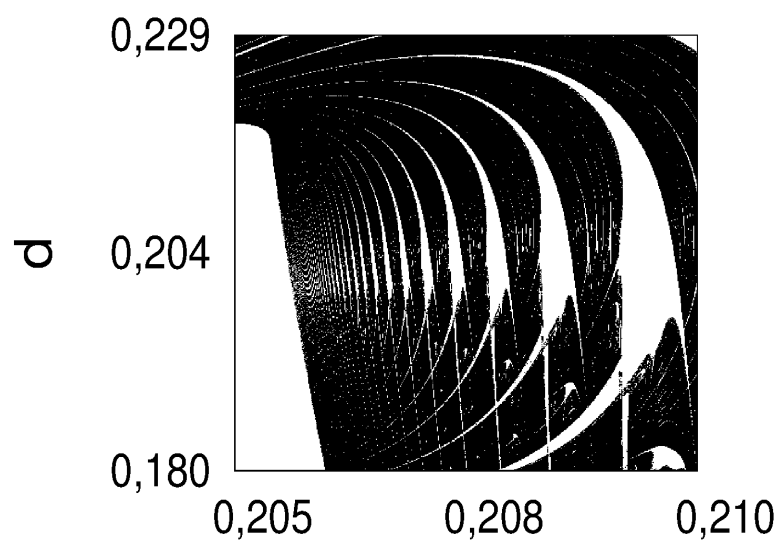

$\omega$

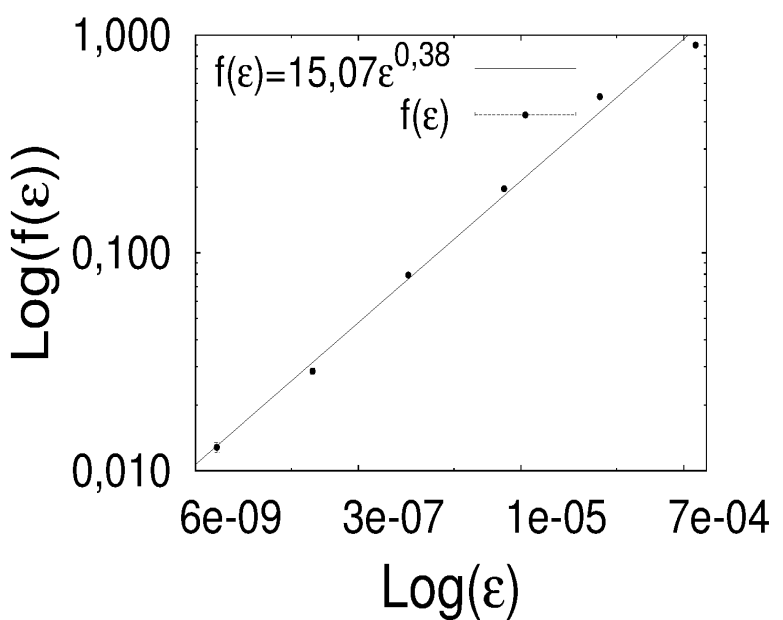

Figura 5.5: (a) Espaço dos parâmetros $(\omega \times d)$ do oscilador de Duffing. Parâmetros representados em preto correspondem ao comportamento caótico, enquanto parâmetros representados em branco ao periódico. (b) Fração de parâmetros incertos $f(\varepsilon)$ dos parâmetros correspondentes ao comportamento ajustados como uma lei de potências com a perturbação/erro $\varepsilon$.

Com as Figuras 5.4 e 5.5, notamos que o expoente de incerteza ajustados para am- 
bos osciladores caóticos estão no mesmo intervalo de confiança. Assim, utilizando a Eq. (5.12), obtemos a dimensão exterior $d_{x}$ do conjunto de parâmetros que levam aos atratores caóticos de ambos osciladores, conforme Tabela 5.1:

\begin{tabular}{|l|l|l|}
\hline Sistema Dinâmico & $\alpha$ & $d_{x}$ \\
\hline \hline Oscilador de Morse & $0,41 \pm 0,04$ & $1,59 \pm 0,04$ \\
\hline Oscilador de Duffing & $0,38 \pm 0,04$ & $1,62 \pm 0,04$ \\
\hline
\end{tabular}

Tabela 5.1: Na primeira coluna mostramos os expoentes de incerteza $\alpha$ ajustados para o oscilador de Morse (primeira linha) e para o oscilador de Duffing (segunda linha). Na segunda coluna representamos a dimensão exterior $d_{x}$, de ambos os osciladores, obtida pela Eq. (5.12).

Os resultados mostrados na Tabela 5.1 sugerem que o expoente de incerteza e consequentemente a dimensão exterior podem ser uma grandeza universal para sistemas dinâmicos. Assim, na seção seguinte analisamos essas grandezas para diversos sistemas dinâmicos em que sequencias de janelas periódicas ocorrem no espaço de parâmetros.

\subsection{Dimensão Exterior Como Universalidade em Sis- temas Dinâmicos}

Para investigar a universalidade da dimensão exterior, realizamos o procedimento descrito na seção anterior para obter o expoente de incerteza de três classes adicionais de sistemas dinâmicos. Começamos com um exemplo bastante popular no estudo de sistemas dinâmicos contínuos, o oscilador de Rössler, que é descrito pelo seguinte sistema de equações:

$$
\begin{aligned}
& \dot{x}=-y-z, \\
& \dot{y}=x+a y, \\
& \dot{z}=(b+z) x-c z .
\end{aligned}
$$

Conforme Fig. 5.6, nesse sistema investigamos o espaço de parâmetros $a \times c$ onde ocorre uma sequência de janelas periódicas complexas. O parâmetro $b$ é mantido constante em $b=0,3$. 

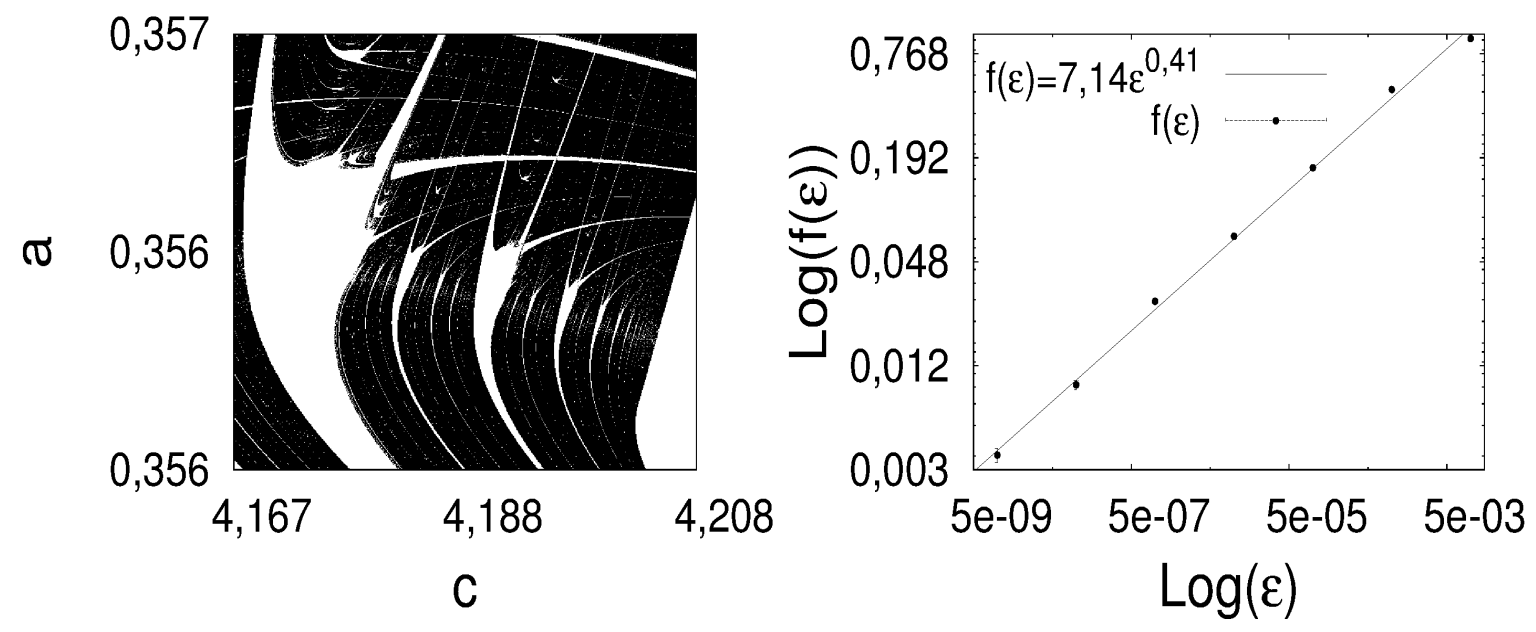

Figura 5.6: (a) Espaço dos parâmetros $(a \times c)$ do oscilador de Rössler. Parâmetros representados em preto correspondem ao comportamento caótico, enquanto parâmetros representados em branco ao periódico. Fração de parâmetros incertos $f(\varepsilon)$ dos parâmetros correspondentes ao comportamento ajustados como uma lei de potências com a perturbação/erro $\varepsilon$.

Também consideramos sistemas dinâmicos descritos por equações diferenciais que descrevem taxas de povoamento de níveis de energia. Como exemplo, tomamos um laser de $\mathrm{CO}_{2}$ com perdas moduladas por um parâmetro depedente do tempo:

$$
\begin{aligned}
& \dot{u}=\frac{1}{\tau}(z-k(t)) u, \\
& \dot{z}=\left(z_{0}-z\right) \gamma-u z,
\end{aligned}
$$

onde $k(t)=k_{0}(1+A \cos 2 \pi f t)$. Conforme resultados mostrados na Fig. 5.7, investigamos uma sequência de janelas periódicas complexas no espaço $f \times A$ dos parâmetros. Os outros parâmetros são mantidos fixos $\tau=3,5 \times 10^{-9} s, \gamma=1,978 \times 10^{5} s^{-1}, z_{0}=0,175$, e $k_{0}=0,1731[26]$.

Finalmente, na Fig. 5.8, consideramos uma sequência de janelas periódicas complexas no espaço de parâmetros de um sistema dinâmico à tempo discreto, o mapa do círculo:

$$
x_{n+1}=x_{n}+\Omega-\frac{K}{2 \pi} \sin \left(2 \pi x_{n}\right),
$$

obtemos o espaço $K \times \Omega$ de parâmetros desse mapa [99].

Na Tabela 5.2 mostramos os valores obtidos para o expoente de incerteza e para a dimensão exterior para as três classes de sistemas dinâmicos estudadas nessa seção: 

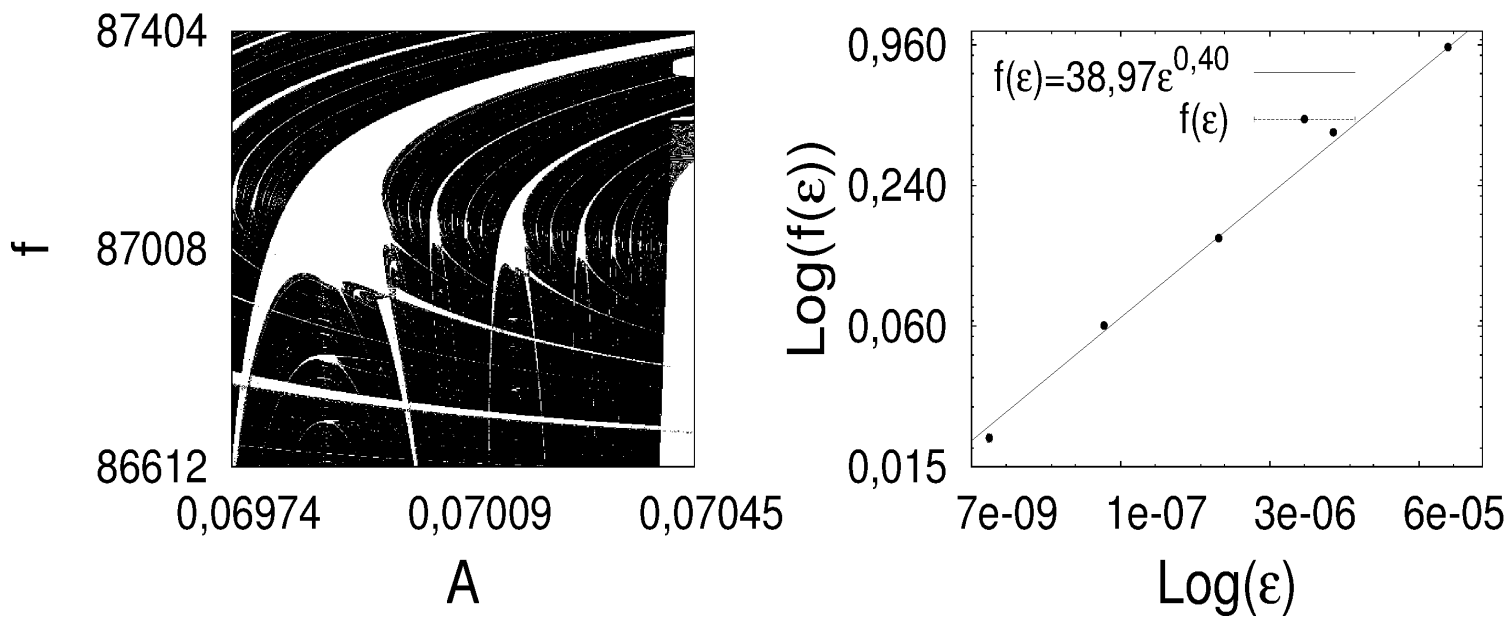

Figura 5.7: (a) Espaço dos parâmetros $(f \times A)$ do laser $\mathrm{CO}_{2}$. Parâmetros representados em preto correspondem ao comportamento caótico, enquanto parâmetros representados em branco ao periódico. (b) Fração de parâmetros incertos $f(\varepsilon)$ dos parâmetros correspondentes ao comportamento ajustados como uma lei de potências com a perturbação/erro $\varepsilon$.
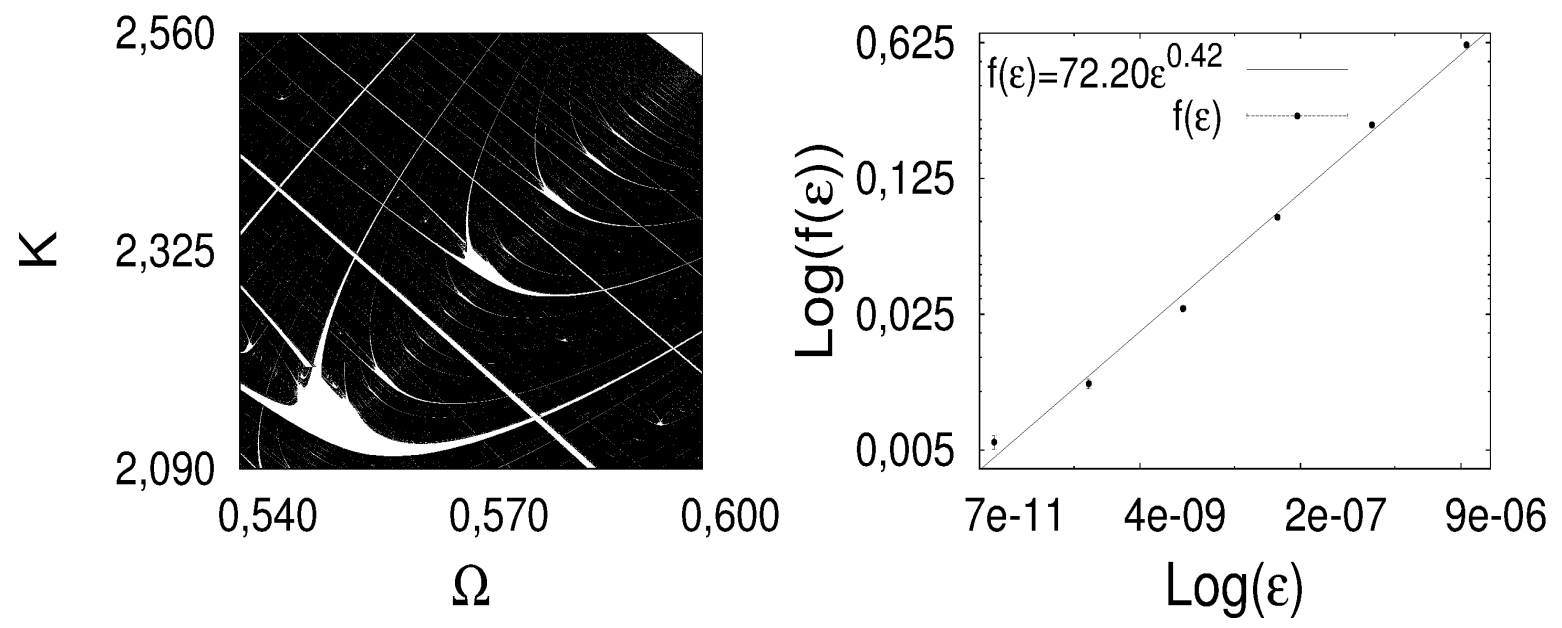

Figura 5.8: (a) Espaço dos parâmetros $(K \times \Omega)$ do mapa do círculo. Parâmetros representados em preto correspondem ao comportamento caótico, enquanto parâmetros representados em branco ao periódico. (b) Fração de parâmetros incertos $f(\varepsilon)$ dos parâmetros correspondentes ao comportamento ajustados como uma lei de potências com a perturbação/erro $\varepsilon$. 


\begin{tabular}{|l|l|l|}
\hline Sistema Dinâmico & $\alpha$ & $d_{x}$ \\
\hline \hline Oscilador de Rössler & $0,41 \pm 0,04$ & $1,59 \pm 0,04$ \\
\hline Laser $\mathrm{CO}_{2}$ & $0,40 \pm 0,04$ & $1,60 \pm 0,04$ \\
\hline Mapa do Círculo & $0,42 \pm 0,04$ & $1,58 \pm 0,04$ \\
\hline
\end{tabular}

Tabela 5.2: Na primeira coluna mostramos os expoentes de incerteza $\alpha$ ajustados para o oscilador de Rössler (primeira linha), para o laser $\mathrm{CO}_{2}$ (segunda linha) e para o mapa do círculo (terceira linha). Na segunda coluna representamos a dimensão exterior $d_{x}$, dos três sistemas, obtida pela Eq. (5.12).

Com isso, nessa seção confirmamos que o valor da dimensão exterior obtida para os osciladores caóticos na seção anterior é reproduzido para sistemas dinâmicos de outras classes. Assim, para os sistemas dinâmicos investigados, argumentamos que essa dimenão é universal em regiões do espaço de parâmetros onde sequências de janelas periódicas ocorrem. As sequências de janelas periódicas complexas estão alinhadas em sequências de adicionamento de período, o tamanho das janelas é reduzido ao longo dessas sequências a medida que o período cresce. Baseados nessa propriedade, na seção seguinte, formulamos um modelo heurístico para explicar a universalidade da dimensão exterior como consequência da redução do tamanho das janelas ao longo da sequência.

\subsection{Modelo Heurístico para Dimensão de Fronteiras no Espaço de Parâmetros}

As observações discutidas nas seções anteriores sugerem que a dimensão exterior do conjunto de parâmetros que correspondem à periodicidade é universal. Suspeitamos que essa universalidade pode ser entendida à medida que as janelas periódicas complexas decrescem ao longo das sequências. Assim, com a finalidade de modelar esse comportamento universal da dimensão exterior, formulamos um modelo heurístico unidimensional para descrever o decrescimento dessas janelas ao longo das sequências em que ocorrem. No modelo, as janelas periódicas serão representadas por intervalos removidos sucessivamente de um segmento de reta inicial, no limite assintótico do processo de remoção, o conjunto remanescente representará os parâmetros correspondentes ao comportamento 
caótico. Entretanto, antes de realizar as considerações do modelo propriamente, investigamos o decrescimento das janelas periódicas ao longo das sequências em que são observadas, com o objetivo principal de verificar a existência de regras para esse decrescimento que possam ser úteis na alimentação do modelo. Nessa investigação consideramos todos os sistemas discutidos na Seção 5.5 e entre os osciladores da Seção 5.4 escolhemos o oscilador de Morse.

Na Figura 5.9, de cima para baixo os diagramas correspondem respectivamente aos sistemas: Oscilador de Rössler, oscilador de Morse, laser $\mathrm{CO}_{2}$ e mapa do círculo. À esquerda, mostramos o espaço de parâmetros dos sistemas investigados, destacamos as sequências de janelas periódicas complexas que escolhemos para estudar o comportamento do decrescimento através de numeração de cada janela que teve a largura mensurada. Na Figura 5.9, à direita, mostramos o decrescimento das dez primeiras janelas ao longo da sequência, adicionalmente verificamos que esse comportamento é ajustado por uma lei de potências, $W(i)=A i^{-l}$.

Dado que o decrescimento da largura da janela é ajustado por uma lei de potência com expoente $l$, a partir de uma reta de comprimento inicial $C_{0}$, o modelo heurístico consiste na remoção sucessiva de segmentos cujo comprimento também é reduzido de acordo com uma lei de potências com o mesmo expoente $l$ obtido para o decrescimento da largura das janelas. Cada passo $i$ de remoção no modelo corresponde à uma janela periódica complexas da sequência. Na Figura 5.10 mostramos um pictograma do modelo heurístico e um comparativo com a sequência de janelas periódicas complexas.

Assim, passamos à analise do expoente de incerteza $\alpha_{M}$ do modelo heurístico. A partir da Eq. (5.14), sabemos que $f_{M}(i) \propto \varepsilon_{M}^{\alpha_{M}}$. Então, inicialmente obtemos uma expressão para o número de elementos incertos $f_{M}(i)$ do modelo. Para tal, consideramos como incertos os elementos que estão na borda dos intervalos removidos, com isso, $f_{M}(i)=2 i$. Adicionalmente, de acordo com a Figura 5.9, sabemos que a fração dos intervalos caóticos que é removida a cada passo é $W(i) \sim A / i^{l}$, então, consideramos o erro $\varepsilon_{M}$ do modelo como sendo inversamente proporcional a esse decrescimento, i.e., $\varepsilon_{M} \propto i^{l}$. O erro aumenta a medida que as janelas periódicas são removidas no processo. Assim, temos o expoente 

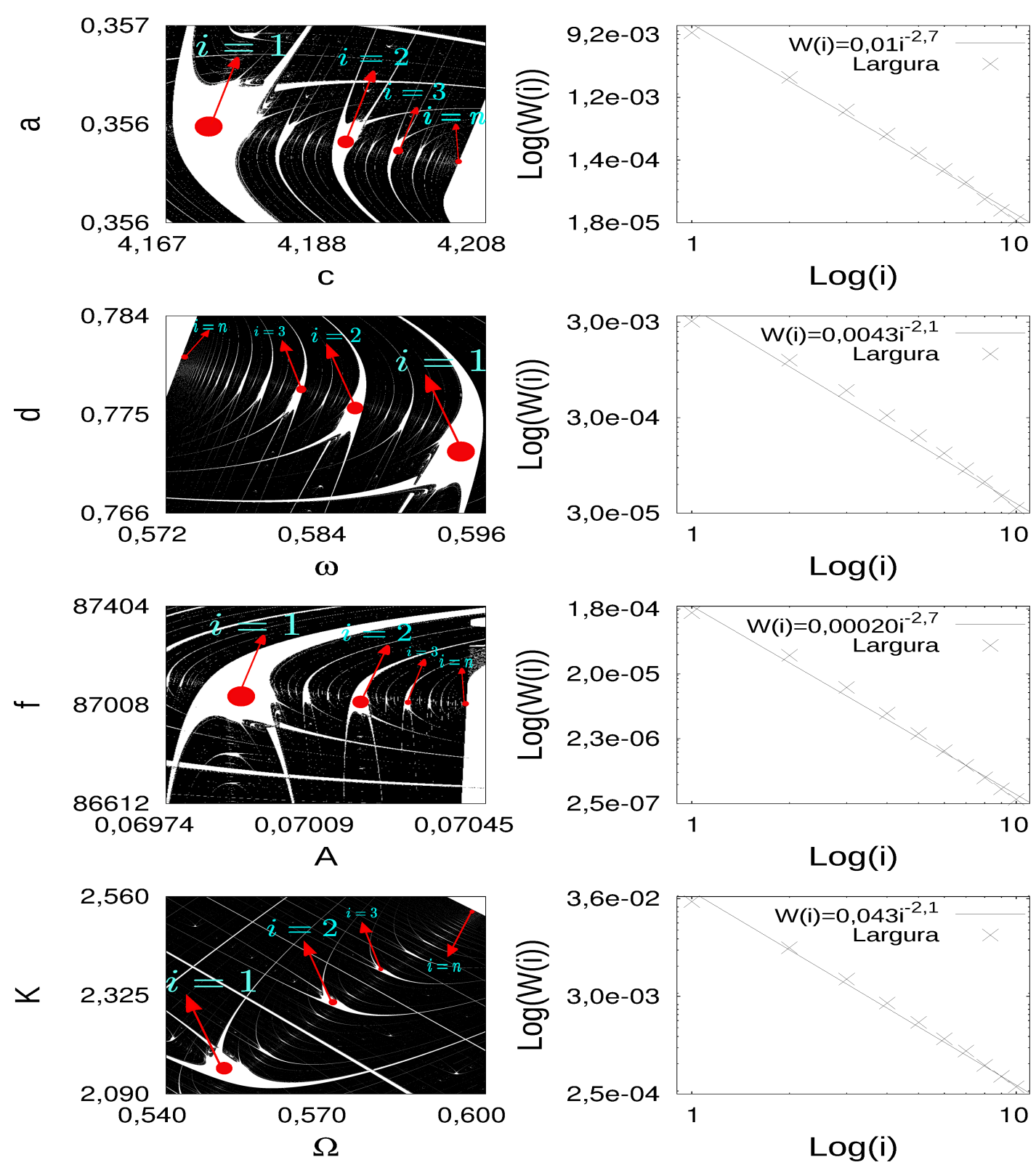

Figura 5.9: De cima para baixo os diagramas correspondem respectivamente aos sistemas: Oscilador de Rössler, oscilador de Morse, laser $\mathrm{CO}_{2}$ e mapa do círculo. À esquerda estão sequências de janelas periódicas cujo largura foi mensurada, os números representam a ordem, $i$, de aparecimento da janela na sequência considerada. À direita estão as medidas de largura das dez primeiras janelas periódicas, o comportamento da largura $W$ ao longo da sequência foi ajustado como uma lei de potências para os sistemas investigados 


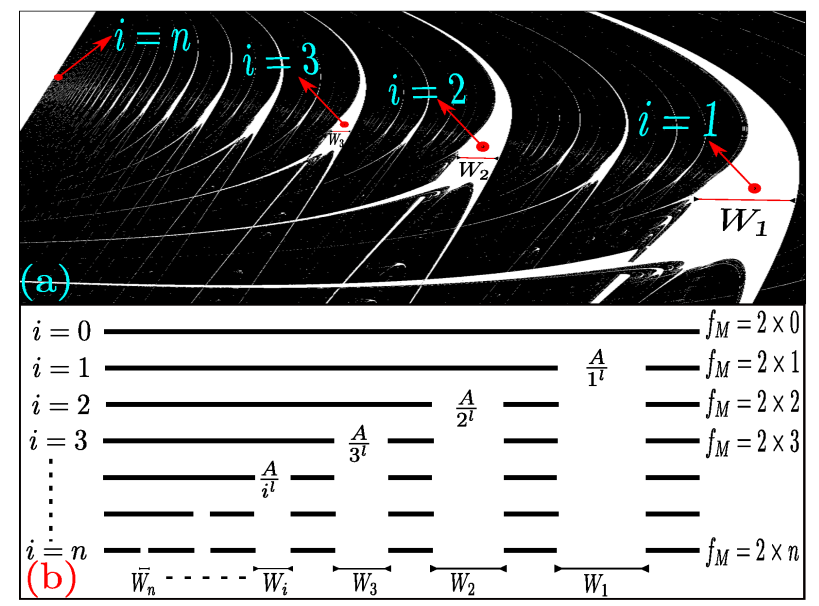

Figura 5.10: (a) Sequência típica de janelas periódicas complexas. Os números representam a ordem de aparecimento da janela na sequência. As letras $W_{i}$ representam a posição onde medimos a largura da janela. (b) Esquema de construção do modelo, à partir de uma reta, os comprimentos $W_{i}$ referente a largura de cada janela são removidos a cada passo $i$ do modelo. $f_{M}$ é o número de parâmetros incertos em cada passo do modelo

de incerteza $\alpha_{M}$ do modelo heurístico:

$$
\alpha_{M}=\lim _{i \rightarrow \infty} \frac{\log (2 i)}{\log \left(i^{l}\right)}=\frac{1}{l}
$$

Usando Eq. (5.19) na Eq.(5.12), obtemos a dimensão exterior $d_{M x}$ do modelo heurístico:

$$
d_{M x}=\frac{l D-1}{l}
$$

onde $l$ é o expoente de decrescimento da largura da janela periódica, $D$ é a dimensão do espaço Euclidiano em que conjunto está imerso.

Com isso, substituindo na Eq. (5.20) os valores dos expoentes $l$ obtidos na Figura 5.9, verificamos que a dimensão exterior obtida para o modelo heurístico está no mesmo intervalo de confiança dos valores obtidos para a dimensão exterior obtida através dos expoentes de incerteza das Seções 5.4 e 5.5.

Na Tabela 5.3 sumarizamos os resultados obtidos para os sistemas analisados. Na primeira coluna mostramos os valores obtidos para os expoentes, $l$, de decrescimento da largura das janelas periódicas. Na segunda coluna mostramos a dimensão exterior $d_{x}$ obtida através dos expoentes de incerteza $\alpha$ mostrados na quarta coluna e obtidos pelo cálculo da fração de incertos no espaço dos parâmetros. Na terceira coluna, mostramos a 
dimensão exterior $d_{M x}$ obtida para o modelo heurístico calculada através dos expoentes $\alpha_{M}$ mostrados na última coluna.

\begin{tabular}{|l|l|l|l|l|l|}
\hline Sistema Dinâmico & $l$ & $d_{x}=D-\alpha$ & $d_{M x}$ & $\alpha$ & $\alpha_{M}$ \\
\hline \hline Oscilador de Rössler & $2,7 \pm 0,1$ & $1,59 \pm 0,04$ & $1,63 \pm 0,06$ & $0,41 \pm 0,04$ & $0,37 \pm 0,01$ \\
\hline Oscilador de Morse & $2,1 \pm 0,1$ & $1,60 \pm 0,04$ & $1,52 \pm 0,07$ & $0,40 \pm 0,04$ & $0,48 \pm 0,02$ \\
\hline Laser de $\mathrm{CO}_{2}$ & $2,7 \pm 0,1$ & $1,60 \pm 0,04$ & $1,63 \pm 0,06$ & $0,40 \pm 0,04$ & $0,37 \pm 0,01$ \\
\hline Mapa do Círculo & $2,1 \pm 0,1$ & $1,58 \pm 0,04$ & $1,52 \pm 0,07$ & $0,42 \pm 0,04$ & $0,48 \pm 0,02$ \\
\hline
\end{tabular}

Tabela 5.3: Na primeira coluna mostramos os expoentes, $l$, de decrescimento da largura das janelas periódicas obtidos nos ajustes da Figura 5.9. Na segunda coluna mostramos a dimensão exterior $d_{x}$ calculada através dos expoentes de incerteza $\alpha$, mostrados na quarta coluna, obtidos na Seções 5.4 e 5.5. Na terceira coluna mostramos a dimensão exterior $d_{M x}$ obtida através do expoente de incerteza $\alpha_{M}$ do modelo mostrados na última coluna.

Assim, de acordo com Tabela 5.3, constatamos que a universalidade observada para dimensão exterior do conjunto de parâmetros que levam ao comportamento periódico é bem descrita por um modelo que incorpora o decrescimento da largura das janelas periódicas complexas.

\subsection{Conclusão}

Neste capítulo, verificamos a existência de incertezas intrínsecas no ajustes dos parâmetros de controle de sistemas dinâmicos não-lineares que exibem caos. Quantificamos essas incertezas através do ajuste da fração de parâmetros incertos como uma lei de potências em função de um erro aplicado. Através do expoente obtido nessa lei de potências, obtivemos a dimensão exterior do conjunto de parâmetros que leva às soluções periódicas, essa dimensão mostrou-se fractal e universal para as classes de sistemas investigados. No espaço de parâmetros, interpretamos essa dimensão como sendo a dimensão da fronteira global entre o conjunto de parâmetros que leva às soluções periódicas e o conjunto que leva às soluções caóticas. Adicionalmente, analisamos o decrescimento da largura das janelas periódicas complexas ao longo de sequências que existem na região de parâmetros em que calculamos a dimensão exterior. Verificamos que essa largura também possui o expo- 
ente caracterśtico de decrescimento que utilizamos em modelo heurístico para explicar a universalidade observada para as fronteiras. 


\section{Capítulo 6}

\section{Conclusões e Considerações Finais}

A realização dos trabalhos relatados nessa tese foi motivada pelo crescente interesse em conhecer a dependência de sistemas dinâmicos com seus parâmetros de controle. Esse tipo de investigação tem sido amplamente realizada com a utilização de diagramas bidimensionais denominados espaço de parâmetros. Esses estudos abrangem sistemas dinâmicos contínuos e discretos provenientes de diversos campo da ciência, e são realizados em caráter teórico, numérico e experimental. Nessa tese, nossas investigações concentraram-se em experimentos numéricos e, quando possível, realizamos interpretações teóricas e heuríticas dos principais resultados obtidos e fenômenos observados. Na escolha dos sistemas dinâmicos a serem investigados consideramos seus respectivos potenciais para posterior implementação em aparatos experimentais. Acreditamos que os resultados aqui relatados são factíveis de confirmação em laboratório. Assim, o cenário escolhido para nossas análises foi o espaço de parâmetros dos osciladores caóticos, uma classe de sistemas dinâmicos simples. Porém, nesses sistemas procedemos sem evitar complexidades decorrentes de sua análise e de seus resultados.

No capítulo 2, inicialmente, discutimos a formalização básica de sistemas dinâmicos a tempo contínuo, bem como, os principais estados finais presentes no espaço de estados desses sistemas. Em seguida, introduzimos a equação geral dos osciladores caóticos, e a partir desse ponto restringimos nossa análise a essa classe de sistemas dinâmicos. Apresentamos as principais ferramentas e artifícios utilizados no tratamento desses osciladores. A integração numérica foi realizada com método de Runge-Kutta de quarta ordem com 
passo fixo. A convergência do método para essa classe de equações, bem como a precisão na obtenção dos estados finais, foram testadas utilizando-se diferentes parâmetros de integração e comparados com estados finais obtidos na literatura. A dinâmica dos estados desses osciladores está contida em um espaço tridimensional $(x, d x / d t, t)$. Utilizando planos de fase e seções de Poincaré estroboscópicas, reduzimos a análise ao plano $(x, d x / d t)$. A sensibilidade estrutural às variações dos parâmetros foi discutida e ilustrada através de diagramas de bifurcações.

Adicionalmente, no Capítulo 2, ressaltamos a importância da distinção entre o comportamento periódico e caótico. Para essa finalidade, introduzimos o conceito de expoentes de Lyapunov. A obtenção desses expoentes para sistemas dinâmicos contínuos, tipicamente, apresenta dificuldades numéricas. Nesse trabalho adotamos o algoritmo de Wolf et al., na Seção 2.4.3, discutimos os principais passos desse procedimento. Com auxílio dos expoentes de Lyapunov, confeccionamos espaços bidimensionais de parâmetros, que contribuíram na análise coletiva de um conjunto de parâmetros de controle dos osciladores não lineares.

As propriedades de torsão dos estados periódicos, os cálculos do número de torsão e do número de rotação também foram introduzidos no Capítulo 2. Definimos inicialmente o conceito usual de número de rotação, geralmente associado às superfícies toroidais. Em seguida, introduzimos o número de rotação e de torsão generalizados propostos por U. Parlitz e W. Lauterborn para osciladores caóticos, o cálculo dessas grandezas considera o número de voltas que uma trajetória descreve antes de convergir para um dado estado periódico. A partir das expressões obtidas para as grandezas que quantificam a torsão, mostramos a convergência do número de rotação, $w$, para uma razão de números inteiros. Consequentemente, a convergência do número de torsão, $n$, também fica garantida uma vez que $n=w m$, onde $m$ é um inteiro correspondente ao período da órbita periódica.

No Capítulo 3, investigamos, no espaço de parâmetros de osciladores caóticos, as consequências da implementação de pequenas perturbações periódicas nas equações que descrevem esses osciladores. Conforme relatado na literatura $[57,58]$, as pequenas perturbações periódicas podem suprimir a existência de estados caóticos, constituindo uma técnica de controle de caos [83]. Nesta tese, observamos que a supressão de caos de- 
vido a essas perturbações ocorre para um conjunto de parâmetros do sistema com uma mesma amplitude da perturbação. Especificamente, as pequenas perturbações periódicas produzem réplicas de janelas periódicas complexas em espaços de parâmetros cujo eixos são parâmetros de controle do sistema dinâmico independente da perturbação [69]. Esse resultado contribui para o entendimento do mecanismo de controle de caos por pequenas perturbações e confere robutez a essa técnica.

No Capítulo 3, restringimos nossa análise à observação fenomenológica da replicação de janelas periódicas complexas. Acreditamos que esse estudo tem potencial para estimular novas investigações teóricas e experimentais para fundamentar a ocorrência desse fenômeno.

No Capítulo 4, investigamos as propriedades de convergência, para pontos fixos e para órbitas periódicas, de mapas de Poincaré obtidos a partir do fluxo gerado pelas equações que descrevem os osciladores caóticos. Para regiões do espaço de parâmetros com ocorrência de janelas periódicas complexas, realizamos uma previsão teórica para o comportamento da convergência baseados no tipo de convergência esperada para as regiões de parâmetros com ocorrência de bifurcações sela-nó e dobramento de período, que delimitam essas janelas [70]. Com auxílio de medidas obtidas numericamente para os osciladores caóticos, número de rotação, $w$, e número de torsão, $n$, quantificamos o comportamento das propriedades de convergência no interior das janelas periódicas complexas. Constatamos a existência de quatro áreas com números de rotação, e torsão, constantes dentro das janelas periódicas complexas, entre essas áreas o número de torsão sofre alteração de $\pm 1 / 2$ devido às mudanças de $\pm \pi$ na orientação da convergência. [70].

Para regiões do espaço de parâmetros com ocorrência de sequências de janelas periódicas complexas, baseados no fenômeno de adicionamento de período conhecido nessas sequências, conjecturamos a existência de um mecanismo de adicionamento das propriedades de torsão ao longo dessas sequências. Com isso, obtivemos uma regra para o adicionamento da torsão, $n$, ao longo de uma dada sequência. Combinando esse resultado com as regras previamente existentes para o adicionamento do período, $m$, obtivemos uma expressão geral para o número de rotação, $w$, ao longo da sequência. Tomando o limite assintótico para essa expressão, obtivemos o número de rotação da região de acúmulo da 
sequência. Em seguida, realizamos experimentos numéricos com o oscilador de Morse e verificamos esses resultados [70].

No Capítulo 4, combinamos experimentos numéricos e interpretações teóricas dos resultados e dos fenômenos observados. Os resultados obtidos nesse capítulo contibuem para o entendimento da organização, no espaço de parâmetros, dos parâmetros que correspondem à soluções periódicas do osciladores caóticos. Especialmente por explorar propriedades do espaço de estados pouco utilizadas na literatura.

No Capítulo 5, investigamos a sensibilidade no ajuste dos parâmetros de controle dos osciladores caóticos e sistemas dinâmicos adicionais. Em um experimento numérico quantificamos a proporção de parâmetros correspondentes à soluções periódicas que são incertos, i.e., a fração de parâmetros que quando perturbados por um erro $\varepsilon$ em sua posição passam a corresponder a uma solução caótica. Verficamos que a fração de parâmetros incertos varia com a perturbação como uma lei de potências, assim $f(\varepsilon) \sim \varepsilon^{\alpha}$. Em uma aproximação, o expoente $\alpha$ desse ajuste é relacionado com a dimensão exterior do conjunto de parâmetros que leva às soluções periódicas. Interpretamos dimensão como sendo uma estimativa para a dimensão da fronteira entre o conjunto de parâmetros que leva às soluções periódicas e o conjunto que leva aos atratores caóticos. Para os experimentos numéricos realizados nesta tese, para diversos sistemas dinâmicos, os valores estimados para a dimensão exterior estão no mesmo intervalo de confiança. Com isso, conjecturamos que a dimensão exterior é uma grandeza universal em sistemas dinâmicos. Além disso, formulamos um modelo heurístico para relacionar a universalidade da dimensão exterior com o decrescimento da largura das janelas periódicas complexas ao longo das sequências que são observadas.

No capítulo 5, utilizamos os artifícios matemáticos desenvolvidos para estimar a dimensão da fronteira de bacias de atração [96, 97]. Os métodos foram adaptados e revelaram resultados satisfatórios para a análise aqui proposta. Além disso, fundamentamos nossos resultados com a formulação de um modelo heurístico que é alimentado com medidas diretas da largura das janelas periódicas complexas.

Por fim, acreditamos que as análises e suas respectivas exposições ao longo da tese atenderam nossas expectivas iniciais. Embora tenhamos optado pela confecção de um 
texto sintético, com exposição direta das observações e respectivas interpretações, acreditamos que a descrição dos nossos principais resultados está acessível ao público iniciante na área. 


\section{Bibliografia}

[1] P. S. de Laplace. Essai philosophique sur les probabilités. Bachelier, France, 1814.

[2] H. Poincaré. Le hasard, In: Poincaré, H (Ed.), Science et méthode, pp. 59. Flammarion, France, 1908.

[3] E. N. Lorenz. Journal of Atmospheric Sciences, 20:130, 1963.

[4] D. Ruelle e F. Takens. Commun. Math. Phys., 20:167, 1971.

[5] T. Y. Li e J. A. Yorke. The American Math. Monthly, 82:985, 1975.

[6] S. Fraser e R. Kapral. Phys. Rev. A, 25:3223, 1982.

[7] J. A. C. Gallas. Phys. Rev. Lett., 70:2714, 1993.

[8] J. A. C. Gallas. Physica A: Stat. Mech. and its Appl., 202:196, 1994.

[9] J. A. C. Gallas. Appl. Phys, B, 60:S203, 1995.

[10] M. S. Baptista e I. L. Caldas. Chaos, Solitons and Fractals, 7:325, 1996.

[11] K. Ullmann e I. L. Caldas. Chaos, Solitons and Fractals, 7:1913, 1996.

[12] J. A. C. Gallas e H. E. Nusse. J. of Econ. Beh. and Org., 29:447, 1996.

[13] M. S. Baptista, C. Grebogi, e E. Barreto. Topology of windows in the highdimensional parameter space of chaotic maps. Int. J. of Bif. and Chaos, 13:2681, 2003.

[14] A. Nandi, D. Dutta, J. K. Bhattacharjee, e R. Ramaswamy. Chaos, 15:023107, 2005. 
[15] P. C. Rech, M. W. Beims, e J. A. C. Gallas. Phys. Rev. E, 71:017202, 2005.

[16] E. N. Lorenz. Physica D, 13:1689, 2008.

[17] L. C. Martins e J. A. C. Gallas. Int. J. Bif. and Chaos, 18:1705, 2008.

[18] T. U. Singh, A. Nandi, e R. Ramaswamy. Phys. Rev. E, 77:066217, 2008.

[19] A. C. J. Luo e Y. Guo. Int. J. Bifurc. and Chaos, 20:3173, 2010.

[20] G. A. Casas e P. C. Rech. Int. J. Bifurc, and Chaos, 20:153, 2010.

[21] G. A. Casas e P. C. Rech. Chin. Phys. Lett., 28:010203, 2011.

[22] A. Celestino, C. Manchein, H. A. Albuquerque, e M. W. Beims. Phys. Rev. Lett., 106:234101, 2011.

[23] S. L. T. de Souza, A. A. Lima, I. L. Caldas, R. O. Medrano-T., e Z. O. GuimarãesFilho. Phys. Lett. A, 376:1290, 2012.

[24] C. Manchein, A. Celestino, e M. W. Beims. Phys. Rev. Lett., 110:114102, 2013.

[25] A. Celestino, C. Manchein, H. A. Albuquerque, e M. W. Beims. Comm. in Non. Sci. and Num. Sim., 19:139, 2014.

[26] C. Bonatto, J. C. Garreau, e J. A. C. Gallas. Phys. Rev. Lett., 95:143905, 2005.

[27] C. Bonatto e J. A. C. Gallas. Phys. Rev. E, 75:055204(R), 2007.

[28] J. G. Freire, C. Bonatto, C. C. DaCamara, e J. A. C. Gallas. Chaos, 18:033121, 2008.

[29] C. Bonatto e J. A. C. Gallas. Phil. Trans. R. Soc. A, 366:505, 2008.

[30] C. Bonatto, J. A. C. Gallas, e Y. Ueda. Phys. Rev. E, 77:026217, 2008.

[31] C. Bonatto e J. A. C. Gallas. Phys. Rev. Lett., 101:0541011, 2008.

[32] H. A. Albuquerque, R. M. Rubinger, e P. C. Rech. Phys. Lett. A, 372:4793, 2008.

[33] H. A. Albuquerque e P. C. Rech. Int. J. Bifurc. and Chaos, 19:1351, 2009. 
[34] J. C. D. Cardoso, H. A. Albuquerque, e R. M. Rubinger. Phys. Lett. A, 373:2050, 2009 .

[35] J. G. Freire, R. J. Field, e J. A. C. Gallas. J. Chem. Phys., 131:044105, 2009.

[36] J. Slipantschuk, E. Ullner, M. S. Baptista, M. Zeineddine, e M. Thiel. Chaos, 20:045117, 2010.

[37] Y. Zou, R. V. Donner, J. F. Donges, N. Marwan, e J. Kurths. Chaos, 20:043130, 2010 .

[38] C. Stegemann, H. A. Albuquerque, e P. C. Rech. Chaos, 20:023103, 2010.

[39] J. A. C. Gallas. Int. J. Bif. and Chaos, 20:197, 2010.

[40] J. C. Xavier e P. C. Rech. Int. J. Bifurc. and Chaos, 20:145, 2010.

[41] O. V. Popovych, V. Krachkovskyi, e P. A. Tass. Phys. Rev. E, 82:046203, 2010.

[42] E. S. Medeiros, S. L. T. de Souza, R. O. Medrano-T, e I. L. Caldas. Phys. Lett. A, 374:2628, 2010 .

[43] R. Barrio, F. Blesa, S. Serrano, e A. Shilnikov. Phys. Rev. E, 84:035201(R), 2011.

[44] R. Vitolo, P. Glendinning, e J. A. C. Gallas. Phys. Rev. E, 84:016216, 2011.

[45] C. Stegemann, H. A. Albuquerque, R. M. Rubinger, e P. C. Rech. Chaos, 21:033105, 2011.

[46] H. A. Albuquerque e P. C. Rech. Int. J. Circ. Theor. Appl., 40:189, 2012.

[47] M. J. Correia e P. C. Rech. Appl. Math. and Comp., 218:6711, 2012.

[48] R. Barrio, F. Blesa, e S. Serrano. Phys. Rev. Lett., 108:214102, 2012.

[49] R. E. Francke, T. Pöschel, e J. A. C. Gallas. Phys. Rev. E, 87:042907, 2013.

[50] D. M. Maranhão, M. S. Baptista, J. C. Sartoreli, e I. L. Caldas. Phys. Rev. E, 77:037202, 2008. 
[51] E. R. Viana, R. M. Rubinger, H. A. Albuquerque, A. G. de Oliveira, e G. M. Ribeiro. Chaos, 20:0231101, 2010.

[52] R. Stoop, P. Benner, e Y. Uwate. Phys. Rev. Lett., 105:074102, 2010.

[53] P. Gaspard, R. Kapral, e G. Nicolis. J. Stat. Phys., 35:697, 1984.

[54] M. L. Cartwright e J. E. Littlewood. J. London Mathematical Society, 20:180, 1945.

[55] Y. Ueda. Int. J. Non-Linear Mechanics, 20:481, 1985.

[56] F. C. Moon. J. of Applied Mech., 47:00, 1980.

[57] Y. Braiman e I. Goldhirsch. Phys. Rev. Lett., 20:2545, 1991.

[58] Z. Qu, G. Hu, G. Yang, e G. Qin. Phys. Rev. Lett., 74:1736, 1995.

[59] C. Grebogi, S. W. McDonald, E. Ott, e J. A. Yorke. Phys. Lett. A, 110:01, 1985.

[60] J. Testa, J. Pérez, e C. Jeffries. Phys. Rev. Lett., 48:714, 1982.

[61] J. M. Perez. Phys. Rev. A, 32:2513, 1985.

[62] W. Ren, S. J. Hu, B. J. Zhang, F. Z. Wang, Y. F. Gong, e J. X. Xu. Intern. J. of Bifur. and Chaos, 7:1867, 1997.

[63] B. Jia, H. Gu, L. Li, e X. Zhao. Dynamics of period-doubling bifurcation to chaos in the spontaneous neural firing patterns. Cogn. Neurodyn., 6:89, 2012.

[64] L. Q. Pei, F. Guo, S. X. Wu, e L. O. Chua. IEEE Trans. Circuits and Syst., CAS$33: 438,1986$.

[65] F. A. C. Pereira, E. Colli, e J. C. Sartorelli. Chaos, 22:013135, 2012.

[66] Y. Yasuda e K. Hoh. Electron. Commun. Japan, 77:654, 1994.

[67] M. J. B. Hauser, L. F. Olsen, T. B. Bronnikova, e W. M. Schaffer. J. Phys. Chem. $B, 101: 5075,1997$.

[68] A. Wolf, J. B. Swift, H. L. Swinney, e J. A. Vastano. Physica D, 16:285, 1985. 
[69] E. S. Medeiros, S. L. T. de Souza, R. O. Medrano-T, e I. L. Caldas. Chaos, Solitons and Fractals, 44:982, 2011.

[70] E. S. Medeiros, R. O. Medrano-T, I. L. Caldas, e S. L. T. de Souza. Phys. Lett. A, $377: 628,2013$.

[71] U. Parlitz e W. Lauterborn. Z. Naturforsch, 41:605, 1985.

[72] F. C. Moon. Phys. Rev. lett., 53:962, 1984.

[73] Giampaolo Cicogna. Phys. Rev. A, 42:1901, 1990.

[74] C. Scheffczyk, U. Parlitz, T. Kurz, W. Konp, e W. Lauterborn. Phys. Rev. A, 43:6495, 1991.

[75] P. Holmes. Philos. Trans. of the Royal Soc. of London. Series A, Math. and Phys. Sciences, 292:419, 1979.

[76] F. T. Arechi, R. Badii, e A. Politi. Phys. Rev. A, 32:402, 1985.

[77] D. D'Humieres, M. R. Beasley, B. A. Huberman, e A. Libchaber. Phys. Rev. A, 26:3483, 1982.

[78] T. Fang e E. H. Dowell. Int. J. Non-Linear Mechanics, 22:401, 1987.

[79] C. Holmes e P. Holmes. J. of Sound and Vibrations, 78:161, 1981.

[80] L. Glass, M. R. Guevara, J. Belair, e A. Shrier. Phys. Rev. A, 29:1348, 1984.

[81] L. H. A. Monteiro. Sistemas Dinâmicos. Editorea Livraria da Física, São Paulo Brasil, 2006.

[82] U. Parlitz. Int. J. Of Bifurc. and Chaos, 3:703, 1993.

[83] T. Kapitaniak. Chaos, Solitons and Fractals, 2:519, 1992.

[84] E. Ott, C. Grebogi, e J. A. Yorke. Phys. Rev. Lett., 64:1196, 1990.

[85] T. Shinbrot, C. Grebogi, E. Ott, e J. A. Yorke. Nature, 363:411, 1993. 
[86] J. P. Gollub e H. L. Swinney. Onset of turbulence in a rotating fluid. Phys. Rev. Lett., 35:927, 1975.

[87] U. Parlitz e W. Lauterborn. Phys. Lett., 107A:351, 1985.

[88] U. Parlitz, V. Englisch, C. Scheffczyk, e W. Lauterborn. J. Acoust. Soc. Am., 88:1061, 1990.

[89] V. Englisch e W. Lauterborn. Phys. Rev. A, 44:916, 1991.

[90] W. Façanha, B. Oldeman, e L. Glass. Bifurcation structures in two-dimensional maps: The endoskeletons of shrimps. Phys. Lett. A, 377:1264, 2013.

[91] E. Barreto, B. R. Hunt, C. Grebogi, e J. A. Yorke. Phys. Rev. Lett., 78:4561, 1997.

[92] R. O. Medrano-T e I. L. Caldas. ArXiv e-prints, 2010.

[93] M. V. Jakobson. Commun. Math. Phys., 81:39, 1981.

[94] J. D. Farmer. Phys. Rev. lett., 55:351, 1985.

[95] R. Eykholt e D. K. Umberger. Phys. Rev. Lett., 57:2333, 1986.

[96] C. Grebogi, S. W. McDonald, E. Ott, e J. A. Yorke. Phys. Lett. A, 99:415, 1983.

[97] S. W. McDonald, C. Grebogi, E. Ott, e J. A. Yorke. Physica D, 17:125, 1984.

[98] H-Otto Peitgen, H. Jürgens, e D. Saupe. Chaos and Fractals: New Frontiers of Science. The National Academies Press, United States of America, 2004.

[99] M. H. Jensen, P. Bak, e T. Bohr. Phys. Rev. Lett., 50:1637, 1983. 